\title{
Charakterisierung und experimentelle Therapien eines neuen Mausmodells für das Rett Syndrom
}

\author{
Dissertation \\ zur Erlangung des mathematisch-naturwissenschaftlichen Doktorgrades \\ "Doctor rerum naturalium" \\ der Georg-August-Universität Göttingen \\ im Promotionsprogramm der \\ Georg-August University School of Science (GAUSS)
}

vorgelegt von

Jan Eike Wegener

aus Berlin

Göttingen, 2015 



\section{Betreuungsausschuss}

Prof. Dr. André Fila, Abt. Molekulare Neurobiologie des Verhaltens, SchwannSchleiden Forschungszentrum, Georg-August-Universität-Göttingen

Prof. Dr. Martin Göpfet, Abt. Zelluläre Neurobiology, Schwann-Schleiden Forschungszentrum, Georg-August-Universität-Göttingen

\section{Mitglieder der Prüfungskommission}

Referent Prof. Dr. André Fila, Abt. Molekulare Neurobiologie des Verhaltens, Schwann-Schleiden Forschungszentrum, Georg-August-UniversitätGöttingen

Korefent Prof. Dr. Martin Göpfet, Abt. Zelluläre Neurobiology, SchwannSchleiden Forschungszentrum, Georg-August-Universität-Göttingen

Weitere Mitglieder der Prüfungskommission

Prof. Dr. Ralf Heinrich, Abtl. Zelluläre Neurobiologie SchwannSchleiden-Forschungszentrum, Georg-August-Universität-Göttingen

Prof. Dr. Michael Müller, Abt. Neuro- und Sinnesphysiologie, Universitätsmedizin Göttingen

Prof. Dr. Holger Reichardt, Abt. Experimentelle Immunologie, Institut für Zelluläre und Molekulare Immunologie

Prof. Dr. Blanche Schwappach, Institut für Molekulare Biologie, Universitätsmedizin Göttingen

Tag der mündlichen Prüfung: 12. Oktober 2015 



\section{Inhaltsverzeichnis}

1.1 Rett Syndrom

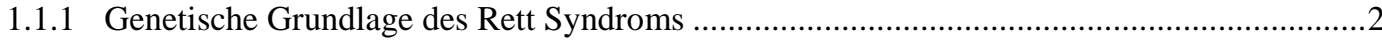

1.2 Das Methyl-CpG-bindende Protein 2 (MeCP2) .........................................................................4

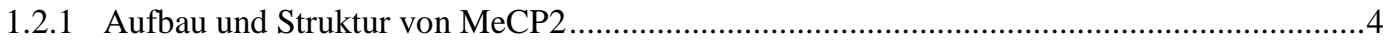

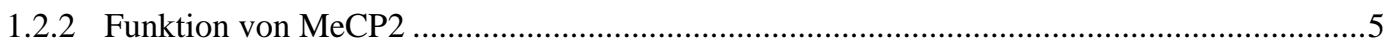

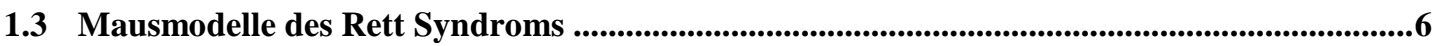

1.4 Therapeutische Ansätze zur Behandlung des Rett Syndroms ...................................................7

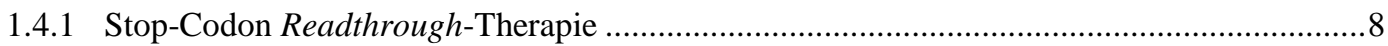

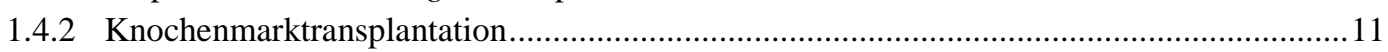

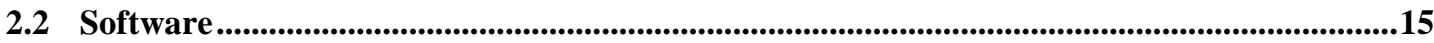

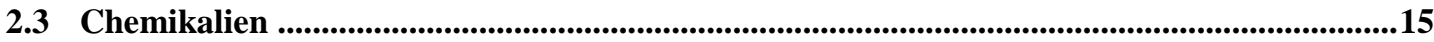

2.3.1 Aminoglykoside, NB-Komponenten und PTC124 ................................................ 15

2.4 Lösungen und Puffer .............................................................................................................................15

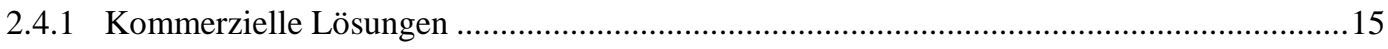

2.4.2 Selbstangesetzte Lösungen und Puffer ................................................................. 17

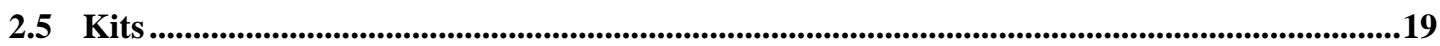

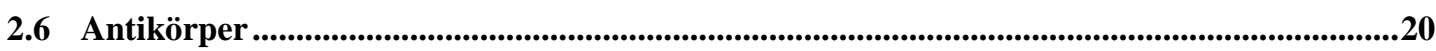

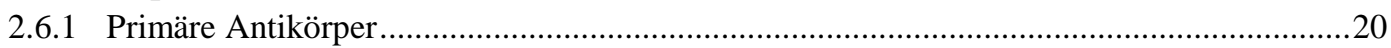

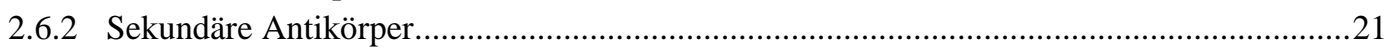

2.7 Allgemeine Molekularbiologische Methoden .......................................................................21

2.7.1 Isolierung von Gesamt-RNS aus Mausgehirn ................................................................2 21

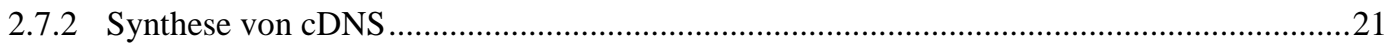

2.7.3 Isolierung genomischer DNS aus Mausschwänzen ...................................................22

2.7.4 Polymerase-Kettenreaktion (PCR) .......................................................................22

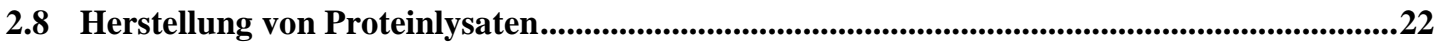

2.9 SDS-Polyacrylamidelektrophorese und Western Blot ..............................................................23

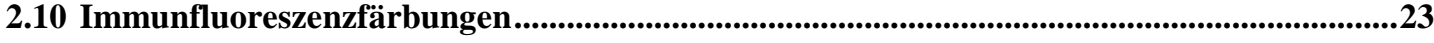

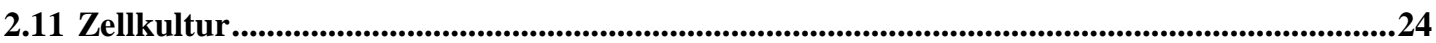

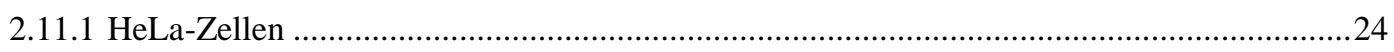

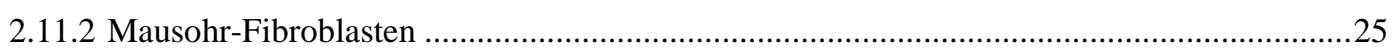




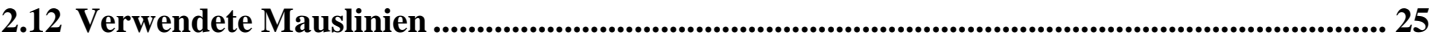

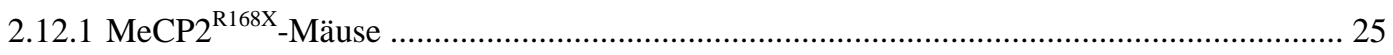

2.12.2 B6.SJL-Ptprca Pepcb/BoyJ-Mäuse ............................................................................ 26

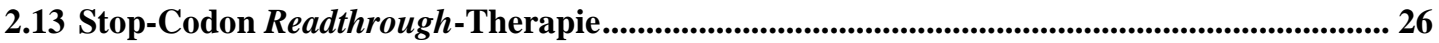

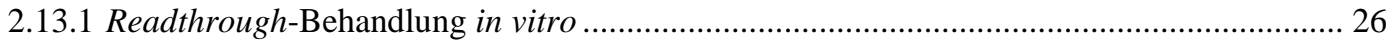

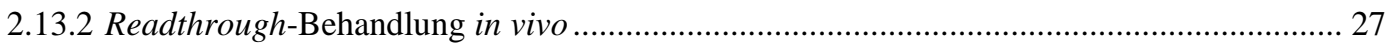

2.14 Knochenmarktransplantation.................................................................................................. 27

2.14.1 FACS-Analyse zum Nachweis der Konchenmarkrekonstitution....................................... 28

2.14.2 Isolierung von Mikroglia neugeborener MeCP2 ${ }^{\mathrm{R} 168 \mathrm{X}}$-Mäuse ............................................. 29

2.14.3 Untersuchung der Phagozytoseaktivität und der Expression von MHC-I und MHC-II als Reaktion auf externe Stimuli ................................................................................... 29

2.14.4 Untersuchung der Phagozytoseaktivität von $\mathrm{MeCP} 2^{\mathrm{R} 168 \mathrm{X}}-$ Mikroglia mittels

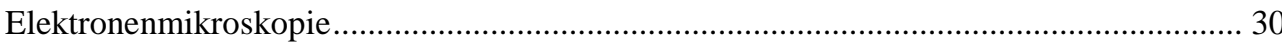

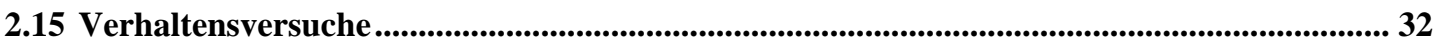

2.15.1 Elevated Plus Maze ................................................................................................ 33

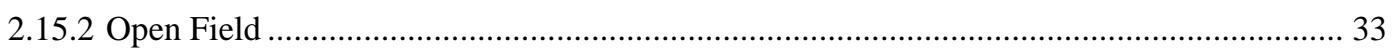

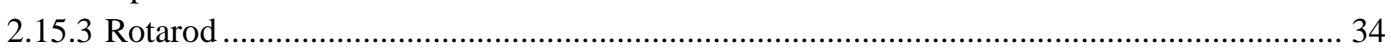

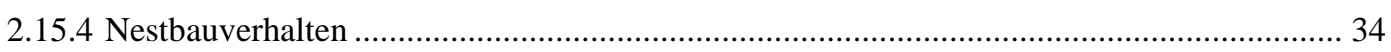

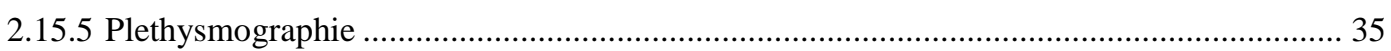

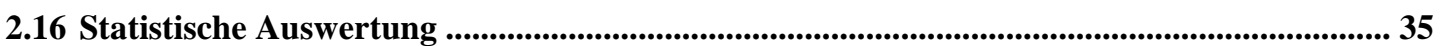

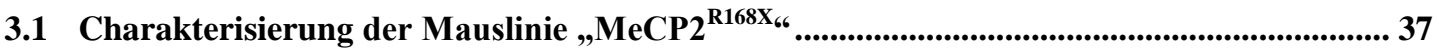

3.1.1 Allgemeines Erscheinungsbild von MeCP2 ${ }^{\mathrm{R} 168 \mathrm{X}}$-Mäusen ................................................ 37

3.1.2 Nestbauverhalten von $\mathrm{MeCP} 2^{\mathrm{R} 168 \mathrm{X}}$-Mäusen................................................................. 38

3.1.3 Atmung und Lungenfunktion von MeCP2 ${ }^{\mathrm{R} 168 \mathrm{X}}$ Mäusen ................................................ 40

3.1.4 Allgmeine lokomotorische Aktivität von MeCP2 ${ }^{\mathrm{R} 168 \mathrm{X}}$-Mäusen ........................................ 41

3.1.5 Motorische Koordination und motorisches Lernen ........................................................ 42

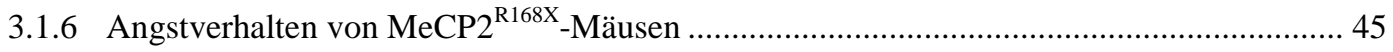

3.2 Experimentelle Therapien des Rett Syndroms ............................................................................... 49

3.2.1 Stop-Codon Readthrough-Therapie in vitro ................................................................ 49

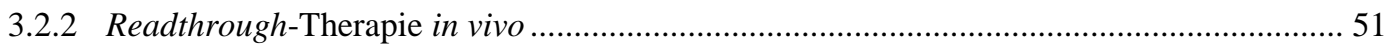

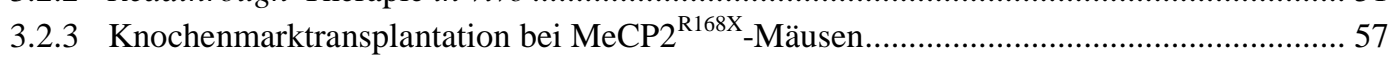

$4 \quad$ DISKUSSION

4.1 Die Charakterisierung des MeCP2 ${ }^{\mathrm{R} 168 \mathrm{X}}$-Mausmodells ............................................................. 77

4.2 Experimentelle Therapien des Rett Syndroms ............................................................8 80

4.2.1 Die Stop-Codon Readthrough-Therapie beim Rett Syndrom ............................................ 80

4.2.2 Knochenmarktransplantation bei MeCP2 ${ }^{\mathrm{R} 168 \mathrm{X}}$-Mäusen................................................... 83 


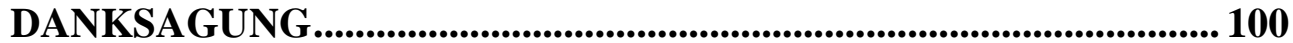

8

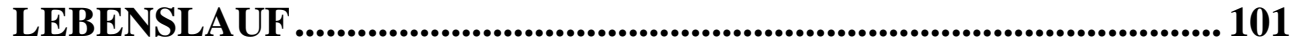

9

VERÖFFENTLICHUNGEN .............................................................. 102

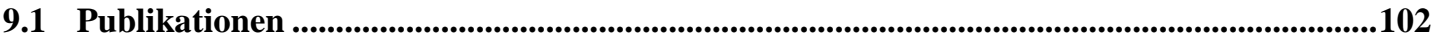

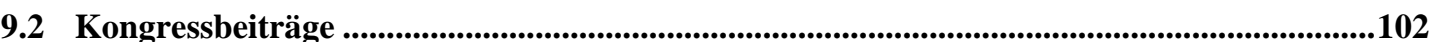




\section{Abkürzungsverzeichnis}

$5 \mathrm{mC}$

$5 \mathrm{hmC}$

ANOVA

AS

A-Site

BDNF

bp

BSA

cDNS

CFTR

CTD

DMEM

DEPC

DNS

EDTA

eIF4G/

FACS

gCSF

$\mathrm{GVH}$

HBSS

HCL

HMGD1

HMGD2

IFN $\gamma$

IrrScore

LPS
5-Methylcytosine

5-Hydroxymethylcytosin

engl. analysis of variance

Aminosäure

engl. Aminoacyl-Site

engl. Brain derived neutrophic factor

Basenpaar

Bovines Serum Albumin

komplentäre (engl.: complementary) DNS

engl. Cystic fibrosis transmembrane conductor protein

C-terminale Domäne

engl. Dulbecco’s Modified Eagle Medium

Diethyldicarbonat

Desoxyribonukleinsäure

Ethylendiamintetraessigsäure

engl. Eukaryotic translation initiation factor $4 \mathrm{E}$ bzw. $4 \mathrm{G}$

engl. fluorescence-activated cell sorting

Granulozyten-Kolonie stimulierender Faktor

engl. Graft vs. Host

engl. Hank's Balanced Salt Solution

Salzsäure

engl. High Mobility Group-like Domain 1

engl. High Mobility Group-like Domain 2

Interferon gamma

engl. Irregularity Score

Lipoplysaccharid 


$\begin{array}{ll}\text { mRNS } & \text { boten (engl.:,,messenger“)-RNS } \\ \text { MBD } & \text { Methyl-DNS-Bindedomäne } \\ \text { MECP2 } & \text { Methyl-CpG-bindende Protein } \\ \text { MFI } & \text { Mittlere Floureszenzintensität } \\ \text { MHC I/II } & \text { engl. Major Histocompatibilty Complex I/II } \\ \text { MW } & \text { Mittelwert } \\ \text { NaCl } & \text { Natrium Chlorid } \\ \text { NLS } & \text { engl. Nuclear Localisation Signal } \\ \text { PABP } & \text { Poly-A-Bindeprotein } \\ \text { PBS } & \text { engl. Phosphatbuffered solution } \\ \text { PCR } & \text { engl. Polymerase Chain Reaction } \\ \text { PFA } & \text { Paraformaldehyd } \\ \text { RF } & \text { transport-Ribonukleinsäure } \\ \text { RNS } & \text { engl. Releasing Factor } \\ \text { tRNS } & \text { Ribonukleinsäure } \\ \text { TRD } & \text { ribosomale RNS } \\ \text { SDS } & \text { engl. Sodium Dodecyl Sulfate } \\ \text { SEM } & \text { Tris }\end{array}$





\section{Einleitung}

Das 1966 erstmalig beschriebene Rett Syndrom ist eine der häufigsten Ursachen geistiger Behinderung von Mädchen und Frauen und ist bis heute nicht therapierbar. Die hier vorgestellte Arbeit wurde mit Fokus auf zwei unterschiedliche Schwerpunkte durchgeführt. Zum einen sollte eine neues Mausmodell für das Rett Syndrom charakterisiert werden, welches erstmals eine humane Mutation aufweist die zu einem physiologischen knockout des MeCP2-Proteins führt. Zum anderen sollten experimentelle Therpaieansätze zur Behandlung des Rett Syndroms analysiert werden. Hierzu gehörten die „Stop-Codon Readthrough-Theraphie“ und die Knochenmarktransplantation nach Derecki.

\subsection{Rett Syndrom}

Das Rett Syndrom (RTT, OMIM \#312750, ICD-10 F84.2) ist eine seltene neurologische Störung die erstmals vom Wiener Pädiater Andreas Rett im Jahre 1966 beschrieben wurde $^{1}$. Das Rett Syndrom betrifft fast ausschließlich Mädchen mit einer Häufigkeit von 1:10.000 - 1:15.000, wobei seltene Fälle betroffener Jungen vorliegen ${ }^{2}$. Das Rett Syndrom ist damit die zweithäufigste monogene Ursache mentaler Retardierung bei Mädchen und Frauen ${ }^{3,4}$. Ursächlich für das Rett Syndrom sind verschiedenen Mutation des X-chromosomal lokalisierten Gens $M E C P 2$, welches das Methyl-CpG-bindende Protein 2 (MECP2) kodiert ${ }^{5}$. Das Rett Syndrom fand allerdings erst 1983 internationale Beachtung, nachdem der schwedische Neurologe Dr. Bengt Hagberg eine detaillierte Beschreibung von 35 Patientinnen in englischer Sprache veröffentlichte ${ }^{6}$. Die peri- und postnatale Entwicklung der betroffenen Kinder verläuft bis zu einem Zeitraum zwischen dem 6. und 18. Lebensmonat normal, gefolgt von der Progression des Rett Syndroms in vier Phasen. Während der ersten Phase, zwischen dem 6. und 18. Lebensmonat, kommt es zu einer Verzögerung in der Entwicklung, hauptsächlich motorischer Fähigkeiten bis diese schließlich zum Erliegen kommen (Stagnationsphase). Die Kinder zeigen vermehrt autistische Anzeichen, wie einen sozialen Rückzug, seltener werdende Blickkontankte und ein steigendes Desinteresse an ihrer Umwelt. Auch kommt es in diesem Stadium zu Wachstumsverminderung und einer Verlangsamung des Kopfwachstums, welche häufig zu einer Mikrozephalie führt. In der zweiten Phase, die meist zwischen dem 1. und 4. Lebensjahr auftritt, kommt es zu einer Regression in der Ent- 
wicklung (Regressionsphase). In dieser Phase gehen bereits erlernte Fähigkeiten wie der Gebrauch der Sprache und motorische Fähigkeiten, insbesondere der sinnvolle Einsatz der Hände, verloren. In dieser Phase des Rett Syndroms treten plötzliche, nächtliche Schreiphasen und die charakteristischen Handbewegungen der „waschenden Hände“ auf. Auch kommt es in dieser Phase zu Störungen der Bewegungsabläufe. Hierzu zählen insbesondere die Störungen gezielter willkürlicher Bewegungen (Apraxien) und plötzlich auftretende unwillkürlichen Bewegungsstörungen des Oberkörpers und der Beine (Rumpf-und Gangataxien), welche sich in einem unkoordinierten breitbasigen Gangbild manifestieren ${ }^{7}$. Desweiteren können ab dieser Phase epileptische Anfälle auftreten, deren Spektrum von leicht bis nicht therapierefraktär reicht ${ }^{8,9}$. Die dritte Phase, zwischen dem 2. und 10. Lebensjahr, zeichnet sich durch eine Abmilderung und Stabilisierung der Symptomatik auf (Plateauphase). In der vierten Phase verschlechtern sich die motorischen Fähigkeiten rapide (Phase des späten motorischen Verfalls). Häufig sind Kinder ab dieser Phase auf einen Rollstuhl angewiesen. Gegensätzlich zu den motorischen Fähigkeiten verbessern sich soziale und kognitive Fähigkeiten in dieser Phase. Weitere häufige Merkmale des Rett Syndroms sind ein Gewichtsverlust trotz normaler Ernährung, das Auftreten einer Skoliose, Zähneknirschen, Verstopfungen, erhöhte Ängstlichkeit, Osteoponie und schwere Beeinträchtigung der Atmung wie z.B. Hyperventilation und das Auftreten von Apnoen ${ }^{10,11}$. Bei Autopsien von Patienten mit Rett Syndrom wurden keine Änderungen der Hirnstruktur, sondern ausschließlich morphologische Veränderungen wie eine Verringerung der Größe des Gehirns, eine Reduzierung dendritischer Verzweigungen und eine erhöhte Dichte von Neuronen gefunden. Anzeichen einer Neurodegeneration konnten nicht gefunden werden.

\subsubsection{Genetische Grundlage des Rett Syndroms}

In mehr als $95 \%$ aller Fälle mit klassischem Rett Syndrom sind Mutationen des Xchromosomal (Xq28) lokalisierten Gens MECP2 nachzuweisen. In über $99 \%$ entstehen diese spontan während der Spermatogenese unabhängig vom Alter des Vaters ${ }^{12}$. Bei den über 300 bekannten pathogenen Mutationen wurden sowohl Missense-, Nonsense-und Frameshift-Mutation, wie auch kleine bis große Insertionen und Deletionen beschrieben $^{13-16}$. Etwa $70 \%$ aller Mutationen werden durch eine Cytosin zu Thymin $(\mathrm{C}>\mathrm{T})$ Transition an acht Positionen im MECP2 Gen verursacht und resultieren in Missenseund Nonsense- Mutationen (Abbildung 1 und Tabelle 1). 
Tabelle 1: Die acht häufigsten pathogenen Mutationen im MECP2 Gen

\begin{tabular}{|c|c|c|}
\hline Nukleotidänderung & Aminosäureänderung & prozentualer Anteil \\
\hline$c .473 C>T$ & p.T158M & 8,01 \\
\hline$c .502 C>T$ & p.R168X & 6,68 \\
\hline$c .763 C>T$ & p.R255X & 5,81 \\
\hline$c .808 C>T$ & p.R270X & 5,29 \\
\hline$c .880 C>T$ & p.R294X & 4,55 \\
\hline$c .916 C>T$ & p.R306C & 4,32 \\
\hline$c .397 C>T$ & p.R133C & 3,90 \\
\hline$c .316 C>T$ & p.R106W & 2,55 \\
\hline
\end{tabular}

Untersuchungen zeigen, dass das Rett Syndrom eine Genotyp-Phänotyp-Korrelation aufweist. Patientinnen mit einer Nonsense-Mutation oder einer Mutation, die die Kernlokalisierungsdomäne (NLS = engl. Nuclear Localization Sequence) betrifft weisen einen schwereren Krankheitsverlauf auf. Bei Nonsense-Mutationen nimmt die Schwere des Krankheitsverlaufs mit der Verkürzung des Proteins $\mathrm{zu}^{17}$. Das Auftreten milderer Erscheinungsformen des Rett Syndroms kann durch die Inaktivierung des XChromosoms verursacht werden ${ }^{18}$. Dieser Prozess ist notwendig, um die Dosis Xchromosmal lokalisierter Gene bei Frauen zu begrenzen, wobei die Inaktivierung des maternalen bzw. paternalen X-Chromosoms willkürlich erfolgt ${ }^{19}$. In der Pathogenese des Rett Syndroms kann dieser Prozess gestört sein und es kommt zu häufiger zu einer Inaktivierung des X-Chromosoms, auf dem sich das mutierte MECP2-Allel befindet ${ }^{20}$. Besonders drastisch kann sich dies bei monozygotischen Zwillingen äußern, die die gleiche Mutation und sich deutlich unterscheidenden Schweregraden des Rett Syndroms aufweisen $^{21}$.

Obwohl das Rett Syndrom hauptsächlich Mädchen betrifft werden auch seltene Fälle von betroffenen Jungen beschrieben ${ }^{22-28}$. Mutationen im MECP2 Gen, die bei Mädchen die klassische Formen des Rett Syndroms verursachen, führen bei Jungen mit normalen Karyotp zu neonatalen Enzephalopathien und verlaufen meist innerhalb des ersten Jahres nach der Geburt tödlich. Bei betroffenen Jungen, die zusätzlich noch positiv für das Klinefelter Syndrom (47, XXY) sind, kommt es zur Ausbildung des klassischen Rett Syndroms, wie es bei betroffenen Mädchen beschrieben wird ${ }^{29-32}$. 


\subsection{Das Methyl-CpG-bindende Protein 2 (MeCP2)}

\subsubsection{Aufbau und Struktur von MeCP2}

Sowohl das humane MECP2 Gen, wie auch das orthologe Gen in der Maus (Mecp2), sind auf dem X-Chromosom lokalisiert und bestehen jeweils aus vier Exons ${ }^{33-35}$. Durch alternatives Spleißen entstehen die beiden Isoformen: MeCP2e1 und MeCP2e2 die sich in ihrem N-Terminus unterscheiden. Das durch die Exons 1, 3 und 4 kodiert MeCP2e1 hat eine Länge von 498 Aminosäuren (AS; human und 501 AS murin) und ist gegenüber MeCP2e2 (486 AS human und 484 AS murin) um 12 saure und hydrophobe Aminosäuren länger. Das durch die Exone 2, 3 und 4 kodierte MeCP2e2, weist neun einzigartige N-terminale Aminosäuren auf, denen bisher keine pathogene Mutation zugeordnet werden konnte. Desweiteren kommt MeCP2e1 im Gehirn etwa zehnmal häufiger $\begin{array}{lllll}\text { vor als } & \text { die } & \text { Isoform }\end{array}$ Das MeCP2-Protein ist aus fünf Domänen zusammengesetzt: die „High Mobility Group-like Domain 1“ (engl. HMGD1; AS 2-77), die Methyl-DNS-Bindedomäne (MBD; AS 78-162; DNS= Desoxyribonukleinsäure), die „High Mobility Group-like Domain 2“ (engl. HMGD2; AS 163-206), die Transkriptionsrepressor-Domäne (TRD; AS 207-310) inklusive der Kernlokalisierungssequenz (NLS; AS 255-271) und der Cterminalen Domäne (CTD; AS 311-486). Die CTD wird dabei noch in CTDa (AS 310354) und CTD $\beta$ (AS 355-486) unterteilt ${ }^{38}$ (Abbildung 1).

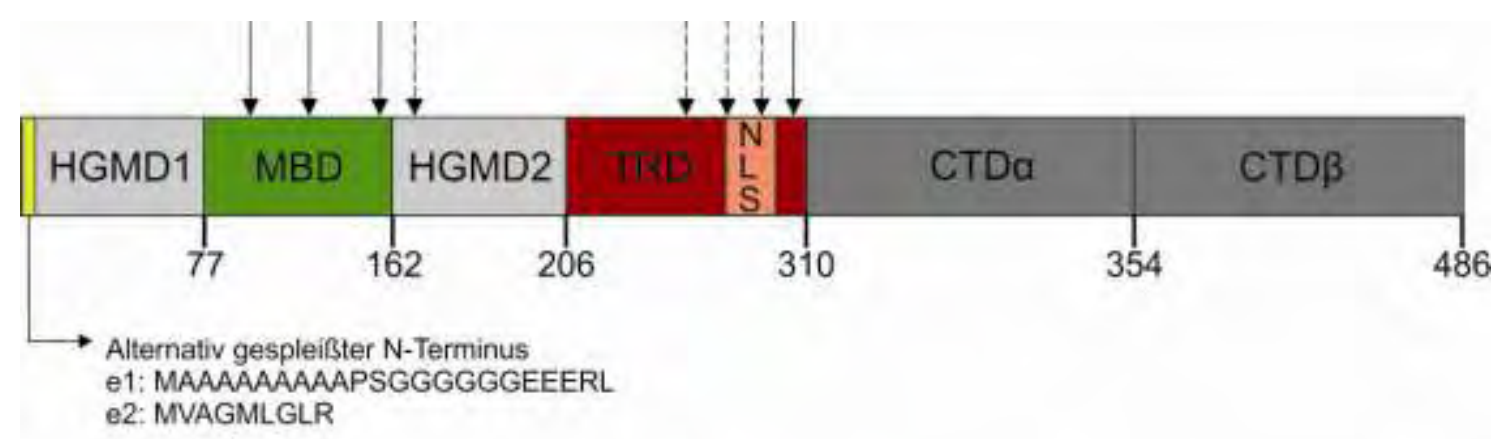

Abbildung 1: Struktur des MeCP2-Proteins mit Lage der acht häufigsten Mutationen. HGDM1 (high mobility group-like domain 1) inklusive beider alternativen N-Termini (gelbe Box), MBD (Methyl-DNS-bindende Domäne), HGDM2 (high mobility group-like domain 2), TRD (Transkriptionsrepressor-Domäne), NLS (Nuclear Localisation Signal), CTD $\alpha / \beta$ (C-terminale Domäne mit $\alpha$ - bzw. $\beta$-Untereinheit). Die Zahlen geben die Positionen der Aminosären an. Die Pfeile verweisen auf die Lage der acht häufigsten Mutationen, wobei durchgehende Pfeile Missense-Mutationen und gestrichelte Pfeile Nonsense-Mutationen anzeigen.

Durch Zirkulardichroismus-Studien und in silico Prognosen konnte gezeigt werden, dass etwa $60 \%$ des MeCP2 Proteins unstrukturiert sind. Die strukturierten Bereiche teilen sich in $\beta$-Faltblätter (35\%) und $\alpha$-Helices (5\%) auf und sind vorwiegend in der 
Methyl-DNS-Bindedomäne zu finden ${ }^{38}$. Durch die großen Anteile unstrukturierter Bereiche des Proteins wird MeCP2 auch in die Gruppe der ,intrinsisch desorganisierten Proteine“ eingeordnet ${ }^{39}$. Diese „desorganisierten“ Bereiche führen zu einer hohen Flexibilität der Proteine, da es diesen Regionen nicht möglich ist eine stabile dreidimensionale Form einzunehmen ${ }^{39,40}$. Es wird vermutet, dass diese Desorganisation für eine erhöhte lokale und temporäre Komplexiztät nötig ist, die es MeCP2 ermöglicht mit DNS, RNS (Ribonukleinsäure) und verschiedensten Proteinen zu interagieren. Diese Theorie wird durch das häufige Vorkommen intrinsisch desorganisierter Bereiche bei eukaryotischen Transkriptionsfaktoren untermauert ${ }^{41}$.

\subsubsection{Funktion von MeCP2}

Die Expression des MeCP2 Proteins und der verschiedenen Transkriptformen ist während der embryonalen Entwicklung niedrig und steigt während der postnatalen neuronalen Entwicklung kontinuierlich $\mathrm{an}^{42,43}$. Hierbei erreicht es die höchste Expression, von etwa $1,6 \times 10^{7}$ Molekülen pro Zellkern, in ausgereiften Neuronen, wobei es auch in nahezu jedem anderen Zelltyp in geringerer Menge zu finden ist und stets an heterochromatischen Zentren der DNS lokalisiert ist ${ }^{44,45}$. Die hohen Mengen an MeCP2 reichen statistisch aus, um eine Bindung von MeCP2 an $50 \%$ aller Nukleosomen zu ermöglichen. Zusätzlich konnte gezeigt werden, dass MeCP2 das Histon H1 in einem methylierungsabhängigen Prozess von der DNS verdrängen und somit als alternatives Histon-Verknüpfungsprotein in Neuronen fungieren $\mathrm{kann}^{46}$. Die Bindung an die methylierte DNS erfolgt über die Bindung der Methyl-DNS bindende Domäne an 5Methylcytosine $(5-\mathrm{mC})$ der DNS ${ }^{33}, 47$. Im Gegensatz zu anderen Proteinen der MBDProteinfamilie ist MeCP2 zusätzlich in der Lage an 5-Hydroxymethylcytosin (5-hmC) zu binden. 5-hmC ist vermehrt in aktiven Genen und am häufigsten in Neuronen zu fin$\operatorname{den}^{48}$.

Durch die Fähigkeit an methylierte und unmethylierte DNS zu binden ist MeCP2 in der Lage regulatorisch in die Transkription einzugreifen. Dies geschieht über die Rekrutierung der Korepressor-Komplexe Sin3A (SWI-INdependent), N-CoR (nuclear receptor corepressor) c-ski, CoREST (REST corepressor 1) und LANA (latency-associated nuclear antigen) ${ }^{46,49-51}$, die Transkriptionsaktivatoren YY1 (Ying Yang 1) und CREB1 (cAMP response element-binding protein) ${ }^{52,53}$, die Chromatinremodulierungskomplexe SMARCC4 (SWI/SNF related, matrix associated, actin dependent regulator of chromatin) und ATRX (alpha thalassemia/mental retardation syndrome X-linked), der DNS- 
Methyltransferasen 1 (DNMT1) und der Histonmethyltransferase Suv39H1 (Suppressor of variegation 3-9 homolog 1 (Drosophila) $)^{51,54-57}$.

Um die Funktion von MeCP2 gezielt zu steuern sind posttranslationelle Modifikationen nötig. Phosphorylierungen verschiedener Aminosäurereste scheinen dabei sowohl für die Bindungsaffinität zu Chromatin als auch für die Bindung verschiedener Interaktionspartner nötig zu sein ${ }^{58,59}$.

$\mathrm{MeCP} 2$ spielt weiterhin eine zentrale regulatorische Rolle bei der Expression von BDNF (Brain derived neutrophic factor), welche durch Acetylierungen und Deacetylierungen des $\mathrm{MeCP} 2$ Proteins beeinflusst wird ${ }^{60,61}$. In Abwesenheit von $\mathrm{MeCP} 2$ wird BDNF stark vermindert expremiert ${ }^{62}$. In MeCP2-Mausmodellen korreliert die verringerte BDNF-Expression konstant mit dem Verzögerten auftreten und Voranschreiten der Symptomatik ${ }^{63-68}$. Aufgrund der hohen Expression von BDNF im zentralen Nervensystem kann davon ausgegangen werden, dass BDNF eine wichtige Rollen bei der neurologischen Differenzierung und Entwicklung spielt ${ }^{69}$. Eine Verringerung der BDNF-Mengen im zentralen Nervensystem könnte somit für die Symptomatik des Rett Syndroms grundlegend $\operatorname{sein}^{62}$.

\subsection{Mausmodelle des Rett Syndroms}

In den letzten 15 Jahren sind viele Mausmodelle für das Rett Syndrom generiert worden. Das erste beschriebene Modell $\left(\mathrm{MeCP}^{\mathrm{tm} 1.1 \text { Bird }}\right)$ aus dem Jahre 2001 trug eine Deletion des dritten Exons und eine Deletion des kodierenden Bereichs von Exon 4. Obwohl Nachkommen beider Geschlechter direkt nach der Geburt keinen Phänotyp aufwiesen, entwickeln sich nach kurzer Zeit, analog zur humanen Pathogenese, erste Symptome. Dazu gehörten eine Versteifung des Ganges, eine Reduzierung spontaner Aktivität und eine ungleichmäßige Atmung. Die Tiere zeigte eine motorische Fehlfunktion der Hinterbeine, die als hindlimb clasping beschrieben wurde ${ }^{70}$. Diese Reaktion kann auf eine allgemeine Störung der Muskelspannung hindeuten. Abhängig vom genetischen Hintergrund wiesen die Mäuse eine drastische Veränderung des Gewichts auf. Nachkommen mit dem genetischen Hintergrund C57BL/6J zeigten ein deutlich verringertes Körpergewicht. Nachkommen mit dem genetischen Hintergrund 129/SvJ zeigten eine deutliche Erhöhung des Körpergewichts. Das auffälligste Merkmal MeCP2defizienter Nachkommen war jedoch eine stark verkürzte Lebenserwartung von 54 Ta$\mathrm{ge}^{71}$. 
Im Laufe der Jahre wurden weitere Mausmodelle generiert die verschiedenste Mutationen wie große Deletionen der Exone $1^{72}$ und $3^{73}$ oder der Methyl-DNS-bindenden Domäne $^{74}$, von Nonsense-Mutationen an den Positionen $308(\mathrm{~S} 308 \mathrm{X})^{75}$ und 168 $(\mathrm{R} 168 \mathrm{X})^{76,77}$ und Missense-Mutationen an den Positionen 80 (S80A), 421 (S421A), 424 $(\mathrm{S} 424 \mathrm{~A})^{58,78}, 140(\mathrm{~A} 140 \mathrm{~V})^{79}$ und $158(\mathrm{~T} 158 \mathrm{~A})^{80}$ tragen. Allen Mauslinien ist gemein, dass die Symptome verzögert auftreten und sich im weiteren Verlauf der Erkrankung Störungen der Atmung, der motorischen Funktionen und der motorische Koordination manifestieren. Auch das Angstverhalten, das bei Rett Patientinnen verstärkt auftritt ${ }^{20}$, ist bei den meisten Mausmodellen verändert ${ }^{81}$. Diese Veränderungen äußern sich in $\mathrm{Ab}$ hängigkeit der Mutation und des genetischen Hintergrundes, in einer Verstärkung ${ }^{75}$ oder einer Verminderung des Angstverhaltens ${ }^{71-73,80}$. Das gravierendste Merkmal das bei allen MeCP2-defizienten Mauslinien auftritt, ist eine deutlich verkürzte Lebensdauer männlicher Tiere, wie sie bereits von Jacky Guy beschrieben wurde ${ }^{71}$. Die Überlebensdauer männlicher Mäuse variiert zwischen 54 Tagen und 16 Wochen und ist von der Mutation und dem genetischen Hintergrund abhängig ${ }^{71,73,74,76,80}$.

\subsection{Therapeutische Ansätze zur Behandlung des Rett Syndroms}

Für das Rett Syndrom gibt es bisher keine kausale Therapie. Die prinzipielle Heilbarkeit der Rett Syndroms konnte jedoch 2007 von Jacky Guy an Mäusen gezeigt werden ${ }^{82}$. In dieser Arbeit wurde die Expression von $\mathrm{MeCP} 2$ durch das Einbringen einer gefloxten Stop-Kassette vor dem Mecp2-Promotor inhibiert (MeCP2 $\left.2^{\text {lox-Stop }}\right)$, was zu einem physiologischen MeCP2 knockout führte. MeCP2 $2^{\text {lox-Stop }}$-Mäuse zeigten dabei eine den knockout Mäusen $\left(\mathrm{MeCP} 2^{\text {tm1.1Bird }}\right.$ ) vergleichbare Symptomatik. In dem MeCP2 $2^{\text {lox-Stop }}-$ Modell kann MeCP2 durch die Expression einer Cre-Rekombinase Zelltyp-spezifisch und unter der Kontrolle des MeCP2-Promotors re-exprimiert werden. Nach einer Verpaarung mit Cre-Rekombinase exprimierenden Mäusen zeigten diese Tiere $\left(\mathrm{MeCP} 2^{\text {Cre, lox-Stop }}\right)$ eine nahezu komplette Abmilderung der Symptomatik ${ }^{82}$.

Es gibt zahlreiche therapeutische Maßnahmen, welche in Abhängigkeit der Schwere der Erkrankung zu einer Linderung der Symptome und somit zu einer deutlichen Erhöhung der Lebensqualität führen können. Physikalische Therapien dienen der Mobilisierung der Patientinnen und verbessern die Koordination und Beweglichkeit. Desweiteren leiden viele Patientinnen an Untergewicht und Osteoporose. Diese Symptome können mit 
einer hochkalorischen Ernährung und dem Zusatz von Vitamin D, Calcium und Bisphosphonaten abgemildert werden. Epileptische Anfälle werden mit antikonvulsiven Medikamenten und ein gastroesophagaler Reflux operativ behandelt.

\subsubsection{Stop-Codon Readthrough-Therapie}

Als „Stop-Codon Readthrough-Therapie“ (kurz Readthrough) bezeichnet man den Prozess bei dem ein vorgelagertes Stop-Codon in Anwesenheit bestimmter Substanzen wie Aminoglykoside „überlesen“ wird. Dies geschieht durch die Bindung der Aminoglykoside an die Dekodierungsstelle (A-site), innerhalb der kleinen Untereinheit des Ribosoms (30S bei Prokaryoten und 40S bei Eukaryoten) ${ }^{83,84}$. Natürliche StopCodons werden von diesem Prozess in der Regel nicht betroffen. Der Grund dafür ist die Zirkularisierung der mRNS (boten (engl. messenger)-Ribonukleinsäure) durch die $\mathrm{N}$-terminale Bindung der eukaryotischen Elongationsfaktoren eIF4E und eIF4G und die Bindung des Poly-A-Bindeproteins (PBAP) am Poly-A-Schwanz der mRNS. Die Erkennung des natürlichen Stop-Codons erfolgt durch den Terminationskomplex, bestehend aus den eukaryotischen Freisetzungsfaktoren eRF1 und eRF3 + GTP, wobei eRF3 mit PABP interagieren kann. Durch die räumliche Nähe des Stop-Codons und des polyA-Schwanzes zueinander, wird die umgehende Freisetzung der fertigen Polypeptidkette, aus dem Ribosom, durch die Interaktion von eRF3 und PABP katalysiert. Einem vorgelagerten Stop-Codon, verursacht durch eine Nonsense-Mutation, fehlt diese räumliche Nähe zum poly-A-Schwanz in den meisten Fällen. In dieser Situation pausiert das Ribosom am vorgelagerten Stop-Codon. Die Bindung eines Aminoglykosids bewirkt eine leichte Konformationsänderung an der kleinen ribosomalen Untereinheit. Die Veränderung bewirkt eine Verringerung der Bindung der eukarytoschen Freisetzungsfaktoren an das, sich in der A-Site (Aminoacyl-Site) des Ribosoms befindliche, Stop-Codon. Gleichzeitig wird die Spezifität der Codon-Anticodon-Bindung zwischen einer mit einer Aminosäure beladenen Aminoacyl-tRNS (transport-Ribonukleinsäure) und der mRNS herabgesetzt. Diese Faktoren begünstigen die Codon-Anitcodon-Bindung einer mit einer zufälligen Aminoacyl-tRNS und somit den Einbau einer zufälligen Aminosäure in die wachsende Polypeptidkette ${ }^{85}$.

Das dieses Prinzip auch in eukaryotischen System erfolgreich eingesetzt werden kann, ist seit Mitte der 80'er Jahre bekannt. Burke und Mogg konnten zeigen, dass das mit einem Amber-Stop-Codon (UAG, an Position 38) mutierten bakterielle Gen „Chloramphenicol-Acetyl-Transferase“ (cat) in transfizierten COS-7 Zellen nach Be- 
handlung mit den Aminoglykosiden G418 und Paromomycin teilweise vollständig translatiert wurde ${ }^{86}$. Diese Eigenschaft konnte später auch für das klinisch verwendete Aminoglykosid Gentamicin bei der Initiierung eines Readthroughs für das „Cystic fibrosis transmembrane conductor protein“ (CFTR) gezeigt werden ${ }^{87}$. Erst Ende der $90^{`}$ er Jahre wurde Gentamicin bei in vivo Versuchen eingesetzt. Hierfür wurden mdxMäusen (DMD (Dystrophin) knockout-Mäuse), ein Modell für die „X-chromosomalen Muskeldystrophien Typ Becker und Duchenne“, 14 Tage mit subkutanen Injektionen von Gentamicin behandelt und anschließend ein Dystrophin-Protein mit voller Länger nachgewiesen $^{88}$. Seither wurde Gentamicin in in vitro und in vivo unter anderem an Krankheitsmodellen der zystischen Fibrose ${ }^{89}$, Muskeldystrophie des Typs Duchenne ${ }^{90}$, Hämophilie $^{91}$, retinale Degeneration ${ }^{92}$, Hurler Syndrom ${ }^{93}$ und dem Rett Syndrom ${ }^{94-96}$ auf seine Wirksamkeit untersucht.

Aufgrund der hohen Nehphro-und Ototoxizität, die bei 10-20\% der chronisch behandelter Patienten zu akuten Nierenversagen ${ }^{97,} 98$ und bei etwa $33 \%$ der behandelten Patienten zum Verlust des Gehörsinns führt ${ }^{99}$, stellt Gentamicin kein geeignetes Medikament für eine potentielle Langzeittherapie dar. Andere Aminoglykoside wie Amikacin weisen eine geringere Toxizität auf, jedoch geht diese mit einer geringeren Effinzienz bei der Initiierung eines Readthroughs einher. Um eine geringere Toxizität bei gleichzeitig erhöhter Readthrough-Effizienz zu ermöglichen, wurden die sogenannten NBKomponenten von Timor Baasov und Igor Nudelman entwickelt ${ }^{100-103}$. Grundlegend für die Herstellung dieser neuen Verbindungen war das Aminoglykosid Paromomycin, da es einen soliden Readthrough bei gleichzeitig relativ geringer Toxizität gewährleistet ${ }^{100}$. Die Struktur von Paromomycin ließ sich dabei auf ein, für den Readthrough, notwendiges Minimum reduzieren (in Rot dargestellte Regionen von Paromomycin, Abbildung 2). Die Generierung der NB-Komponenten erfolgte nun über eine gezielte Anheftung bzw. Entfernung einzelner chemischer Gruppen dieser Grundstruktur. NB54 wurde durch den Einbau der (S)-4-amino-2-hydroxybutanoyl-Gruppe des Amikacins (Grün in Abbildung 2 Amikacin bzw. NB54) in das Paromomycin-Grundgerüst erstellt, was zu einer drastischen Reduzierung der Toxizität und einer Erhöhung der ReadhroughEffizienz führte (Abbildung 2) ${ }^{101}$. 


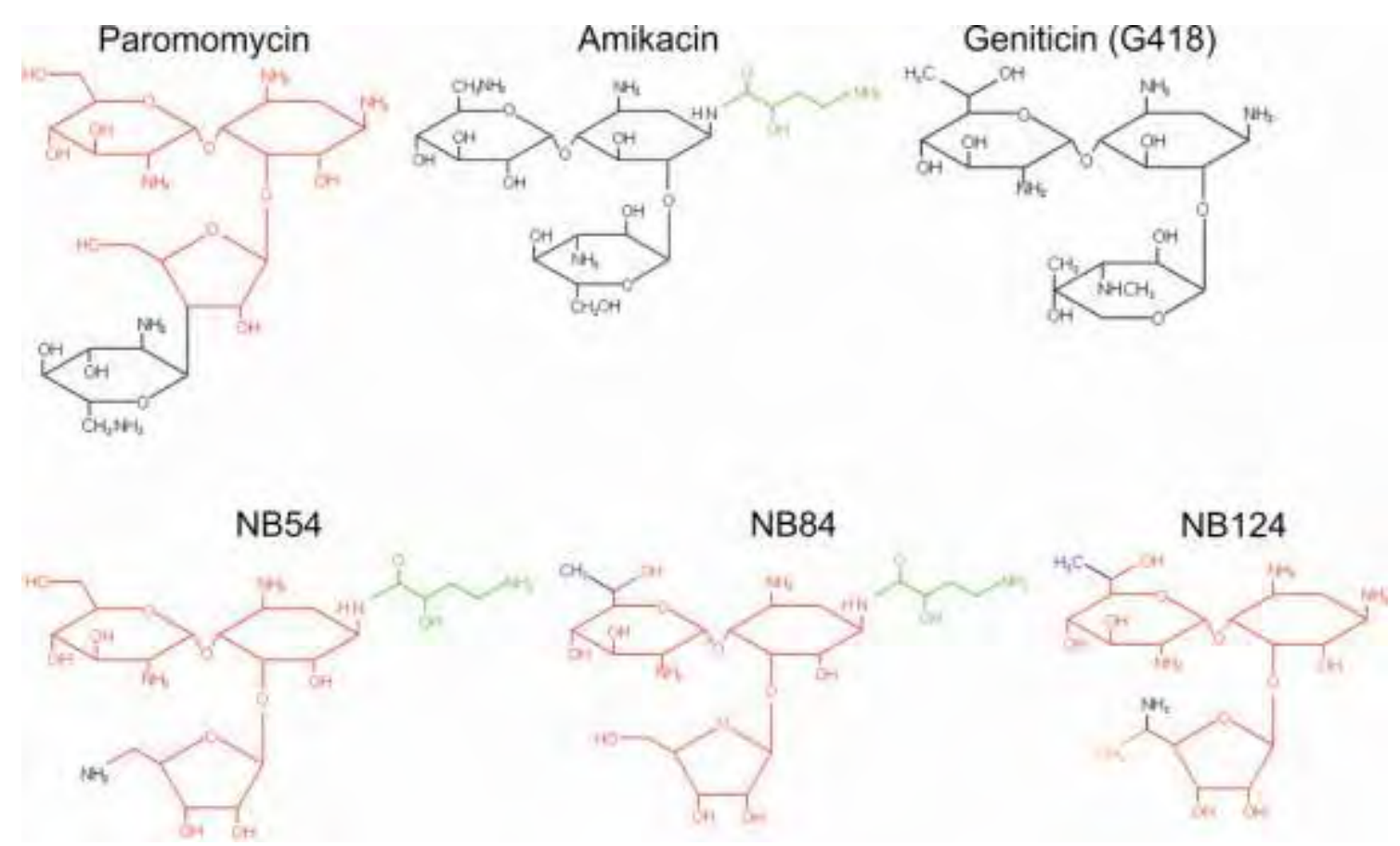

Abbildung 2: Schematische Darstellung der natürlichen Aminoglykoside Paromoycin, Geneticin, Amikacin und Gentamicin, sowie der synthetischen NB-Komponenten NB54, NB84 und NB124.

Eine weitere Erhöhung der Readthrough-Effizienz konnte durch die Übertragung einer Methylgruppe des Geneticins (Abbildung 2 Geneticin) auf die Struktur von NB54 erreicht werden. Das Resultat dieser Arbeit stellt die Komponente NB84 dar (Abbildung 2 NB84 ${ }^{104}$. Die Einführung einer zweiten Methylgruppe an die Ribose von NB84 (Abbildung 2, orange Gruppe bei NB124) zeigte einen synergetischen Effekt zu der bei NB84 eingeführten Methylgruppe bei der Initiation des Readthroughs ${ }^{103}$. Die reduzierte Toxizität und die erhöhte Effizienz bei der Einleitung des Readthroughs konnte an verschiedenen Krankheitsmodellen in vitro gezeigt werden ${ }^{94,95,101,104-107}$. Die durchgeführten Modifikationen führen $\mathrm{zu}$ einer erhöhten Affinität der NBKomponenten gegenüber den eukaryotischen Ribosomen. Da mitochondriale Ribosomen den prokayrotischen Ribosomen in ihrer Struktur ähneln, führt die erhöhte Affinität an eukaryotische Ribosomen zu einer geringeren Toxizität und einer höheren Effizienz des Readthroughs ${ }^{108}$.

Ein weiterer Ansatz ist die Verwendung niedermolekularer Substanzen wie der SMRT (small molecule readthrough)-Komponenten und PTC124. Die SMRT-Komponenten RTC\#13 und \#14 konnten bisher nur bei in vitro Modellen zur DucheneMuskeldystrophie ${ }^{109}$ und der Ataxia teleangiectatica (Louis-Bar-Syndrom) getestet werden $^{110,111}$. Diese Substanzen zeigen eine, den NB-Komponenten vergleichbare, erhöhte Readthrough-Effizienz, bei einer gleichzeitig niedrigeren Zytotoxizität ${ }^{109}$. Es ist anzu- 
nehmen das die RTC-Komponenten wie Aminoglykoside und die NB-Komponenten an die 16S rRNS (ribosomale Ribonukleinsäure) der 30S Untereinheit des prokaryotischen bzw. an die 18S rRNS der 40S Untereinheit des eukaryotischen Ribosoms binden ${ }^{112,113}$. Für PTC124 konnte gezeigt werden, dass dieses an die 60S Untereinheit des eukaryotischen Ribosoms bindet ${ }^{114-116}$. PTC124 konnte in vielen in vitro ${ }^{106,117-123}$ und in vivo ${ }^{117,124}$ Krankheitsmodellen erfolgreich getestet werden. Im Juli 2014 wurde PTC124 von der EMA (European Medicine Agency) in Europa für die Behandlung der Duchenne Muskeldystrophie im Kindesalter als Medikament (Translarna®) zugelassen (http://www.ema.europa.eu; Agency product number: EMEA/H/C/002720) ${ }^{125}$.

\subsubsection{Knochenmarktransplantation}

Bei der Knochenmarktransplantation werden dem Patienten Knochenmarkstammzellen gesunder immunkompetenter Spender intravenös injiziert. Dabei muss das Knochenmark des Empfängers vor der Transplantation durch eine Chemotherapie oder einer Ganzkörperbestrahlung mit $\gamma$-Strahlen abgetötet werden (Konditionierung). Bei der Art der Transplantation ist dabei zwischen autologer (Reinfusion eigner Stammzellen), syngener (Infusion von Stammzellen eines eineiigen Zwillingsgeschwisters (immungenetisch identisch)) oder allogener (Transplantation von Stammzellen eines immungenetisch fremden Spenders) Transplantation zu unterscheiden. Bei syngenen und allogenen Transplantationen besteht sowohl das Risiko einer Abstoßungsreaktion als auch einer Transplantat-gegen-Wirt-Reaktion (GVH (Graft vs. Host-Krankheit). Die GVHKrankheit stellt eine Immunreaktion des Transplantats dar, das sich gegen die Organe des Patienten richtet. Hierbei sind vor allem Darm, Haut, das hämatopoetische System und die Leber betroffen. Die Mortalität einer Knochenmarktransplantation liegt bei etwa $10-20 \%{ }^{126,127}$.

Die für die Transplantation benötigten $\mathrm{CD} 34^{+}$Vorläuferzellen können auf verschiedenen Wegen gewonnen werden: 1. Die direkte Entnahme von Knochenmark aus dem Beckenkamm, bei der etwa 1-2 Liter eines Blut-Knochenmark-Gemischs entnommen werden. 2. Die Isolierung mobilisierter Stammzellen aus dem Blut (Stammzellapharese) durch Injektionen des Granulozyten-Kolonie stimulierenden Faktors (G-CSF). In beiden Fällen werden nach der Entnahme CD $34^{+}$Stammzellen für die Transplantation vorbereitet $^{128,129}$. 


\subsubsection{Knochenarktransplantation und das Rett Syndrom}

Es konnte gezeigt werden, dass die Abwesenheit von MeCP2 in Astrozyten allein ebenfalls zu neurologischen Beeinträchtigungen bei Mäusen führt, die den Beeinträchtigungen bisheriger MeCP2 knockout Mausmodelle ähneln ${ }^{130,131}$. Ebenfalls konnte gezeigt werden, dass Mikroglia von MeCP2-defizienten Mäusen schwere Beeinträchtigungen aufweisen. Mikroglia sind die ansässigen Immunzellen des zentralen Nervensystems, mit hämatopoetischen Ursprung ${ }^{132}$, und spielen eine essentielle Rolle bei der Aufrechterhaltung des zellulären Umfelds ${ }^{133,134}$.

2012 konnte Noël Derecki zeigen, dass eine Knochenmarktransplantation nach einer Ganzkörperbestrahlung bei MeCP2-defizienten Mäusen eine Einwanderung von Mikroglia in das Gehirn der Mäuse verursacht und zu einer drastischen Verbesserung der Symptome, allen voran der mittleren Überlebensdauer, bei männlichen Mäusen führt $^{135}$. Die aufgestellte Hypothese dieser Arbeit war, dass die Mikroglia die Fähigkeit der Phagozytose verloren und somit die Zellreste apoptotisch verstorbener Zellen nicht mehr aus dem Gewebe des zentralen Nervensystems entfernen können. Die Anreicherung zellulärer Überreste führt zu einer Verschlechterung des Milieus des zentralen Nervensystems, wodurch die Funktion der, schon durch den Verlust von MeCP2 beeinträchtigten, Neurone weiter gestört wird. 


\section{Material und Methoden}

\subsection{Geräte}

\section{Gerätename}

Thermocycler

T3 Thermocycler

T3000 Thermocycler

\section{Zentrifugen und Rotoren}

Zentrifuge 5424

Rotor FA-45-24-11

Zentrifuge 5804R

Rotor A-4-44

Kühlzentrifuge Mikro 200R

Rotor 2424-B

Zentrifuge Universal 320

Rotor 1619

Rotor A-4-44

Kühlzentrifuge Mikro 200R

Rotor 2424-B

Zentrifuge Universal 320

Rotor 1619

\section{Histologie}

Mikrotom RM2165

Paraffinausgießstation EG1150 H

Citadel 1000

Mikroskopie

IMAGER.M1

AxioCam HRm

\section{Hersteller}

Biometra GmbH, Göttingen

Biometra GmbH, Göttingen

Eppendorf AG, Hamburg

Eppendorf AG, Hamburg

Eppendorf AG, Hamburg

Eppendorf AG, Hamburg

Andreas Hettich GmbH, Tuttlingen

Andreas Hettich GmbH, Tuttlingen

Andreas Hettich GmbH, Tuttlingen

Andreas Hettich GmbH, Tuttlingen

Eppendorf AG, Hamburg

Andreas Hettich GmbH, Tuttlingen

Andreas Hettich GmbH, Tuttlingen

Andreas Hettich GmbH, Tuttlingen

Andreas Hettich GmbH, Tuttlingen

Leica Biosystems Nussloch GmbH, Nussloch Leica Biosystems Nussloch GmbH, Nussloch Thermo Fisher Scientific GmbH, Schwerte

Carl Zeiss AG, Oberkochen

Carl Zeiss AG, Oberkochen 
$\underline{\text { Material und Methoden }}$

AxioCam HR

\section{Elektronenmikroskopie}

Vibratom VT1200S

Ultramicrotom Ultracut-S

Leica EMTP

Leica EM-Trim

EM900

Heidolph PD5201 Perfusionspumpe

\section{Molekularbiologie}

Fastblot B 43

LAS-3000

\section{Sonstiges}

Ultra Thuraxx

Dispergierwerkzeug S25N-8G

Xstrahl RS225A

FACS Canto II

Rotarod Advanced

Ultraschallprozessor UP50H
Carl Zeiss AG, Oberkochen

Leica Microsystems GmbH, Wien, Österreich

Carl Zeiss AG, Oberkochen

Heidolph Instruments GmbH \& Co. KG, Schwabach

Biometra GmbH, Göttingen

Fujifilm Europe GmbH, Düsseldorf

IKA-Werke GmbH \& Co. KG, Staufen

IKA-Werke GmbH \& Co. KG, Staufen

Xstrahl Ltd., Camberley, England

Beckman Coulter GmbH, Krefeld

TSE Systems GmbH, Bad Homburg

Hielscher Ultrasonics GmbH, Teltow 


\subsection{Software}

$\begin{array}{cc}\text { Software } & \text { Hersteller } \\ \text { VideoMot2 } & \text { TSE Systems GmbH, Bad Homburg } \\ \text { GraphPad Prism 5 } & \text { GraphPad Software, Inc., La Jolla, USA } \\ \text { ImageJ } & \text { National Institute of Health, Bethesda, } \\ \text { Struktureditor } & \text { USA } \\ & \text { SimpleSoft, Braunschweig }\end{array}$

\subsection{Chemikalien}

Soweit nicht anders erwähnt, wurden alle Chemikalien mit dem Reinheitsgrad „zur Analyse" eingesetzt und von den Firmen Carl Roth GmbH + Co. KG (Karlsruhe, Deutschland), Merck KGaA (Darmstadt, Deutschland), AppliChem GmbH (Darmstadt, Deutschland) oder SERVA Electrophoresis GmbH (Heidelberg, Deutschland) erworben.

\subsubsection{Aminoglykoside, NB-Komponenten und PTC124}

\section{Substanz}

Geneticin (G418)

Gentamicin

Neomycin

NB54

NB84

NB124

PTC124
Carl Roth $\mathrm{GmbH}+\mathrm{Co} . \mathrm{KG}$, Karlsruhe

Ratiopharm GmbH, Ulm

Sigma-Aldrich Laborchemikalien $\mathrm{GmbH}$, Hamburg

Timor Baasov, Technion -

Israel Institute of Technology,

Haifa, Israel

Selleck Chemicals, München

\subsection{Lösungen und Puffer}

\subsubsection{Kommerzielle Lösungen}

\section{Lösung}

Antibody Diluent

\section{Hersteller}

Dako Deutschland GmbH, Hamburg 
Material und Methoden

Antigendemaskierungspuffer (pH 6,1)

\section{Lösung}

DEPC (Diethyldicarbonat)

\section{DirectPCR-Tail}

DMEM (Dulbecco's Modified Eagle Medium), low/high Glucose

Eukitt

Fötales Kälberserum (FKS)

HBSS (Hank's Balanced Salt Solution)

L-Glutamin

LPS (Lipoplysaccharid) des E. col-

Serotyps R515

Lumi-Light western blotting substrate

Myco-3

OptiyLyse B

Osmiumtetraoxid

PFA $4 \%$ (Paraformaldehyd) in PBS

PBS (Phosphatbuffered solution)

peqGoldTriFast

ProLong Gold Antifade Reagent with DAPI

Rekombinantes Maus-Interferon gamma (IFN $\gamma)$

Rodent Block M
Dako Deutschland GmbH, Hamburg

\section{Hersteller}

Sigma-Aldrich Laborchemikalien GmbH,

Hamburg

PEQLAB Biotechnologie GmbH, Erlan-

gen

Biochrom GmbH, Berlin

Sigma-Aldrich Laborchemikalien GmbH, Hamburg

Biochrom GmbH, Berlin

PAA Laboratories GmbH, Pasching, Österreich

PAA Laboratories GmbH, Cölbe

Enzo Life Sciences GmbH, Lörrach

Roche Deutschland Holding GmbH, Mannheim AppliChem GmbH, Darmstadt

Beckman Coulter GmbH, Krefeld

SPI Chem West Chester, PA, USA

(Science Services, München)

Addmymetrix, Wien, Österreich

Biochrom GmbH, Berlin

PEQLAB Biotechnologie GmbH, Erlangen

Thermo Fisher Scientific GmbH, Schwer-

te

R\&D Systems GmbH, Wiesbaden-

Nordstadt

Zytomed Systems GmbH, Berlin 


\section{Lösung}

SDS (Sodium Dodecyl Sulfate) $10 \%$

Trypsin/EDTA

(Ethylendiamintetraessigsäure)

Uranylacetat

\section{Hersteller}

Thermo Fisher Scientific GmbH, Schwer-

te

PAA Laboratories GmbH, Cölbe

SPI Chem West Chester, PA, USA

(Science Services, München, Deutschland)

\subsubsection{Selbstangesetzte Lösungen und Puffer}

\begin{tabular}{|c|c|}
\hline Lösung & Konzentrati \\
\hline Tris (Tris(hydroxymethyl)-aminomethan)-HCl, pH 6,8 & $0,5 \mathrm{M}$ \\
\hline Tris-HCl, $\mathrm{pH} 8,8$ & $1,5 \mathrm{M}$ \\
\hline Tris-HCl, $\mathrm{pH} 7,5$ & $1 \mathrm{M}$ \\
\hline $\mathrm{NaCl}$ & $2 \mathrm{M}$ \\
\hline NP-40 & $10 \%$ \\
\hline Natrium-Deoxycholat & $10 \%$ \\
\hline PFA & $4 \%$ PFA \\
\hline \multicolumn{2}{|l|}{ ALSEVER's } \\
\hline $\mathrm{NaCl}$ & $70 \mathrm{mM}$ \\
\hline Tri-Natriumcitrat Dihydrat & $30 \mathrm{mM}$ \\
\hline Zitronensäure & $3 \mathrm{mM}$ \\
\hline \multicolumn{2}{|l|}{ Blot Puffer } \\
\hline Tris & $48 \mathrm{mM}$ \\
\hline Glycin & $39 \mathrm{mM}$ \\
\hline SDS & $0,04 \%$ \\
\hline Methanol & $20 \%$ \\
\hline
\end{tabular}




$\begin{array}{cc}\text { Glycidether } 100 & 21,4 \mathrm{~g} \\ \text { 2-Dodecylsäure Anhydrid } & 14,4 \mathrm{~g} \\ \text { Methynadic Anhydrid } & 11,3 \mathrm{~g} \\ \text { 10 Minuten bei RT rühren } & \\ \text { 2,4,6-Tris (dimethylaminomethyl)phenol } & 0,84 \mathrm{ml}\end{array}$

\section{FACS Puffer I}

PBS

$\mathrm{x} 1$

BSA

$0,1 \%$

Natriumazid $\left(\mathrm{NaN}_{3}\right)$

$0,01 \%$

\section{FACS Puffer II}

PBS $\quad x 1$

FKS $2 \%$

EDTA pH $8 \quad 0,01 \mathrm{M}$

Natriumazid $\left(\mathrm{NaN}_{3}\right) \quad 0,1 \%$

Karslon und Schulz (KS) Phosphatpuffer pH 7,4
$\mathrm{NaH}_{2} \mathrm{PO}_{4} * \mathrm{H}_{2} \mathrm{O}$
$15,12 \mathrm{mM}$
$\mathrm{Na}_{2} \mathrm{HPO}_{4} \cdot 2 \mathrm{H}_{2} \mathrm{O}$
$109,92 \mathrm{mM}$
$\mathrm{NaCl}$
$86,2 \mathrm{mM}$

Aqua dest.

Glutaraldehyd (25\%) $\quad 2,5 \%$

Formaldehyd (16\%) $\quad 1,6 \%$

RIPA (Radioimmunoprecipitation assay buffer) Puffer

$\begin{array}{cc}\text { Tris } & 50 \mathrm{mM} \\ \mathrm{NaCl} & 400 \mathrm{mM} \\ \mathrm{NP}-40 & 1 \%(\mathrm{v} / \mathrm{v})\end{array}$

RIPA (Radioimmunoprecipitation assay buffer) Puffer

Natrium-Deoxycholat

$0,8 \%(\mathrm{v} / \mathrm{v})$ 


\begin{tabular}{|c|c|}
\hline EDTA & $5 \mathrm{mM}$ \\
\hline SDS & $0,1 \%(\mathrm{v} / \mathrm{v})$ \\
\hline Protease-Inhibitor & \\
\hline $\begin{array}{l}\text { cOmplete, EDTA frei, Roche Deutschland Holding GmbH, Mann- } \\
\text { heim }\end{array}$ & $\mathrm{x} 1$ \\
\hline SDS-Laufpuffer (x5) & \\
\hline Tris & $120 \mathrm{mM}$ \\
\hline Glycin & $1,04 \mathrm{M}$ \\
\hline SDS & $0,625 \%$ \\
\hline
\end{tabular}

TBST-Waschpuffer für Western Blots

$\begin{array}{cc}\text { Tris } & 20 \mathrm{mM} \\ \mathrm{NaCl} & 150 \mathrm{mM} \\ \text { Tween20 } & 0,05 \%(\mathrm{v} / \mathrm{v})\end{array}$

TBST-Waschpuffer für Immunfluoreszenzfärbungen

$\begin{array}{cc}\text { Tris } & 20 \mathrm{mM} \\ \mathrm{NaCl} & 150 \mathrm{mM} \\ \text { Tween20 } & 0,025 \%(\mathrm{v} / \mathrm{v})\end{array}$

\subsection{Kits}

Alle in dieser Arbeit verwendeten Kits wurden nach den Vorgaben des Herstellers verwendet.

Kit

Effectene Transfection Reagent

FITC-Labeling Kit

Taq DNA Polymerase

Kit

TaqMan Reverse Transcription Reagents
Hersteller

Qiagen GmbH, Hilden

Pierce Perbio Science, Germany

Qiagen $\mathrm{GmbH}$, Hilden

\section{Hersteller}

Thermo Fisher Scientific GmbH, Schwerte 


\subsection{Antikörper}

\subsubsection{Primäre Antikörper}

$\begin{array}{ccc}\text { Antigen } & \text { Spezies } & \text { Hersteller } \\ \text { MeCP2 } & \text { Kaninchen } & \text { Cell Signaling Technology, Danvers, USA } \\ \text { Tubulin } & \text { Maus } & \text { Sigma-Aldrich Laborchemikalien GmbH, Ham- } \\ \text { burg }\end{array}$

Antikörper für Durchflusszytometrie

$\begin{array}{cccc}\text { Antigen } & \text { Spezies } & \text { Konjugat } & \text { Hersteller } \\ \text { CD4 } & \text { Maus } & \text { PerCP } & \text { BD Bioscience, Heidelberg } \\ \text { CD8 } & \text { Ratte } & \text { Cy7 } & \text { eBioscience GmbH, Frankfurt am Main } \\ \text { CD11b } & \text { Ratte } & \text { Pacific-Blue } & \text { Biolegend, Fell } \\ \text { CD11b } & \text { Maus } & \text { APC } & \text { eBioscience GmbH, Frankfurt am Main } \\ \text { GR-1 } & \text { Maus } & \text { APC-Cy7 } & \text { BD Bioscience, Heidelberg } \\ \text { CD45.1 } & \text { Maus } & \text { PE } & \text { BD Bioscience, Heidelberg } \\ \text { CD45.2 } & \text { Maus } & \text { APC } & \text { BD Bioscience, Heidelberg } \\ \text { MHC-I } & \text { Maus } & \text { AlexaFluor647 } & \text { Biolegend, Fell } \\ \text { MHC-II } & \text { Maus } & \text { APE } & \text { Biolegend, Fell } \\ \text { TCRb } & \text { Maus } & \text { FITC } & \text { BD Bioscience, Heidelberg }\end{array}$




\subsubsection{Sekundäre Antikörper}

\begin{tabular}{|c|c|c|c|}
\hline Antigen & Spezies & Konjugat & Hersteller \\
\hline Kaninchen-IgG & Ziege & $\begin{array}{l}\text { Meerettich- } \\
\text { peroxidase }\end{array}$ & $\begin{array}{c}\text { Jackson ImmunoResearch Europe } \\
\text { Ltd., Suffolk, England }\end{array}$ \\
\hline Kaninchen-IgG & Ziege & Су-3 & $\begin{array}{l}\text { Jackson ImmunoResearch Europe } \\
\text { Ltd., Suffolk, England }\end{array}$ \\
\hline Maus-IgG & Esel & $\begin{array}{l}\text { Meerettich- } \\
\text { peroxidase }\end{array}$ & $\begin{array}{c}\text { Jackson ImmunoResearch Europe } \\
\text { Ltd., Suffolk, England }\end{array}$ \\
\hline
\end{tabular}

\subsection{Allgemeine Molekularbiologische Methoden}

\subsubsection{Isolierung von Gesamt-RNS aus Mausgehirn}

Gesamt-RNS aus Mausgehirnen wurde mittels peqGOLD TriFast nach Angaben des Herstellers isoliert. Die Gehirne wurden in kleinere Fragmente geschnitten und nachfolgend mittels „Ultra Thuraxx“ und eines RNase-freien Dispergierwerkzeuges zerkleinert. Hierfür wurden $800 \mu 1$ TriFast für ein halbes Gehirn verwendet. Nach einer 5 minütigen Inkubation bei Raumtemperatur wurden $200 \mu \mathrm{L}$ zu jedem Ansatz hinzugefügt, für weitere 10 Minuten bei Raumtemperatur inkubiert und anschließend für 5 Minuten bei $12.000 * \mathrm{~g}$ und $4{ }^{\circ} \mathrm{C}$ zentrifugiert. Der die RNS enthaltende wässrige Überstand wurde mit gleichem Volumen Isopropanol gefällt, 15 Minuten bei $4^{\circ} \mathrm{C}$ inkubiert und anschließend für 10 Minuten bei $12.000 * \mathrm{~g}$ und $4^{\circ} \mathrm{C}$ zentrifugiert. Das RNS-Pellet wurde mit 70 $\%$ Ethanol in DEPC gewaschen, in DEPC-Wasser (0,1\% DEPC) aufgenommen und anschließend bei $-80^{\circ} \mathrm{C}$ gelagert.

\subsubsection{Synthese von cDNS}

Die Synthese komplementärer (engl. complentary) DNS (cDNS) erfolgte mit Hilfe des Kits „TaqMan Reverse Transcription Reagents“ nach Angaben des Herstellers. Hierfür wurden $1.000 \mu \mathrm{g}$ Gesamt-RNS eingesetzt. Für die Synthese dienten ,zufällige Hexamere“, sechs zufällig aneinander synthetisierte Nukleotide, als Primer. Um einen Abbau von RNS zu verhindern wurde dem Ansatz ein RNase-Inhibitor zugesetzt. Die Synthese der cDNS erfolgte in einem Thermocycler mit folgendem Programm: 
Material und Methoden

$\begin{array}{ll}25^{\circ} \mathrm{C} & 10^{\circ} \\ 48^{\circ} \mathrm{C} & 30^{\circ} \\ 95^{\circ} \mathrm{C} & 5^{\circ}\end{array}$

\subsubsection{Isolierung genomischer DNS aus Mausschwänzen}

Die Isolierung genomischer DNS zur Bestimmung des Genotyps der Mäuse erfolgte mittels DirectPCR-Tail. Die Biopsien wurden über Nacht bei $55^{\circ} \mathrm{C}$ inkubiert und die Reaktion wurde am Folgetag bei einer Temperatur von $85{ }^{\circ} \mathrm{C}$ abgestoppt. Gewebereste wurden für die PCR-Reaktion abzentrifugiert.

\subsubsection{Polymerase-Kettenreaktion (PCR)}

Die Amplifikation spezifischer DNS Sequenzen erfolgte mit Taq Ploymerase (Quiagen, Hilden) und sequenzspezifischen Primern. Als Templates dienten cDNS und genomische DNS.

Primer

$$
\begin{gathered}
\text { Geno-Neo for } \\
\text { Geno-Neo rev } \\
\text { Mecp2 Ex3/4 for } \\
\text { Mecp2 Ex3/4 rev }
\end{gathered}
$$

Sequenz

\author{
GCC TGA AGG TTG GAC ACG AAA GC \\ GGG CTA GAC TGA ATA TCT TTG GTT GGT AC \\ GAT CTG CTG GAA AGT ATG ATG \\ CTG GAG CTT TGG GAG ATT
}

\subsection{Herstellung von Proteinlysaten}

Die Isolation der Proteine erfolgte mit einfacher Lyse bei Zelllinien oder mittels mechanischen Gewebeaufschluss in Kombination mit Zelllyse bei Geweben. Für die Lyse von inkubierten Zellen wurden diese mit PBS gewaschen und nach Zugabe von $250 \mu \mathrm{l}$ RIPA-Puffer für 15 Minuten bei $4{ }^{\circ} \mathrm{C}$ unter gelegentlichem Abschlagen inkubiert. Anschließend wurde der proteinhaltige Überstand nach der Zentrifugation für 30 Minuten bei $4{ }^{\circ} \mathrm{C}$ und $18.000 * \mathrm{~g}$ abgenommen und bei $-80{ }^{\circ} \mathrm{C}$ gelagert. Mausgewebe wurden mittels „Ultra Thuraxx“ und Dispergierwerkzeug in RIPA-Puffer zerkleinert und 30 Minuten auf Eis inkubiert. Anschließend wurde die DNS mit 5 Ultraschallpulsen (Amplitude $100 \%$, Frequenz 0,5 Herz) geschert. 


\subsection{SDS-Polyacrylamidelektrophorese und Western Blot}

Für den immunologischen Nachweis von Proteinen wurden Lysate aus Geweben und Zellen mittels Elektrophorese unter denaturierenden Bedingungen (SDS-PAGE) nach ihrer Größe aufgetrennt. Standardmäßig erfolgte die Elektrophorese mit 1 \%igen Sammelgelen und $10 \%$ igen Trenngelen. Die Proteinlysate wurden im Verhältnis 1:3 mit 4xLaemmli-Ladepuffer versetzt und 5 Minuten bei $95{ }^{\circ} \mathrm{C}$ denaturiert. Anschließend wurden die Proteine und der Marker (PageRuler Plus Prestained Protein Ladder, Thermo Fisher Scientific, Schwerte) geladen und für $2 \mathrm{~h}$ bei $80 \mathrm{~V}$ elektrophoretisch getrennt. Der Transfer der Proteine auf eine Nitrocellulosemembran erfolgte über das semi-dry Blot-Verfahren mit $2 \mathrm{~mA} / \mathrm{cm}^{2}$ für 90 Minuten. Anschließend wurden die Membranen in TBST gewaschen und mit $5 \%$ Trockenmilch in TBST für $1 \mathrm{~h}$ blockiert. Alle Antikörper wurden in $5 \%$ Trockenmilch in TBST verdünnt und eine Stunde bei Raumtemperatur oder über Nacht bei $4{ }^{\circ} \mathrm{C}$ inkubiert. Nach drei Waschschritten von je 15 Minuten wurde die Membran mit dem jeweiligen Sekundärantikörper in $5 \%$ Trockenmilch in TBST für eine Stunde bei Raumtemperatur inkubiert. Die Detektion des Signals erfolgte nach drei weiteren Waschschritten mittels „Lumi Light Western Blotting Substrate“ (Roche) und einem digitalen Detektionssystem (LAS-3000, FujiFilm).

\subsection{Immunfluoreszenzfärbungen}

Um die Gewebe der MeCP2 $2^{\mathrm{R} 168 \mathrm{X}}$-Mäuse in immunologischen Färbungen analysieren zu können, wurden diese nach der Tötung, durch Genickbruch, der Tiere in PBS gewaschen und über Nacht in $4 \%$ PFA/PBS fixiert. Die Präparate wurden $1 \mathrm{~h}$ bei $4{ }^{\circ} \mathrm{C}$ mit PBS gewaschen und in $70 \%$ Ethanol bis zur Einbettung aufbewahrt. Die Einbettung erfolgte automatisiert mittels des Einbettautomaten „Citadel 1000“ und folgendem Programm:

$\begin{array}{ccc}\text { Schritt } & \text { Lösung } & \text { Dauer [h:min] } \\ 1 & 70 \% \mathrm{EtOH} & 3: 30 \\ 2 & 80 \% \mathrm{EtOH} & 2: 00 \\ 3 & 96 \% \mathrm{EtOH} & 1: 00 \\ 4 & 100 \% \mathrm{EtOH} & 1: 00 \\ 5 & 100 \% \mathrm{EtOH} & 1: 00\end{array}$




$\begin{array}{ccc}\text { Schritt } & \text { Lösung } & \text { Dauer [h:min] } \\ 6 & 100 \% \text { EtOH } & 1: 00 \\ 7 & \text { Xylol } & 1: 30 \\ 8 & \text { Xylol } & 1: 30 \\ 9 & \text { Paraffin } & 1: 00 \\ 10 & \text { Paraffin } & 1: 00 \\ 11 & \text { Paraffin } & 3: 00\end{array}$

Nach der Fixierung musste die Antigenität wieder hergestellt werden (Demaskierung). Hierfür wurden die Schnitte für 40 Minuten bei $90{ }^{\circ} \mathrm{C}$ in einem Antigendemaskierngspuffer ( $\mathrm{pH} \mathrm{6,1)} \mathrm{erwärmt.} \mathrm{Um} \mathrm{nicht-spezifische} \mathrm{Bindungen} \mathrm{der}$ primären Antikörper zu vermeiden wurden unspezifische Bindungsstellen und MausIgG's mit „Rodent Block“ blockiert. Die Schnitte wurden mit den primären Antikörper über Nacht bei $4{ }^{\circ} \mathrm{C}$ in einer feuchten Kammer inkubiert. Nach zwei 5 minütigen Waschschritten wurden die Schnitte mit dem jeweils zum Primärantikörper passenden Sekundärantikörper $1 \mathrm{~h}$ bei RT gelagert und anschließend zweimal 5 Minuten gewaschen und mit „ProLong Gold“ eingedeckelt. Die Mikroskopie erfolgte nach allen Färbungen mit dem „Imager.M1“ (Carl Zeiss) mit einer 400 fachen Vergrößerung.

\subsection{Zellkultur}

Die in dieser Arbeit verwendeten Zellkulturmedien, DMEM low/high glucose, wurden mit $10 \%$ FKS und $1 \%$ L-Glutamin versetzt. Auf den Gebrauch von Pen/Strep (Penicillin/ Streptomycin) wurde aufgrund des zu untersuchenden Readthroughs verzichtet.

\subsubsection{HeLa-Zellen}

HeLa-Zellen wurden für Versuche verwendet bei denen ein Konstrukt (von Dr. Cornelia Brendel zur Verfügung gestellt) mit der Mutation $\mathrm{MeCP} 2^{\mathrm{R} 168 \mathrm{X}}(c .502 C>T)$ transient in die Zellen transfiziert werden musste. Die Versuche dienten zur Verifizierung der Readthrough-Funktion. Als Kontrollen dienten hier sowohl nicht-transfizierte Zellen als auch Zellen, die mit dem Konstrukt transfiziert jedoch nicht behandelt wurden. $3 * 10^{5}$ Zellen wurden in 6-Well Kulturschalen ausgesät und über Nacht bei $37{ }^{\circ} \mathrm{C}$ und $5 \% \mathrm{CO}_{2}$ inkubiert. Den Angaben des Herstellers folgend wurden $2 \mu \mathrm{g}$ des Konstrukts mit dem Transfektionsansatz zu den Zellen dazu gegeben und für $8 \mathrm{~h}$ inkubiert. 


\subsubsection{Mausohr-Fibroblasten}

Mausohr-Fibroblasten wurden für Readthrough-Versuche des endogenen MeCP2 $2^{\mathrm{R} 168 \mathrm{X}}$ $(c .502 A>T)$ aus transgenen Mäusen verwendet. Als Kontrollen dienten Fibroblasten aus Ohren gesunder Mäuse. Hierfür wurden von, bereits in einem anderen Experiment verwendeten, Mäusen Teile der Ohren abgeschnitten, mit Isopropanol abgesprüht und in DMEM aufbewahrt. Die Ohren wurden in kleine Stücke geschnitten auf den Boden einer zuvor mit Medium benetzten $25 \mathrm{~cm}^{2}$ Zellkultur-Flasche gelegt. Die Flasche wurde senkrecht für $1 \mathrm{~h}$ bei $37^{\circ} \mathrm{C}$ aufbewahrt. Anschließend wurde die Flasche langsam um 90 ${ }^{\circ}$ gedreht und über Nacht bei $37{ }^{\circ} \mathrm{C}$ und $5 \% \mathrm{CO}_{2}$ gelagert. Nachfolgend wurden $3 \mathrm{ml}$ Medium langsam hinzugegeben und die Gewebe für etwa zwei Wochen kultiviert, bis genügend Fibroblasten ausgewachsen waren. Diese wurden vermehrt und für Experimente verwendet.

\subsection{Verwendete Mauslinien}

Haltung und Zucht aller in dieser Arbeit verwendeten Mauslinien erfolgte in der „Zentralen Tierexperimentellen Einrichtung“ unter Leitung von Frau Dr. med. vet. Sarah Kimmina. Die Haltung der Mäuse erfolgte in einem 12:12 (h:h) Hell-Dunkel-Rhythmus, wobei die Tiere mit Wasser und Futter ad libitum versorgt wurden.

\subsubsection{MeCP2 ${ }^{\mathrm{R} 168 \mathrm{X}}$-Mäuse}

Die Generierung der MeCP2 $2^{\mathrm{R} 168 \mathrm{X}}-$ Mäuse erfolgte durch Dr. Cornelia Brendel ${ }^{95}$. Für die Zucht wurden heterozygote Weibchen mit C57BL6/J-Männchen verpaart. Die Genotypisierung erfolgte mittels PCR mit den Primern Geno-Neo for und Geno-Neo rev (2.7.4) und folgendem PCR-Programm: 
Material und Methoden

$\begin{array}{ll}95^{\circ} \mathrm{C} & 5^{\circ} \\ 95^{\circ} \mathrm{C} & 30^{\circ ،} \\ 58^{\circ} \mathrm{C} & 30^{\circ} \\ 72^{\circ} \mathrm{C} & 30^{\circ} \\ 72^{\circ} \mathrm{C} & 5^{\circ} \\ 10^{\circ} \mathrm{C} & \infty\end{array}$

Ein Wildtypallel ergab dabei eine Länge von 300 bp und ein mutiertes Allel eine Länge von $330 \mathrm{bp}$.

\subsubsection{B6.SJL-Ptprca Pepcb/BoyJ-Mäuse}

Die B6.SJL-Ptprc ${ }^{a} P e p c^{b}$ /BoyJ Mäuse (im Weiteren kurz „CD45.1“ genannt) dienten als Spendertiere für die Knochenmarktransplantation und wurden freundlicherweise von Prof. Dr. Holger Reichardt (Abteilung Zelluläre und Molekulare Immunologie, Universitätsmedizin Göttingen) zur Verfügung gestellt. Die Zucht dieser Linie erfolgte mit ausschließlich homozygoten Tieren so dass diese keiner Genotypisierung unterzogen werden mussten.

\subsection{Stop-Codon Readthrough-Therapie}

Für in vitro und in vivo Therapien wurden folgende Substanzen verwendet:

$\begin{array}{ccc}\text { Aminoglykoside } & \text { NB-Komponenten } & \text { Niedermolekulare Substanzen } \\ \text { Gentamicin } & \text { NB54 } & \text { PTC124 } \\ \text { Geneticin (G418) } & \text { NB84 } & \\ \text { Neomycin } & \text { NB124 }\end{array}$

Detaillierte Angaben der verwendeten Konzentrationen befinden sich in den jeweiligen Punkten des Ergebnissteils (Tabelle 6, Tabelle 7 und Tabelle 8).

\subsubsection{Readthrough-Behandlung in vitro}

Für in vitro Behandlungen wurden sowohl transient transfizierte HeLa-Zellen als auch Mausohr-Fibroblasten aus mutationstragenden $\left(\mathrm{MeCP}^{\mathrm{R} 168 \mathrm{X} / \mathrm{y}}\right)$ und gesunden männlichen $\left(\mathrm{MeCP} 2^{\mathrm{WT}}\right.$ ) Mäusen genutzt. Die verwendeten Substanzen (Tabelle 6) wurden dem Medium in löslicher Form zugegeben und das Medium alle zwei Tagen gewechselt. Nach der fünftägigen Behandlung wurden die Zellen geerntet (siehe 2.8). 


\subsubsection{Readthrough-Behandlung in vivo}

Für die Behandlung von MeCP2 $2^{\mathrm{R} 168 \mathrm{X} / \mathrm{y}}$ (symptomatisch) und $\mathrm{MeCP} 2^{\mathrm{WT} / \mathrm{y}}$ (gesund) Männchen wurden ebenfalls die in Punkt 2.13 aufgeführten Substanzen verwendet. Die Substanzen Gentamicin (Refobacin ${ }^{\circledR}$, Merck Soreno, Darmstadt, Deutschland), NB54, NB84 und NB124 wurden dabei sowohl intraperitoneal (i.p.) wie auch subkutan (s.c.) injiziert. Eine weitere Applikationsform für die Substanzen Gentamicin, NB54 und NB84 stellte dabei die Implantation einer osmotischer Pumpen der Marke „ALZET“ (Charles River Laboratories, Research Models and Services, Germany GmbH, Sulzfeld, Deutschland) dar. Die Pumpen des Models „1004“ ermöglichten eine 28-tägige Behandlung der Tiere mit 35 mg Gentamicin/ kg/ Tag. Die Implantation der Pumpe erfolgte subkutan dorsal, unter Isoflurannarkose (Abbott GmbH, Wiesbaden, Deutschland) und Gabe der Analgetika Finadyne (Essex Tierarznei, München, Deutschland) und Metapyrin (MEDISTAR Arzneimittelvertrieb GmbH, Ascheberg, Deutschland). Alle Tierversuche erfolgten mit der Genehmigung des Niedersächsischen Landesamtes für Verbraucherschutz und Lebensmittelsicherheit (LAVES) und der Zentralen Tierexperimentellen Einrichtung (ZTE) der Universitätsmedizin Göttingen (UMG).

\subsection{Knochenmarktransplantation}

Für eine erfolgreiche Rekonstitution des Knochenmarks muss das Knochenmark der Empfängertiere zuerst ablatiert werden. Dies wird über eine Ganzkörperbestrahlung mit $\gamma$-Strahlen von einer Gesamtdosisleitung von 12,5 Gray (Gy) erreicht. Die Bestrahlung erfolgte mittels „RS 225 X-Ray Research System“ (X-Strahl Ltd., Camberley, England) betrieben bei $200 \mathrm{kV}, 15 \mathrm{~mA}$ und mit einem 0,5 mm dünnen Kupfer-Filter. Die Tiere mussten vor dem Auftreten der ersten Symptome ( Tag 33) transplantiert werden. Die Bestrahlung wurde auf 2 Sitzungen geteilt, da die Tiere eine Einzelbestrahlung mit 12,5 Gy, aufgrund der geringen Körpergröße nicht überleben würden. Bei der ersten Sitzung wurden die Tiere mit 3,5 Gy und 48 Stunden später mit 9 Gy bestrahlt. Um Infektionen der bestrahlten Tiere zu vermeiden wurden ab einem Tag vor der ersten Bestrahlung bis 3 Wochen nach der Transplantation $25 \mu \mathrm{g} / \mathrm{ml}$ Neomycin dem Trinkwasser hinzugefügt und das Trinkwasser alle zwei Tage gewechselt. Um nach der Transplantation des Knochenmarks eine Aussage über die Effizienz der Rekonstitution machen zu können wurde das Knochenmark jeweils aus geschlechts-und altersgepaarten B6.SJL-Ptprc ${ }^{a} P e p c^{b} /$ BoyJ-Mäusen isoliert. Die Tiere dieser Linie un- 
Material und Methoden

terscheiden sich im Oberflächenmolekül CD45 in der Ausprägung CD45.1 ${ }^{+}$bzw. Ptprc ${ }^{\mathrm{a}}$ (Protein tyrosine phosphatase, receptor type, C), während Tiere mit dem genetischen Hintergrund C57BL6/J normalerweise CD45.2 $2^{+}$bzw. Ptprc ${ }^{\mathrm{b}}$ positiv sind. Die Isolation des geschlechtsidentischen Knochenmarks, aus gesunden CD45.1 ${ }^{+}$-, $\mathrm{MeCP} 2^{\mathrm{R} 168 \mathrm{X} / \mathrm{y}}$ - und MeCP2 $2^{\mathrm{R} 168 \mathrm{X} / \mathrm{x}}$-Mäusen, erfolgte durch Freilegung der Femores nach Euthanasie der Tiere mit $\mathrm{CO}_{2}$. Hierbei wurden die Epiphysen an beiden Seiten des Knochens mit einer sterilen Schere abgeschnitten. Das Knochenmark wurde mit 5 ml PBS mit 0,5 \% BSA und einer 24G Kanüle aus dem Knochen gespült und mit einer 20G Kanüle durch aufziehen und ausdrücken homogenisiert. Anschließend wurde das Homogenat durch ein $40 \mu \mathrm{m}$ Zellsieb (Beckman Coulter GmbH, Krefeld) gedrückt um es von Geweberesten $\mathrm{zu}$ befreien und bis zur Injektion bei $4{ }^{\circ} \mathrm{C}$ gelagert. Die Injektion des frisch isolierten Knochenmarks erfolgte 4 Stunden nach der zweiten Bestrahlung. Die Empfängertiere wurden mit Isofluran betäubt und $5^{*} 10^{6}$ Knochenmarkzellen mit einer sterilen Insulinspritze 30G (Beckman Coulter GmbH, Krefeld) in den retrobulbären Venenplexus injiziert.

Aus der Kombination der Isolierten Spenderzellen und nach Injektion in die Empfängertiere ergaben sich somit folgende Gruppen:

$\begin{array}{ccc}\text { Gruppe } & \text { Spendertier } & \text { Empfängertier } \\ \mathrm{MeCP}^{\mathrm{WT} / \mathrm{y}}(\mathrm{WT}) & - & - \\ \mathrm{MeCP}^{\mathrm{WT} / \mathrm{x}}(\mathrm{WT}) & - & - \\ \mathrm{R} 168 \mathrm{X} / \mathrm{y} & - & - \\ \mathrm{R} 168 \mathrm{X} / \mathrm{x} & - & \mathrm{MeCP} 2^{\mathrm{WT} / \mathrm{y}} \\ \mathrm{WT} \rightarrow \mathrm{WT} & \mathrm{MeCP} 2^{\mathrm{WT} / \mathrm{y}} & \mathrm{MeCP} 2^{\mathrm{R} 168 \mathrm{X} / \mathrm{x}} \\ \mathrm{WT} \rightarrow \mathrm{WT} & \mathrm{MeCP} 2^{\mathrm{R} 168 \mathrm{X} / \mathrm{x}} & \mathrm{MeCP} 2^{\mathrm{R} 168 \mathrm{X} / \mathrm{y}} \\ \mathrm{WT} \rightarrow \mathrm{R} 168 \mathrm{X} / \mathrm{y} & \mathrm{MeCP} 2^{\mathrm{WT} / \mathrm{y}} & \mathrm{MeCP} 2^{\mathrm{R} 168 \mathrm{X} / \mathrm{x}} \\ \mathrm{WT} \rightarrow \mathrm{R} 168 \mathrm{X} / \mathrm{x} & \mathrm{MeCP} 2^{\mathrm{WT} / \mathrm{x}} & \mathrm{MeCP} 2^{\mathrm{R} 168 \mathrm{X} / \mathrm{y}} \\ \mathrm{R} 168 \mathrm{X} / \mathrm{y} \rightarrow \mathrm{R} 168 \mathrm{X} / \mathrm{y} & \mathrm{MeCP} 2^{\mathrm{R} 168 \mathrm{X} / \mathrm{y}} & \end{array}$

\subsubsection{FACS-Analyse zum Nachweis der Konchenmarkrekonsti- tution}

Zur Überprüfung der Effizienz der Knochenmarktransplantation wurde allen Tieren fünf Wochen nach der Transplantation Blut aus der Schwanzvene abgenommen. Um eine 
Koagulation der Blutproben zu verhindern, wurden diese bis zur Weiterverarbeitung in Alsever's Lösung aufbewahrt. Das Blut wurde für 5 Minuten bei Raumtemperatur und $370 *$ g abzentrifugiert und zweimal mit FACS-(fluorescence-activated cell sorting) Puffer I gewaschen (Zentrifugation bei Raumtemperatur und $370 * \mathrm{~g}$ ). Die Fluorophorgekoppelten Antikörper (2.6.1) wurden 1:1.00 bis 1:2.00 fach verdünnt und zusammen den Proben zugefügt. Der Ansatz wurde kurz gevortext und für 20 Minuten bei $4{ }^{\circ} \mathrm{C}$ inkubiert. Nach einem weiteren Waschschritt wurden die verbliebenen Erythrozyten mit OptiLyse B für 1 Stunde bei Raumtemperatur im Dunkeln verdaut. Nach einem letzten Waschschritt wurde der Überstand abgeschüttet und im FACS CantoII (Beckman Coulter GmbH, Krefeld) gemessen.

\subsubsection{Isolierung von Mikroglia neugeborener MeCP2 ${ }^{\mathrm{R} 168 \mathrm{x}_{-}}$ Mäuse}

Um Mikroglia von männlichen $\mathrm{MeCP} 2^{\mathrm{R} 168 \mathrm{X}}$-Mäusen untersuchen zu können, mussten diese aus Gehirnen neugeborener Mäuse isoliert werden. Nach Tötung der Tiere durch Dekapitation wurden die Meningen (Dura mater encephali, Arachnoidea encephali und Pia mater encephali) mit einer Pinzette entfernt. Anschließend wurden alle verbliebenen und sichtbaren Blutgefäße ebenfalls mit einer Pinzette entfernt und die Gehirne anschließend in DMEM mit $10 \%$ FKS bei $4{ }^{\circ} \mathrm{C}$ aufbewahrt. Für die Erstellung von Einzelzellsuspensionen wurde das Medium vollständig abgesaugt und mit $100 \mu 1$ Trypsin für fünf Minuten bei $37^{\circ} \mathrm{C}$ inkubiert und anschließend kurz geschüttelt. Nach einer weiteren fünfminütigen Inkubation bei $37{ }^{\circ} \mathrm{C}$ wurde der Lösung $50 \mu 1$ DNase zugegeben und ein weiteres Mal für fünf Minuten bei $37^{\circ} \mathrm{C}$ inkubiert. Anschließend wurden die Zellen in, mit poly-L-Lysin beschichteten, $75 \mathrm{~cm}^{2}$ Flaschen ausgesät und bei $37{ }^{\circ} \mathrm{C}$ mit $5 \% \mathrm{CO}_{2}$ inkubiert.

\subsubsection{Untersuchung der Phagozytoseaktivität und der Expressi- on von MHC-I und MHC-II als Reaktion auf externe Sti- muli}

Die Analyse der Phagozytose und der Expression der Haupthistokompatibilitätskomplexe I und II (Major Histocompatibilty Complex I bzw. II (MHC-I bzw. -II)) erfolgte mittels FACS-Analyse. Je nach Anzahl vorhandener Zellen wurden mindestens Duplikate mit $2 * 10^{5}$ Zellen pro Durchlauf angefertigt. Die Zellen wurden für 24 Stunden in Anwesenheit von $10 \mathrm{ng}$ LPS/ ml oder $10 \mathrm{ng} \mathrm{INF} / \mathrm{ml}$ stimuliert. $10 \mathrm{ng} / \mathrm{ml}$ 
Material und Methoden

floureszenz-markiertes Myelin wurden zwei Stunden vor der Messung dem Medium zugesetzt. Zellen, die als Kontrolle dienten, wurden nur mit dem Medium inkubiert. Die Zellen wurden nach Inkubation mit 0,05\% Trypsin + 0,02\% EDTA für fünf Minuten bei $37{ }^{\circ} \mathrm{C}$ inkubiert, die Trypsin-Reaktion durch Zugabe von Medium abgestoppt, die Zellen vorsichtig abgekratzt und in 1,5 ml Reaktionsgefäße überführt. Die Zellen wurden für zehn Minuten bei $700 * \mathrm{~g}$ bei $4^{\circ} \mathrm{C}$ abzentrifugiert und in FACS Puffer II resuspendiert. Nach wiederholter Zentrifugation erfolgte ein Blockierungs-Schritt für zehn Minuten bei $4^{\circ} \mathrm{C}$. Anschließend wurden die Fluorophor-gekoppelten Antikörper gegen CD11b, MHC-I und MHC-II in einer Endverdünnung von 1:200 zugegeben und für 25 Minuten bei $4^{\circ} \mathrm{C}$ im dunklen inkubiert. Nach Abstoppen der Reaktion durch die Zugabe von FACS Puffer II wurden die Zellen erneut zentrifugiert, in FACS Puffer II resuspendiert und mittels analysiert. Für die Analyse der Myelinphagozytose wurde die Zahl der prozentuale Anteil der CD11b- und Myelin-positiven Zellen ausgewertet. Für die Auswertung der Expression der Oberflächenmoleküle MHC-I und MHC-II wurde die mittlere Fluoreszenzintensität der CD11b und MHC-I bzw. MHC-II positiven Zellen herangezogen.

\subsubsection{Untersuchung der Phagozytoseaktivität von MeCP2 ${ }^{\mathrm{R} 168 \mathrm{X}_{-}}$ Mikroglia mittels Elektronenmikroskopie}

Für die Elektronenmikroskopie wurden die Mäuse mit einer intraperitonealen Injektion von 0,2 ml Avertin (Sigma-Aldrich, Sigma-Aldrich Laborchemikalien GmbH, Hamburg) pro $10 \mathrm{~g}$ Körpergewicht anästhesiert. Die Perfusion erfolgte mit einer konstanten Durchlaufgeschwindigkeit von $1 \mathrm{ml} / \mathrm{min}$ mit 3,5 ml Salzlösung nach Hanks (HBSS) gefolgt von $15 \mathrm{ml}$ Fixativ nach Karlson und Schulz ${ }^{136}$ (siehe 2.4.2). Die Gehirne wurden anschließend frei-präpariert und mit einem Vibratom (Leica VT1200S) saggital in 200 $\mu \mathrm{M}$ dünne Scheiben geschnitten. Die zu untersuchenden Regionen (Corpus callosum und Hippocampus) wurden mit einem „Harris punch“ (Harris Univore 2mm,) ausgestanzt und nach einer Postfixierung in Karlson und Schulz-Puffer für mindesten 24 Stunden nach folgendem Protokoll mit dem automatisierten Einbettsystem EMTP (Leica Microsystems GmbH, Wetzlar) in Epon eingebettet:

Reagenz

Phosphatpuffer 0,1 M

Phosphatpuffer $0,1 \mathrm{M}$
Zeit

15 Minuten

15 Minuten
Temperatur

$4{ }^{\circ} \mathrm{C}$

$4{ }^{\circ} \mathrm{C}$ 


\section{Reagenz Zeit $\quad$ Temperatur}

\begin{tabular}{|c|c|c|}
\hline Phosphatpuffer 0,1 M & 15 Minuten & $4{ }^{\circ} \mathrm{C}$ \\
\hline $\mathrm{OsO}_{4}$ in $0,1 \mathrm{M}$ PBS & 4 Stunden & $4{ }^{\circ} \mathrm{C}$ \\
\hline Phosphatpuffer 0,1 M & 15 Minuten & $4{ }^{\circ} \mathrm{C}$ \\
\hline Phosphatpuffer $0,1 \mathrm{M}$ & 15 Minuten & $4{ }^{\circ} \mathrm{C}$ \\
\hline Phosphatpuffer 0,1 M & 15 Minuten & $4{ }^{\circ} \mathrm{C}$ \\
\hline $30 \%$ Ethanol & 20 Minuten & $4^{\circ} \mathrm{C}$ \\
\hline $50 \%$ Ethanol & 20 Minuten & $4^{\circ} \mathrm{C}$ \\
\hline $70 \%$ Ethanol & 20 Minuten & $4{ }^{\circ} \mathrm{C}$ \\
\hline $90 \%$ Ethanol & 20 Minuten & $4{ }^{\circ} \mathrm{C}$ \\
\hline $100 \%$ Ethanol & 10 Minuten & $4{ }^{\circ} \mathrm{C}$ \\
\hline $100 \%$ Ethanol & 10 Minuten & $4^{\circ} \mathrm{C}$ \\
\hline $100 \%$ Ethanol & 10 Minuten & $4{ }^{\circ} \mathrm{C}$ \\
\hline 2-Propanol & 10 Minuten & $4{ }^{\circ} \mathrm{C}$ \\
\hline Propylenoxid & 10 Minuten & RT \\
\hline Propylenoxid & 10 Minuten & RT \\
\hline Propylenoxid & 10 Minuten & RT \\
\hline Propylenoxid/ Epon 2:1 & 2 Stunden & RT \\
\hline Propylenoxid/ Epon 1:1 & 2 Stunden & RT \\
\hline Propylenoxid/ Epon 1:2 & 4 Stunden & $\mathrm{R}^{\prime}$ \\
\hline Epon rein & 4 Stunden & RT \\
\hline
\end{tabular}

Die Gewebe wurden anschließend in mit EPON gefüllte Förmchen platziert und für die EPON-Polymerisation über Nacht bei $60{ }^{\circ} \mathrm{C}$ im Ofen gelagert. Die Auspolymerisierten Epon Blöcke wurden mittels Leica „EM-Trim“ mit einer Kantenneigung von $30^{\circ}$ getrimmt. Mit einem Mikrotom (Ultracut S, Leica Microsystems GmbH, Wien, Österreich) und dem Diamantmesser „Diatome Histo 45 wurden Übersichtsschnitte, „semi-dünn“ $(0,50 \mu \mathrm{m})$, angefertigt. Die semi-dünn-Schnitte wurden auf einem Objektträger (Histo-Bond, Paul Marienfeld GmbH \& Co. KG, Lauda Königshofen) gezogen, bei $60{ }^{\circ} \mathrm{C}$ getrocknet und anschließend mit Methylenblau-Azure II nach Richardson für eine Minute gefärbt ${ }^{137}$. Nach Trocknung der Schnitte wurden 
Material und Methoden

diese mit Eukitt eingebettet.

Nach der Verifizierung der Region mit Hilfe der semi-dünn-Schnitte und erneuten Trimmen der Proben, wurde Ultradünn-Schnitte $(50 \mathrm{~nm})$ mit dem Diamantmesser „Diatome Ultra $45^{\circ}$ „(Diatome AG, Biel, Schweiz) angefertig. Die Schnitte wurden auf 100Mesh hexagonalen Kupfer Grids (Gilder Grids Ltd. Grantham, England) gezogen und getrocknet. Die Kontrastierung der Schnitte erfolgte kopfüberliegend auf Tropfen nach folgendem Protokoll:

$\begin{array}{cc}\text { Substanz } & \text { Zeit } \\ \text { Uranylacetat } & 30 \text { Minuten } \\ \text { Aqua dest. } & 3 \times 1 \text { Minute } \\ \text { Bleizitrat nach Reynolds } & 6 \text { Minuten } \\ \text { Aqua dest. } & 4 \times 1 \text { Minute }\end{array}$

Die Grids wurden vorsichtig mit Filterpapier getrocknet und bei Raumtemperatur gelagert. Die Mikroskopie und Dokumentation erfolgte mit dem Elektronenmikroskop „EM900“ (Carl Zeiss AG, Oberkochen) ausgestattet mit einer 2k-CCDWeitwinkelkamera (TRS, Moorenweis) in einer 7000-fachen Vergrößerung. Die Auswertung und Quantifizierung der Bilder erfolgte mit ImageJ (National Institute of Health, Bethesda, USA) über die Auszählung degenerierter Neurone. Hierfür wurden pro Tier und Gehirnregion 7 Bilder mit einer Fläche von jeweils $14740 \mathrm{~nm}^{2}$ verblindet ausgewertet.

\subsection{Verhaltensversuche}

Um eine Aussage über die Auswirkung der Mutation $\mathrm{MeCP} 2^{\mathrm{R} 168 \mathrm{X}}$ auf das Verhalten und die motorischen Fähigkeiten der Tiere zu gewinnen wurden diese mittels des automatischen Trackingsystems „VideoMot2“ und dem „RotaRod Advanced“(TSE Systems) analysiert und ausgewertet. Die „VideoMot2“ Software erkennt die Versuchstiere über die Kontrastdifferenz zum Hintergrund und ist somit in der Lage die Maus während des gesamten Experiments zu verfolgen. Die Software berechnet die zurückgelegte Strecke und die durchschnittliche Geschwindigkeit in Echtzeit. Virtuelle Zonen, die in der Software erstellt werden, überlagern dabei das Live-Bild der Kamera und ermöglichen eine Echtzeiterfassung der Tiere in den für die Versuche jeweils definierten Zonen. 
Um mit möglichst geringen Tierzahlen arbeiten zu können, wurden die unbehandelten Weibchen aus der Knochenmarktransplantation ebenfalls für die Charakterisierung des Verhaltens der Linie MeCP2 ${ }^{\mathrm{R} 168 \mathrm{X}}$ genutzt.

\subsubsection{Elevated Plus Maze}

Um festzustellen ob die mutationstragenden Tiere Veränderungen im Angstverhalten aufweisen wurden diese im Elevated Plus Maze-Experiment getestet $^{138}$. Die Apparatur besteht hier aus einer kreuzförmigen Anordnung von zwei offenen (ohne Seitenwände) und zwei geschlossenen Armen (mit Seitenwänden), wobei sich jeweils zwei identische Arme gegenüber stehen und durch ein quadratisches Zentrum voneinander getrennt sind (Abbildung 3). Die gesamte Arena befindet sich dabei in etwa 60 $\mathrm{cm}$ Höhe. Die Maße der Arme, sowohl offene wie auch geschlossene, betragen $30 \mathrm{~cm}$ in der Länge und $10 \mathrm{~cm}$ in der Breite. Daraus ergibt sich eine Gesamtlänge von $70 \mathrm{~cm}$ für beide Arme inklusive des Zentrums. Die Seitenwände der geschlossenen Arme sind 15 $\mathrm{cm}$

hoch.

Als Parameter für diesen Versuch wurden die prozentuale Aufenthaltszeit in den verschiedenen Armen, Besuche in die verschiedenen Arme und die durchschnittliche Geschwindigkeit gemessen.

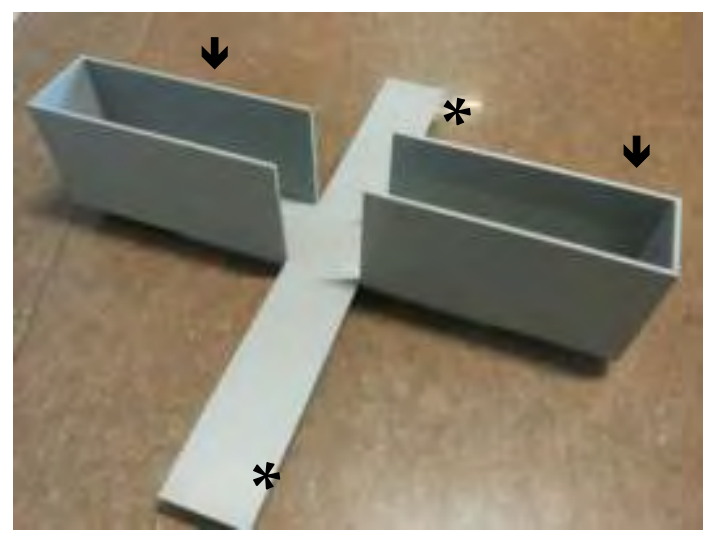

Abbildung 3: Darstellung einer „Elevated Plus Maze“ mit offenen (Sternchen) und geschlossenen (Pfeile) Armen. Die Arena wird ohne Erhöhung dargestellt.

\subsubsection{Open Field}

Der Open Field-Versuch dient zur Überprüfung der motorischen Fähigkeiten und des Angstverhaltens ${ }^{139}$ der Mäuse. Die Arena besteht aus einem Quadrat mit einer Seitenlänge von $50 \mathrm{~cm}$ umgeben von etwa $15 \mathrm{~cm}$ hohen Wänden, wie bei den geschlossenen Armen der Elevated Plus Maze. Die Versuchstiere wurden in die Mitte der Arena gesetzt und von einer Kamera aufgenommen. Mittels der Software VideoMot2 wurden 16 
virtuelle Quadrate über die Fläche gelegt um die prozentuale Aufenthaltsdauer, die Durchschnittsgeschwindigkeit und die zurückgelegte Distanz in allen Bereichen der Arena zu ermitteln. Für die Bestimmung der motorischen Fähigkeiten wurden durchschnittliche Geschwindigkeit und die zurückgelegte Distanz gemessen. Über das Verhältnis der Aufenthaltszeit von „Ecken“ und „Zentrum“ konnte ermittelt werden ob die Tiere eine Veränderung im Angstverhalten aufweisen. Tiere deren Angst überwiegt hielten sich vermehrt in geschützten (,Ecken“) als in exponierten Bereichen (,Zentrum") auf.

\subsubsection{Rotarod}

Der Rotarod-Versuch diente der Überprüfung der Fähigkeit des motorischen Lernens und der motorischen Koordination. Hierfür wurden die Versuchstiere auf eine rotierende Walze gesetzt und die Zeit bis zum ersten Fall gemessen. Der Versuch erstreckt sich über vier Tage mit einer jeweils zweitägigen Trainings- und Testphase. Die Versuchstiere wurden zweimal pro Tag mit einer sechsstündigen Pause getestet. Während der Trainingsphase (Tag 1 und 2) wurde die Walze mit einer konstanten Geschwindigkeit von zehn Umdrehungen pro Minute [UpM] angesteuert und die Versuchstiere für drei Minuten getestet. Während der Trainingsphasen wurden die Versuchstiere nach jedem Fall wieder auf die Walze gesetzt bis zu Ende des Intervalls. In der Testphase beschleunigte die Walze über einen Zeitraum von drei Minuten von fünf auf $40 \mathrm{UpM}$ und drehte sich anschließend eine Minute mit 40 UpM. Während der Testphase wurden die Tiere nach dem Herunterfallen in ihren Käfig zurück gesetzt. Sowohl für das Training als auch für die Testphase diente die Zeit bis zum ersten Herunterfallen als Messgröße.

\subsubsection{Nestbauverhalten}

Der Nestbau ist für Mäuse ein wichtiger Faktor für Wärmekonservierung, Reproduktion, soziale Interaktionen und bedingten Schutz gegen Umwelteinflüsse. Der Nestbau verlangt den Tieren sowohl kognitive wie auch motorische Fähigkeiten ab, weshalb er einen Test für die Bestimmung des allgemeinen Zustands der Tiere darstellt. Das hier genutzte Protokoll basiert auf der Arbeit von Robert Deacon ${ }^{140}$. Um eine Quantifizierung der Nester zu ermöglichen wurden die Tiere für diesen Versuch einzeln gehalten. Als Nestmaterial dienten autoklavierte Papiertücher, die eine Stunde vor Beginn der Dunkelphase flach in der Mitte des Käfigs platziert wurden. Die Qualität der Nester 
wurde nach 24 und 48 Stunden ausgewertet. Für die Quantifizierung der Nester wurde folgende Bewertung genutzt:

$\begin{array}{cc}\text { Nestqualität } & \text { Erklärung } \\ 0 & \text { Keine Veränderung } \\ 1 & \text { Minimale Strukturen erkennbar } \\ 2 & \text { Papier an einer Seite zur Wand gefaltet } \\ 3 & \text { Papier an zwei Seiten zur Wand gefaltet } \\ 4 & \text { Papier an drei Seites zur Wand gefaltet } \\ 5 & \text { Komplette Höhle erkennbar }\end{array}$

\subsubsection{Plethysmographie}

Die Bestimmung des Atmungsverhaltens der Mäuse wurde mittels der Ganzkörperplethysmographie gemessen. Hierbei werden kleinste Druckveränderungen gemessen die durch die Erwärmung der Luft bei der Einatmung und Abkühlung bei der Ausatmung entstehen. Die Tiere wurden in eine Plexiglaskammer mit einem Volumen von $300 \mathrm{ml}$ gesetzt die mit einem Niedrigdrucksensor („DP1 03”, Validyne Engineering, Northridge, CA, USA) verbunden war. Über einen zweiten Kanal war der Sensor mit einer Referenzkammer gleichen Volumens verbunden. Eine Anreicherung von $\mathrm{CO}_{2}$ $(<3 \%)$ in den Kammern wurde verhindert indem diese mit $150 \mathrm{ml} \mathrm{O}_{2}$ pro Minute belüftet wurden. Die Messungen wurden automatisch mitttels „clampfit 10.3“ (Molecular Devices, Sunnyvale, CA, USA) analysiert ${ }^{141,142}$. Die Auswertung der Messergebnisse erfolgte durch Prof. Swen Hülsmann, Klinik für Anästhesiologie, Universitätsmedizin Göttingen.

\subsection{Statistische Auswertung}

Die statistische Auswertung erfolgte mittels „GraphPad Prism 5.0“ (GraphPad Software, Inc., La Jolla, USA). Die Art des statistischen Tests, des Posttests, und des Signifikanzniveaus (p-Wert) sind jeweils im Text angegeben. Signifikanzen in Abbildungen wurden wie folgt dargestellt: 
$\underline{\text { Material und Methoden }}$

$\begin{array}{ll}\mathrm{p}<0,05 & =* \\ \mathrm{p}<0,01 & =* * \\ \mathrm{p}<0,001 & =* * *\end{array}$




\section{Ergebnisse}

\subsection{Charakterisierung der Mauslinie "MeCP2 ${ }^{\mathrm{R} 168 \mathrm{X}}$ “}

Der erste Teil dieser Arbeit war die Charakterisierung der Mauslinie „MeCP2 ${ }^{\mathrm{R} 168 \mathrm{X} \text { “ }}$ im Hinblick auf die Physiologie und des Verhaltens. Da sowohl bei hemizygoten Männchen $\left(\mathrm{MeCP} 2^{\mathrm{R} 168 \mathrm{X} / \mathrm{y}}\right)$ als auch bei heterozygoten Weibchen $\left(\mathrm{MeCP} 2^{\mathrm{R} 168 \mathrm{X} / \mathrm{x}}\right)$ dieser Linie die Mutation Mecp2 c.502 A>T (MeCP2 $\left.2^{\mathrm{R} 168 \mathrm{X}}\right)$ zu finden ist, wurden Tiere beider Geschlechter untersucht. Obwohl das Rett Syndrom eine Erkrankung ist, die überwiegend Frauen betrifft, zeigen männliche Mäuse bisher beschriebener MeCP2-defizienter Linien einen deutlich schwereren Krankheitsverlauf und stehen somit im Mittelpunkt der Forschung und Therapie des Rett Syndroms. Alle Versuche wurden an symptomatischen Tieren durchgeführt. Dieses entspricht einem Alter sechs Wochen bei Männchen und neun Monate bei Weibchen.

\subsubsection{Allgemeines Erscheinungsbild von MeCP2 ${ }^{\mathrm{R} 168 \mathrm{X}}$-Mäusen}

Das äußere Erscheinungsbild von Nachkommen beider Geschlechter war nach der Geburt und während der ersten zwei Lebenswochen von gesunden Tieren nicht zu unterscheiden. Genotypen und Geschlechter waren nach Mendel verteilt. Ab der dritten Lebenswoche zeigten $\mathrm{MeCP} 2^{\mathrm{R} 168 \mathrm{X}}$-Männchen ein verringertes Wachstum, das mit einem signifikant verringerten Körpergewicht einherging ( $p<0,001$ für die Wochen 3 bis 11 und Woche 15, p<0,01 für die Wochen 13 und 14, zweifache ANOVA (analysis of variance) mit Bonferroni's Posttest; $\mathrm{n}_{\mathrm{R} 168 \mathrm{X} / \mathrm{y}}=8$ bis 96, $\mathrm{n}_{\mathrm{WT}}=29$ bis 82, Abbildung 4A). Das Gewicht heterozygoter Weibchen war während der gesamten Entwicklung von gesunden Tieren nicht zu unterscheiden (Abbildung 4B). Ab einem mittleren Alter von 47 Tagen (Spanne: 27 bis 78 Tage) zeigten $65 \%$ der 96 untersuchten hemizygoten Männchen das sogenannte hindlimb clasping, ein Klammerreflex der Hinterbeine, der nach Verlust des Bodenkontaktes durch Anheben der Maus zu beobachten ist (Abbildung 4C). Einen Tremor, ein durch unkontrollierte Muskelkontraktionen verursachtes Zittern, trat im Mittel ab Tag 48 (Spanne: 27 bis 78 Tage) in $63 \%$ der hemizygoten Männchen auf. Bei heterozygoten Weibchen traten in $100 \%$ der 31 untersuchten Tiere sowohl Tremor, ab einem Alter von 40 Tagen (Spanne: 30 bis 88 Tage), als auch das hindlimb clasping ab einem Alter von 48 Tagen (Spanne: 36 bis 84 Tage) auf. Eine posturale Instabilität und verringerte bis fehlende posturale Reflexe der hinteren Extremitäten konn- 
te bei beiden Geschlechtern beobachtet werden. Die mittlere Lebenserwartung war bei MeCP2 $2^{\text {R168X }}$-Männchen mit 57 Tagen $(\mathrm{p}=0,0311, \mathrm{n}=71$, Mantel-Cox Test) und einer Spanne von 23 bis 150 Tagen gegenüber gesunden Tieren deutlich reduziert (Abbildung 4D). Bei MeCP2 $2^{\mathrm{R} 168 \mathrm{X}}$-Weibchen konnte keine Verringerung der Lebenserwartung festgestellt werden.

Um auszuschließen, dass durch die Mutation ein verkürztes Protein mit Restaktivität entsteht, wurden Gesamtproteinlysate aus Gehirnen von gesunden und betroffenen Männchen mit einem Antikörper gegen den N-terminalen Bereich von MeCP2 untersucht. Dieses Experiment zeigte das hemizygote Männchen kein verkürztes Protein exprimieren (Abbildung 4E).
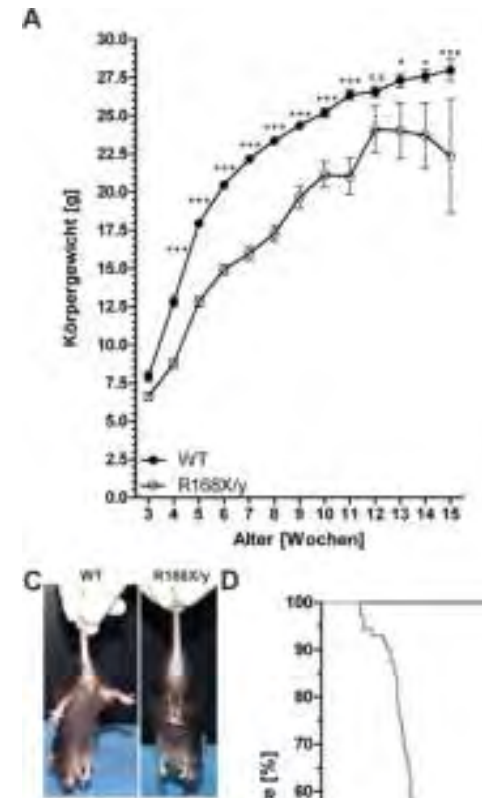

B

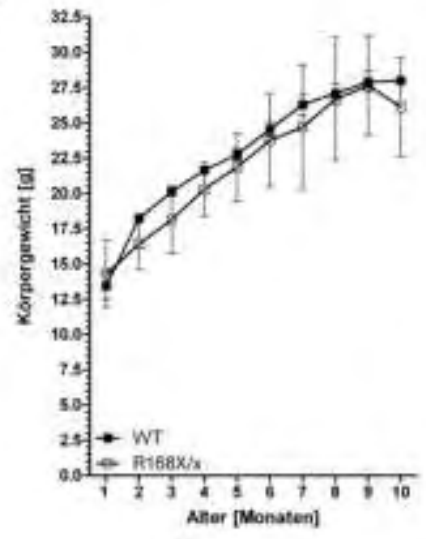

E

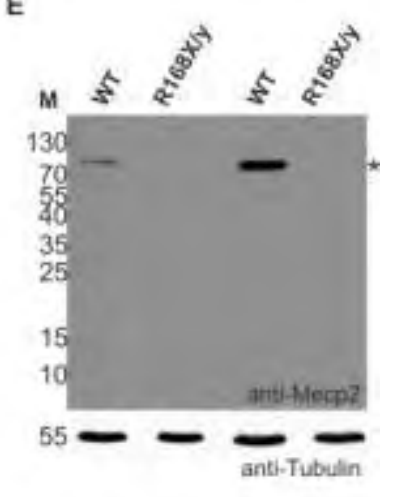

\begin{abstract}
Abbildung 4: Allgemeiner Phänotyp männlicher und weiblicher MeCP2 ${ }^{\text {R168X }}$-Mäuse. A: Gewichtsentwicklung von $\mathrm{MeCP2}^{\mathrm{R} 168 \mathrm{x}}$-Männchen. B: Gewichtsentwicklung von $\mathrm{MeCP2}^{\mathrm{R} 168 \mathrm{X}}$-Weibchen während der Entwicklung. $\mathrm{C}$ : Repräsentatives Foto des „Hind limb claspings“ von $\mathrm{MeCP2}^{\mathrm{R} 168 \mathrm{X} / \mathrm{y}}$-und $\mathrm{MeCP2}^{\mathrm{R} 168 \mathrm{X} / \mathrm{x}}$-Tieren. Gezeigt sind hier nur männliche Tiere. D: $\mathrm{MeCP}^{\mathrm{R} 168 \mathrm{X} / \mathrm{y}-}$ Mäuse weisen ein stark verringertes mittleres Überleben auf. E: Ein repräsentativer Western Blot von Proteinlysaten aus ganzen Gehirnen männlicher Tiere mit einem Nterminalen Antikörper (Sigma Aldrich M7448) zeigt kein verkürztes Protein in $\mathrm{MeCP2}^{\mathrm{R} 168 \mathrm{X} / \mathrm{y}}$-Mäusen.
\end{abstract}

\title{
3.1.2 Nestbauverhalten von MeCP2 ${ }^{\text {R168X }}$-Mäusen
}

Das Nestbauverhalten stellt ein instinktives Verhalten dar, welches dem Schutz vor Umwelteinflüssen und Prädatoren, sowie zur Aufzucht des Nachwuchses dient ${ }^{140,143-145}$. 
Um eine Aussage über die Gesamtverfassung der $\mathrm{MeCP} 2^{\mathrm{R} 168 \mathrm{X}}$-Mäuse, auch im Hinblick auf motorische und kognitive Fähigkeiten, treffen zu können wurde das Nestbauverhalten von $\mathrm{MeCP} 2^{\mathrm{R} 168 \mathrm{X}}$-Mäusen und deren altersgepaarten, gleichgeschlechtlichen gesunden Geschwistertieren untersucht. Dabei konnte gezeigt werden, dass die Nester hemizygoter Männchen $(\mathrm{n}=17)$ nach 24 Stunden eine signifikant geringere, mittlere Nestqualität von 1 (Spanne: 0 bis 3) aufwiesen als die gesunder Tiere $(n=15)$ mit einer mittleren Nestqualität von 4 (Spanne: 3 bis 5; $p<0,0001$ zweiseitiger ungepaarter t-Test; Abbildung 5A). Auch nach 48 Stunden konnte bei hemizygoten Männchen $(n=17)$ keine komplexen Nester (mittlere Nestqualität=2, Spanne: 0 bis 4) im Vergleich zur gesunden Kontrollgruppe $(n=15$, mittlere Nestqualität $=5$, Spanne: 4 bis $5 ; p<0,0001$ Mann-Whitney Test) festgestellt werden (Abbildung 5A).

A

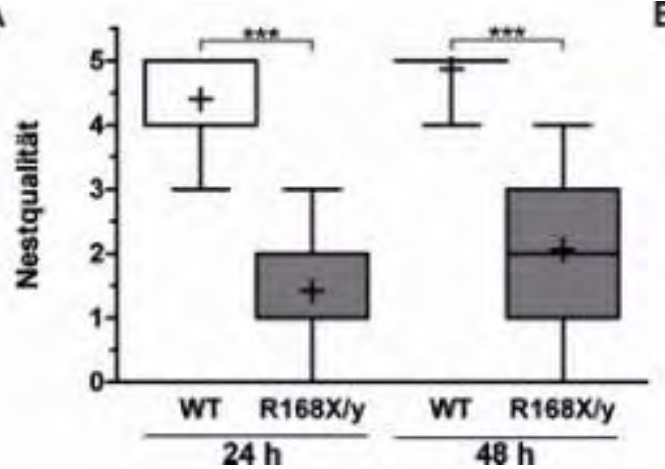

B

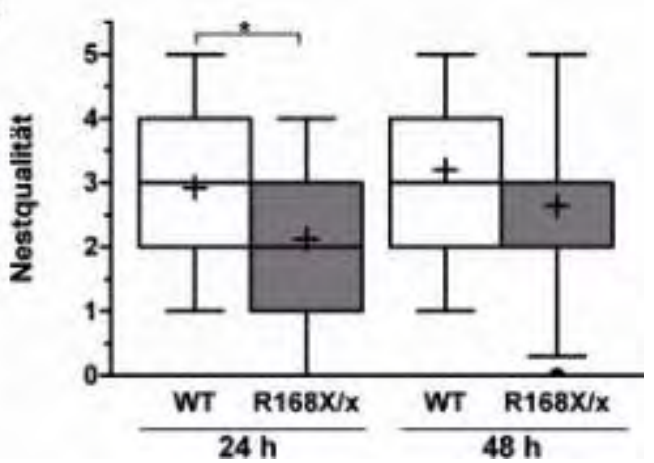

Abbildung 5: Nestbauverhalten von $\mathrm{MeCP2}^{\mathrm{R} 168 \mathrm{X} / \mathrm{y}}$-und $\mathrm{MeCP2}^{\mathrm{R} 168 \mathrm{X} / \mathrm{x}}$-Mäusen nach 24 und 48 Stunden dargestellt im Boxplot mit Minima und Maxima. A:Die mittlere Nestqualität ist bei MeCP2 ${ }^{\mathrm{R} 168 X / y}-M_{a ̈ u s e n ~}$ sowohl nach $24 \mathrm{~h}$, wie auch nach 48 h signifikant reduziert. B: Die mittlere Nestqualität von MeCP2 ${ }^{\mathrm{R} 168 \mathrm{X} / \mathrm{x}}$-Mäusen ist nach 24 Stunden verringert, während sie nach 48 Stunden vergleichbar mit den gesunder Tiere ist. Das ,+““ markiert den Mittelwert, der Strich in der Mitte der Box markiert den Median.

Die Nester heterozygoter Weibchen $(n=25)$ zeigten nach 24 Stunden ebenfalls eine signifikant verringerte Qualität (mittlere Nestqualität=2, Spanne: 0 bis 4) im Vergleich zu gesunden Tieren $(n=36$, mittlere Nestqualität $=3$, Spanne: 1 bis $5 ; p=0,0147$ zweiseitiger ungepaarter t-Test; Abbildung 5B). Nach 48 Stunden konnte noch eine leichte Verringerung der Nestqualität der beobachteten heterozygoten Weibchen gemessen werden, die jedoch im Mittel gleich war und kein signifikantes Niveau erreichte (mittlere Nestqualität $\mathrm{het}_{\mathrm{h}}=3$, Spanne het 0 bis 5 ; Nestqualität $\mathrm{wT}_{\mathrm{wT}}=3$, Spanne: 1 bis $5 ; \mathrm{p}=0,0854$ zweiseitiger ungepaarter t-Test; Abbildung 5B). 


\subsubsection{Atmung und Lungenfunktion von MeCP2 ${ }^{\mathrm{R} 168 \mathrm{X}}$ Mäusen}

Um festzustellen ob Tiere der Linie MeCP2 $2^{\mathrm{R} 168 \mathrm{X}}$ die Atemstörungen der Rett Patientinnen rekapitulieren, wurden Tiere beider Geschlechter einer Ganzkörperplethysmographie (Abbildung 6A und B) unterzogen. Hierbei zeigte sich, dass bei männlichen hemizygoten Tieren $(n=13)$ im Vergleich zu gesunden Tieren $(n=8)$ deutlich mehr Apnoen mit einer Länge von über einer Sekunde auftraten (WT=0,38 Apnoen pro vier Minuten $\pm 0,38$; $\mathrm{R} 168 \mathrm{X} / \mathrm{y}=3,00$ Apnoen pro vier Minuten $\pm 0,69 ; \mathrm{p}=$ 0,0046 Mann-Whitney Test, Abbildung 6A und C). Die Atemfrequenz hemizygoter Männchen war signifikant verlangsamt $\left(\mathrm{Hz}_{\mathrm{R} 168 \mathrm{X} / \mathrm{y}}=5,30 \pm 0,29, \mathrm{~Hz}_{\mathrm{WT}}=7,07 \pm 0,23 ; \mathrm{p}=\right.$ 0,0021 Mann-Whitney Test; Abbildung 6E) und der Irregularity Score (IrrScore), ein Maß für die Unregelmäßigkeit der Atmung, war signifikant erhöht (IrrScore R168X/y $=$ 0,42 $\pm 0,02$, IrrSore $_{\mathrm{WT}}=0,28 \pm 0,02, \mathrm{p}=0,0010$ Mann-Whitney Test; Abbildung 6F). Bei heterozygoten Weibchen $(n=10)$ konnte im Vergleich zu gesunden Tieren $(n=10)$ kein vermehrtes Auftreten von länger als eine Sekunde andauernden Apnoen während des Versuchs detektiert werden (WT=0,70 Apnoen pro vier Minuten $\pm 0,52 ; \mathrm{R} 168 \mathrm{X} / \mathrm{X}=$ 0,60 Apnoen pro vier Minuten $\pm 0,27 ; \mathrm{p}=0,5435$ Mann-Whitney Test; Abbildung 6B und D). Die Atemfrequenz war bei MeCP2 $2^{\mathrm{R} 168 \mathrm{X} / \mathrm{x}}-$ Tieren im Vergleich zu gesunden Tieren leicht verringert $\left(\mathrm{Hz}_{\mathrm{R} 168 \mathrm{X} / \mathrm{x}}=6,54 \pm 0,37, \mathrm{~Hz}_{\mathrm{WT}}=7,33 \pm 0,34 ; \mathrm{p}=0,1287\right.$ zweiseitiger ungepaarter t-Test, Abbildung 6G) jedoch ohne ein signifikantes Niveau zu erreichen. Auch bei der Gleichmäßigkeit der Atmung, angegeben durch den Irregularity Score, war kein signifikanter Unterschied festzustellen (IrrScore ${ }_{\mathrm{R} 168 \mathrm{X} / \mathrm{x}}=0,32 \pm 0,02$, IrrScore $_{\mathrm{WT}}=0,30 \pm 0,01, \mathrm{p}=0,4359$ Mann-Whitney Test, Abbildung $6 \mathrm{H}$ ). 
A
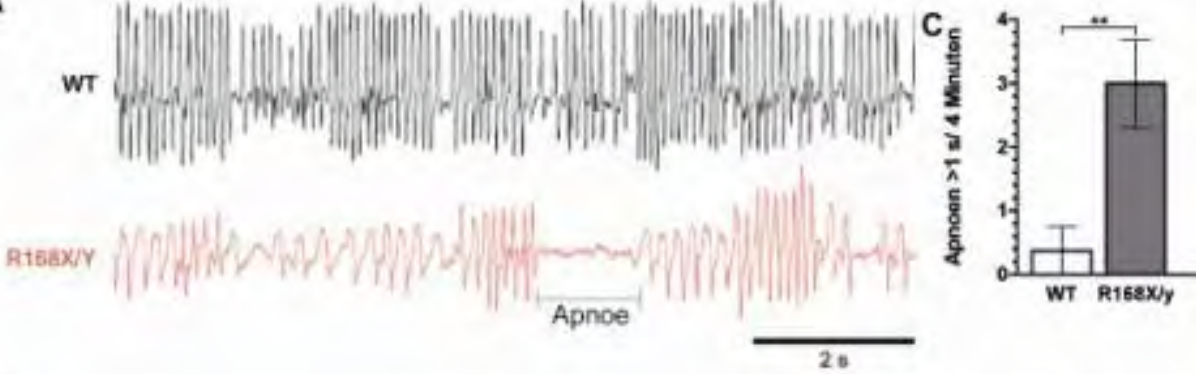

B

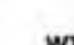

WT

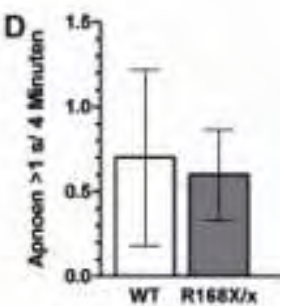

E
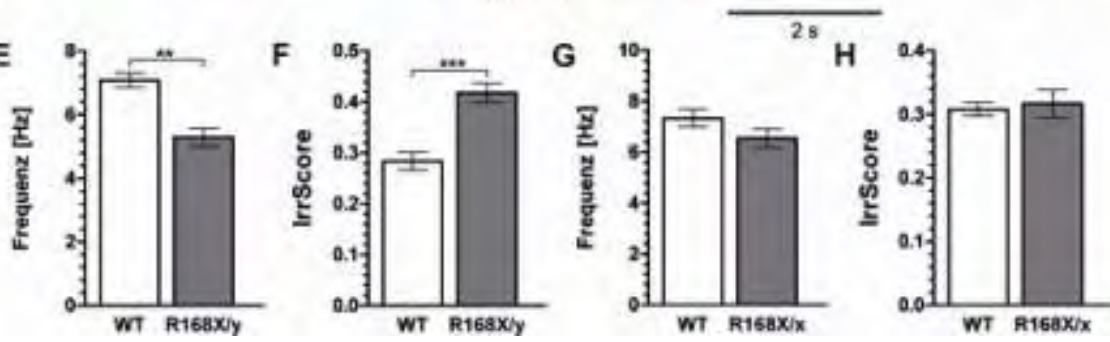

Abbildung 6: Plethysmographische Untersuchungen von männlichen und weiblichen Tieren der Linie $\mathrm{MeCP2}^{\mathrm{R} 168 \mathrm{x}}$. A: Eine repräsentative Aufnahme einer Ganzkörperplethysmographie zeigt eine verringerte Atemfrequenz und das Auftreten langer Apnoen bei $\mathrm{MeCP2}^{\mathrm{R} 168 \mathrm{X} / \mathrm{y}}$-Mäusen. B: In einer repräsentativen Aufnahme einer Ganzkörperplethysmographie sind keine Unterschiede zwischen beiden Genotypen zu erkennen. C: Durchschnittliche Anzahl an Apnoen pro vier Minuten mit einer minimalen Länge von einer Sekunden in $\mathrm{MeCP}^{\mathrm{R} 168 \mathrm{X} / \mathrm{y}}$-Mäusen. D:Durchschnittliche Anzahl an Apnoen pro vier Minuten mit einer Länge von mindestens einer Sekunde. $\mathrm{E}$ : $\mathrm{MeCP}^{\mathrm{R} 168 \mathrm{X} / \mathrm{y}}$-Mäuse zeigen eine signifikante Verringerung der Atemfrequenz. F: Der Irregularity Score (IrrScore) ist in $\mathrm{MeCP2}^{\mathrm{R} 168 \mathrm{X} / \mathrm{y}}$-Mäusen deutlich erhöht und zeigt somit Unregelmäßigkeiten in der Atmung auf. G: Die Atemfrequenz von $\mathrm{MeCP2}^{\mathrm{R} 168 \mathrm{X} / \mathrm{x}}$-Mäusen ist leicht verringert weißt jedoch keinen signifikanten Unterschied zu gesunden Tieren auf. H: Der IrrScore ist bei MeCP2 ${ }^{\mathrm{R} 168 \mathrm{X} / \mathrm{x}}$-Mäusen leicht erhöht, weißt jedoch keinen signifikanten Unterschied zu gesunden Tieren auf.

\subsubsection{Allgmeine lokomotorische Aktivität von MeCP2 ${ }^{\mathrm{R} 168 \mathrm{X}_{-}}$}

\section{Mäusen}

Die Überprüfung der lokomotorischen Aktivität der Tiere erfolgte im Open FieldExperiment. Männliche $\mathrm{MeCP} 2^{\mathrm{R} 168 \mathrm{X}}$-Mäuse $(\mathrm{n}=21)$ bewegten sich hier mit einer Durchschnittsgeschwindigkeit von $3,45 \mathrm{~cm} / \mathrm{s} \pm 0,33 \mathrm{im}$ Vergleich zu gleichaltrigen gesunden Tieren $(n=22)$ mit einer Durchschnittsgeschwindigkeit von $5,17 \mathrm{~cm} / \mathrm{s} \pm 0,39$ signifikant langsamer $(\mathrm{p}=0,002$ zweiseitiger ungepaarter t-Test; Abbildung 7A). Die gesamte zurückgelegte Strecke während des Experiments war mit $1034 \mathrm{~cm} \pm 99,58$ ebenfalls signifikant geringer als die gesunder Männchen, die eine Strecke von $1548 \mathrm{~cm}$ $\pm 117,80$ zurïcklegten ( $\mathrm{p}=0,0019$ zweiseitiger ungepaarter t-Test; Abbildung 7B). 

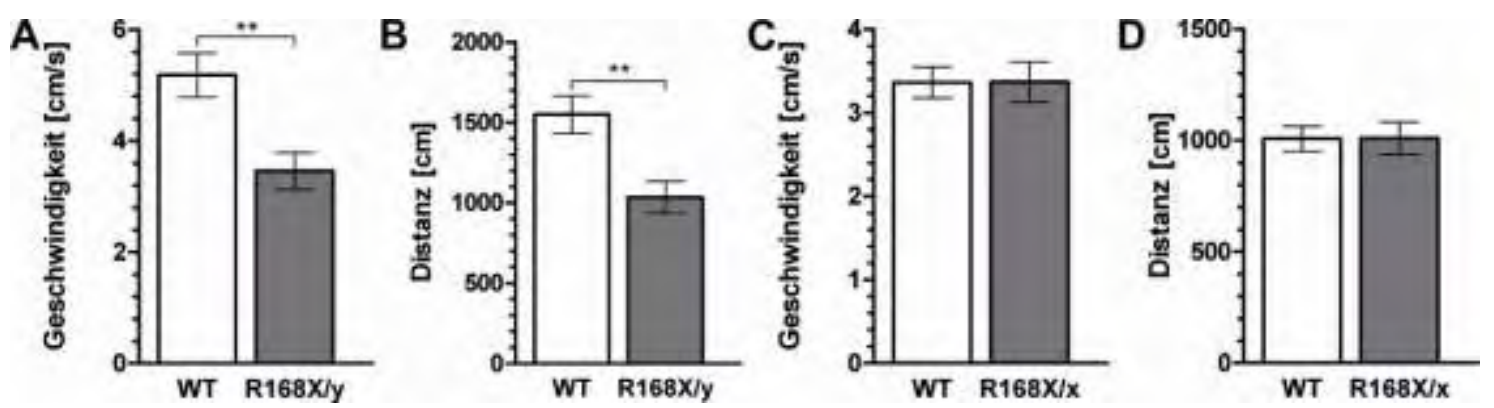

Abbildung 7: Ergebnisse des Open Field-Experiments bei männlichen (A und B) und weiblichen (C und D) Tieren. A: Die durchschnittliche Geschwindigkeit männlicher $\mathrm{MeCP2}^{\mathrm{R} 168 \mathrm{x}}$-Mäuse zeigt eine signifikante Verringerung gegenüber gesunden Männchen. B: Die gesamte zurückgelegte Distanz während des Open FieldExperiments ist in $\mathrm{MeCP}^{\mathrm{R} 168 \mathrm{X} / \mathrm{y}}$-Mäusen um etwa 1/3 deutlich reduziert. C: Die durchschnittliche Bewegungsgeschwindigkeit ist bei Tieren beider Genotypen gleich. D: Die zurückgelegte Distanz während des Open Field-Experiments ist bei gesunden und $\mathrm{MeCP2}^{\mathrm{R} 168 \mathrm{X} / \mathrm{x}}$ - Mäusen vergleichbar.

Zwischen heterozygoten Weibchen $(n=23)$ und gleichalten gesunden Tieren $(n=33)$ konnten keine signifikanten Unterschiede bei der durchschnittlichen Geschwindigkeit $\left(\mathrm{v}_{\mathrm{WT}}=3,36 \mathrm{~cm} / \mathrm{s} \pm 0,18, \mathrm{v}_{\mathrm{R} 168 \mathrm{X} / \mathrm{x}}=3,37 \mathrm{~cm} / \mathrm{s} \pm 0,24 ; \mathrm{p}=0,9777\right.$ zweiseitiger ungepaarter $\mathrm{t}-$ Test) und der zurückgelegten Gesamtstrecke $\left(\mathrm{s}_{\mathrm{WT}}=1008 \mathrm{~cm} \pm 55,51, \mathrm{~s}_{\mathrm{R} 168 \mathrm{X} / \mathrm{x}}=1011 \mathrm{~cm}\right.$ $\pm 72,27 ; \mathrm{p}=0,9728$ zweiseitiger ungepaarter t-Test) ermittelt werden (Abbildung 7C und D).

\subsubsection{Motorische Koordination und motorisches Lernen}

Die Untersuchung der motorischen Koordination und des motorischen Lernens erfolgte durch das Rotarod-Experiment.

Während der Trainingssitzungen mit einer konstanten Geschwindigkeit von 5 Umdrehungen pro Minute (UpM) wurde die Zeit ermittelt bis die Tiere das erste Mal von der rotierenden Walze fielen. Hemizygote Männchen fielen dabei deutlich schneller von der Walze als gesunde Männchen, jedoch ohne ein signifikantes Niveau zu erreichen (Abbildung 8A und Tabelle 2). 

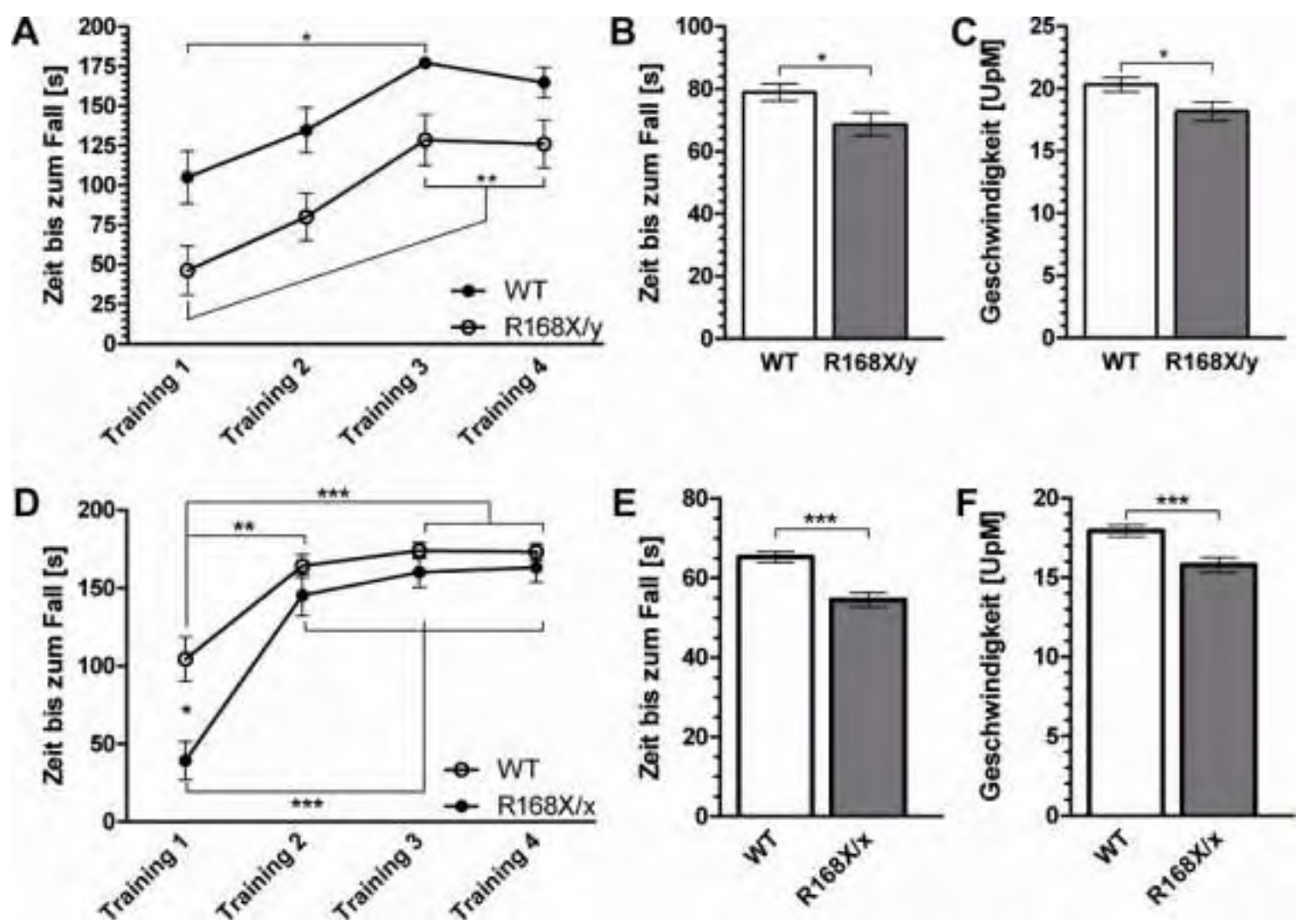

Abbildung 8: Analyse des motorischen Lernens und der motorischen Koordination in $\mathrm{MeCP2}^{\mathrm{R} 168 \mathrm{X} / \mathrm{x}}$-und $\mathrm{MeCP2}^{\mathrm{R} 168 \mathrm{x} / \mathrm{y}}$-Mäusen im Rotarod-Experiment. A: Die Trainingsintervalle männlicher Tiere zeigen eine eindeutig Zunahme der Zeit, die die Tiere auf der Apparatur verbrachten. B: Die Gesamtleistung (durchschnittliche Zeit bis zum Fallen aller vier Testläufe) auf dem beschleunigten Rotarod ist bei $\mathrm{MeCP2}^{\mathrm{R} 168 \mathrm{X} / \mathrm{y}}$-Mäusen deutlich reduziert. C: Die Geschwindigkeit bei der $\mathrm{MeCP2}^{\mathrm{R} 168 \mathrm{X} / \mathrm{y}}$-Mäuse von der Apparatur fallen ist signifikant geringer als die gleichalter gesunder Tiere. D: Die Trainingsintervalle weiblicher Tiere zeigen eine signifikante Steigerung der auf der Apparatur verbrachten Zeit verglichen zum ersten Trainingstag. MeCP2 ${ }^{\mathrm{R} 168 \mathrm{X} / \mathrm{x}}$ Mäuse weisen während des ersten Trainings eine signifikant kürzere Zeit bis zum Fall auf, verglichen mit gleichalten gesunden Tieren.

Im Verlauf der Trainingsintervalle konnten gesunde männliche Mäuse die Zeit die sie auf der Apparatur verbrachten im Vergleich zum ersten Trainingstag um bis zu 68,7 \% steigern (Abbildung 8A und Tabelle 3). Die hemizygoten Männchen steigerten die Zeit die sie auf der Apparatur verbrachten um bis zu $178 \%$ (Abbildung 8A und Tabelle 3).

Tabelle 2: Wertetabelle der Trainingsintervalle des Rotarod-Experiments von gesunden und $\mathrm{MeCP2}^{\mathrm{R} 168 \mathrm{x} / \mathrm{y}}$ Mäusen. Die p-Werte wurden mittels einfacher ANOVA und dem Bonferroni's Posttest ermittelt.

\begin{tabular}{|c|c|c|c|c|c|}
\cline { 2 - 5 } \multicolumn{1}{c|}{} & \multicolumn{2}{c|}{ WT } & \multicolumn{2}{c|}{$\mathrm{MeCP}^{\mathrm{N}}{ }^{\mathrm{R} 168 \mathrm{X} / \mathrm{y}}$} & \multicolumn{1}{c}{} \\
\cline { 2 - 5 } \multicolumn{1}{c|}{ Zeit [s] } & $\mathrm{n}$ & Zeit [s] & $\mathrm{n}$ & $\mathrm{p}$-Wert \\
\hline Training 1 & $105,06 \pm 16,49$ & 18 & $46,21 \pm 15,49$ & 21 & $>0,05$ \\
\hline Training 2 & $134,74 \pm 14,35$ & 18 & $80,07 \pm 14,85$ & 21 & $>0,05$ \\
\hline Training 3 & $177,23 \pm 2,77$ & 18 & $128,53 \pm 15,99$ & 21 & $>0,05$ \\
\hline Training 4 & $164,86 \pm 9,64$ & 18 & $126,16 \pm 15,12$ & 21 & $>0,05$ \\
\hline
\end{tabular}


Tabelle 3: Prozentualer Anstieg der Verweildauer männlicher Mäuse auf der Apparatur im Vergleich zum ersten Trainingsintervall. Die p-Werte wurden mittels einfacher ANOVA und dem Bonferroni's Posttest ermittelt.

\begin{tabular}{|c|c|c||c|c|}
\cline { 2 - 5 } \multicolumn{1}{c|}{} & $\begin{array}{c}\text { WT } \\
\text { Steigerung [\%] }\end{array}$ & $\begin{array}{c}\text { WT } \\
\text { p-Wert }\end{array}$ & $\begin{array}{c}\text { MeCP2 } \\
\text { Steigerung [\%] }\end{array}$ & $\begin{array}{c}\text { MeCP2 } \\
\text { p-Wert }\end{array}$ \\
\hline Training 1 vs. 2 & 28,3 & $>0,05$ & 73,3 & $>0,05$ \\
\hline Training 1 vs. 3 & 68,7 & $<0,01$ & 178,1 & $<0,01$ \\
\hline Training 1 vs. 4 & 56,9 & $<0,05$ & 173,0 & $<0,01$ \\
\hline
\end{tabular}

Bei Versuchen, bei denen die Walze der Apparatur gleichmäßig von 5-40 UpM ( $\triangleq$ 13,33 Umdrehungen/ Minute $^{2}$ ) beschleunigt wurde, fielen gesunde Tiere im Durchschnitt nach 78,88 s $\pm 2,82$ von der Apparatur. Dies entspricht einer durchschnittlichen Rotationsgeschwindigkeit von 20,33 UpM $\pm 0,59$. Im Vergleich fielen $\mathrm{MeCP} 2^{\mathrm{R} 168 \mathrm{X} / \mathrm{y}_{-}}$ Tiere nach 68,65 s $\pm 3,59$ ( $\mathrm{p}=$ 0,0257 Mann-Whitney Test; Abbildung 8B), deutlich früher und bei deutlich niedrigeren Geschwindigkeiten, 18,17 UpM $\pm 0,76$ ( $p=0,0260$ Mann-Whitney Test) von der Apparatur (Abbildung 8C).

Heterozygote Weibchen $(n=24)$ wiesen während des ersten Trainings im Vergleich zu gesunden Tieren $(n=35)$ eine signifikante Verringerung der Zeit auf, die diese auf der Apparatur verbrachten (Abbildung 8D und Tabelle 4).

Tabelle 4: Wertetabelle der Trainingsintervalle des „Rotarod““-Experiments von gesunden und MeCP2 ${ }^{\mathrm{R} 168 \mathrm{X} / \mathrm{x}}$ Mäusen. Die p-Werte wurden mittels Kruskal-Wallis Tests mit Dunn's Posttest ermittelt.

\begin{tabular}{|c|c|c|c|c|c|}
\cline { 2 - 5 } \multicolumn{1}{c|}{} & \multicolumn{2}{c|}{ WT } & \multicolumn{2}{c|}{ MeCP2 ${ }^{\mathrm{R} 168 \mathrm{X} / \mathrm{x}}$} & \multicolumn{1}{c}{ p-Wert } \\
\cline { 2 - 5 } & Zeit [s] & $\mathrm{n}$ & Zeit [s] & $\mathrm{n}$ & p-W, \\
\hline Training 1 & $104,50 \pm 14,30$ & 35 & $39,40 \pm 12,23$ & 24 & $<0,01$ \\
\hline Training 2 & $164,10 \pm 7,38$ & 35 & $145,30 \pm 13,20$ & 24 & $>0,05$ \\
\hline Training 3 & $175,00 \pm 5,07$ & 35 & $160,10 \pm 9,82$ & 24 & $>0,05$ \\
\hline Training 4 & $173,10 \pm 5,30$ & 35 & $163,20 \pm 9,46$ & 24 & $>0,05$ \\
\hline
\end{tabular}

Gesunde weibliche Mäuse konnten die Zeit bis zum Fall von der Apparatur während der Trainingsintervalle um bis zu 67,5 \% verlängern (Abbildung 8D und Tabelle 5). Im starken Gegensatz dazu, konnte bei erkrankten weiblichen Tieren eine Verlängerung um bis zu 314,2 \% beobachtet werden, jedoch ohne die Zeit von gesunden Tieren zu erreichen (Abbildung 8D und Tabelle 5). 
Tabelle 5: Prozentualer Anstieg der Verweildauer weiblicher Mäuse auf der Apparatur im Vergleich zum ersten Trainingsintervall. Die p-Werte wurden mittels Kruskal-Wallis Tests mit Dunn's Posttest ermittelt.

\begin{tabular}{|c|c|c||c|c|}
\cline { 2 - 5 } \multicolumn{1}{c|}{} & $\begin{array}{c}\text { WT } \\
\text { Steigerung [\%] }\end{array}$ & $\begin{array}{c}\text { WT } \\
\text { p-Wert }\end{array}$ & $\begin{array}{c}\text { MeCP2 }{ }^{\mathrm{R} 168 \mathrm{X} / \mathrm{x}} \\
\text { Steigerung [\%] }\end{array}$ & $\begin{array}{c}\mathrm{MeCP} 2^{\mathrm{R} 168 \mathrm{X} / \mathrm{x}} \\
\mathrm{p} \text {-Wert }\end{array}$ \\
\hline Training 1 vs. 2 & 57,0 & $<0,05$ & 268,8 & $<0,001$ \\
\hline Training 1 vs. 3 & 67,5 & $<0,001$ & 306,3 & $<0,001$ \\
\hline Training 1 vs. 4 & 65,6 & $<0,001$ & 314,2 & $<0,001$ \\
\hline
\end{tabular}

Während der Untersuchung bei gleichbleibender Beschleunigung von 5-40 UpM wurde bei heterozygoten Weibchen eine signifikante Verringerung der Verweildauer $\left(t_{\mathrm{WT}}=\right.$ $65,24 \mathrm{~s} \pm 1,46 ; \mathrm{t}_{\mathrm{R} 168 \mathrm{X} / \mathrm{x}}=54,53 \mathrm{~s} \pm 1,83 ; \mathrm{p}<0,0001$ zweiseitiger ungepaarter $\mathrm{t}$-Test; Abbildung $8 \mathrm{E}$ ) und der maximalen Rotationsgeschwindigkeit $\left(\mathrm{n}_{\mathrm{WT}}=17,92 \mathrm{UpM} \pm 0,37\right.$; $n_{\mathrm{R} 168 \mathrm{X} / \mathrm{x}}=15,78 \mathrm{UpM} \pm 0,47 ; \mathrm{p}=0,0003$ zweiseitiger ungepaarter t-Test) im Vergleich zu gesunden Tieren beobachtet (Abbildung 8F).

\subsubsection{Angstverhalten von MeCP2 ${ }^{\mathrm{R} 168 \mathrm{X}}$-Mäusen}

Das Angstverhalten bei Mäusen wurde mittels des Elevated Plus Maze- und des Open Field-Experiments untersucht. Hierbei wird die Aufenthaltsdauer in den exponierten Bereichen (offene Arme bzw. Zentrum) und in den geschützten Bereichen (geschlossene Armen bzw. Ecken) der Apparatur gemessen.

Während des Experiments verbrachten gesunde männliche Tiere $(n=22) 63,22 \% \pm 2,89$ der Zeit in den geschlossenen Armen und 22,95 \% $\pm 2,70$ der Zeit in den offenen Armen der Apparatur. Dieser signifikante Unterschied $(\mathrm{p}<0,0001$ einfache ANOVA mit Bonferroni's Posttest) konnte in MeCP2 defizienten Männchen $(n=20)$ nicht beobachtet werden. Diese verbrachten im Mittel 33,56 \% $\pm 3,36$ der Zeit in den geschlossenen Armen und 44,41\% $\pm 2,93$ der Zeit in den offenen Armen. Damit verbrachten die MeCP2 defizienten Männchen im Vergleich zu gesunden Tieren signifikant mehr Zeit in den offenen Armen und signifikant weniger Zeit in den geschlossenen Armen der Apparatur $(\mathrm{p}<0,0001$ jeweils für offene und geschlossene Arme, einfache ANOVA mit Bonferroni's Posttest; Abbildung 9A). Dieses verringerte Angstverhalten konnte ebenfalls während des Open Field-Experiments beobachtet werden. Während der Erkundung des Areals verbrachten MeCP2 defiziente Männchen $(n=20)$ mit 21,49 \% $\pm 4,00$ der Zeit, signifikant mehr Zeit im Zentrum der Apparatur als gesunde männliche Tiere mit $10,31 \% \pm 1,73$ ( $\mathrm{p}=$ 0,0097 Mann-Whitney Test; Abbildung 9B). 
Gesunde und MeCP2 defiziente Tiere legten während des Elevated Plus Maze-Versuchs vergleichbare Strecken zurück $\left(\mathrm{s}_{\mathrm{WT}}=742,60 \mathrm{~cm} \pm 66,68, \mathrm{~s}_{\mathrm{MeCP} 2}{ }^{\mathrm{R} 168 \mathrm{X} / \mathrm{y}}=804,60 \mathrm{~cm}\right.$ $\pm 69,91 ; p=0,5225$; Abbildung 9C). Dabei zeigte sich, dass gesunde Tiere sich mit 464,40 cm $\pm 38,92$ signifikant mehr in den geschlossenen Armen der Apparatur bewegten, als in den offen Armen $(171,20 \mathrm{~cm} \pm 23,97 \mathrm{p}<0,001$ einfache ANOVA mit Bonferroni’s Posttest; Abbildung 9D). MeCP2 defiziente Männchen legten mit 319,10 $\mathrm{cm} \pm 34,02$ in den geschlossenen Armen und 353,30 cm $\pm 42,06$ in beiden Bereichen vergleichbare Strecken zurück ( $p>0,05$ einfache ANOVA mit Bonferroni ‘s Posttest; Abbildung 9D). Die Gesamtanzahl von Besuchen der einzelnen Bereiche war bei MeCP2 defizienten Mäusen mit 46,60 \ 4,36 gegenüber gesunden Tieren leicht erhöht $(39,18 \pm 3,89 ; p=0,2101$ zweiseitiger ungepaarter t-Test; Abbildung 9E). Im Vergleich zu gesunden Tieren besuchten $\mathrm{MeCP} 2^{\mathrm{R} 168 \mathrm{X} / \mathrm{y}}$-Mäuse die offenen Arme im Durchschnitt 14,55 mal $\pm 1,69$ und die geschlossenen Arme 9,15 mal $\pm 0,98(\mathrm{p}<0,05$ einfache ANOVA mit Bonferroni's Posttest). Gesunde Tiere besuchten hingegen die offenen Arme nur 8,68 mal \pm ,099 während sie die geschlossenen Arme 11,14 mal $\pm 1,14$ aufsuchten ( $\mathrm{p}>0,05$ einfache ANOVA mit Bonferroni's Posttest; Abbildung 9F). Gegenüber gesunden Tieren besuchten betroffene Männchen die offenen Arme signifikant öfter ( $p<0,01$ einfache ANOVA mit Bonferroni’s Posttest; Abbildung 9F).

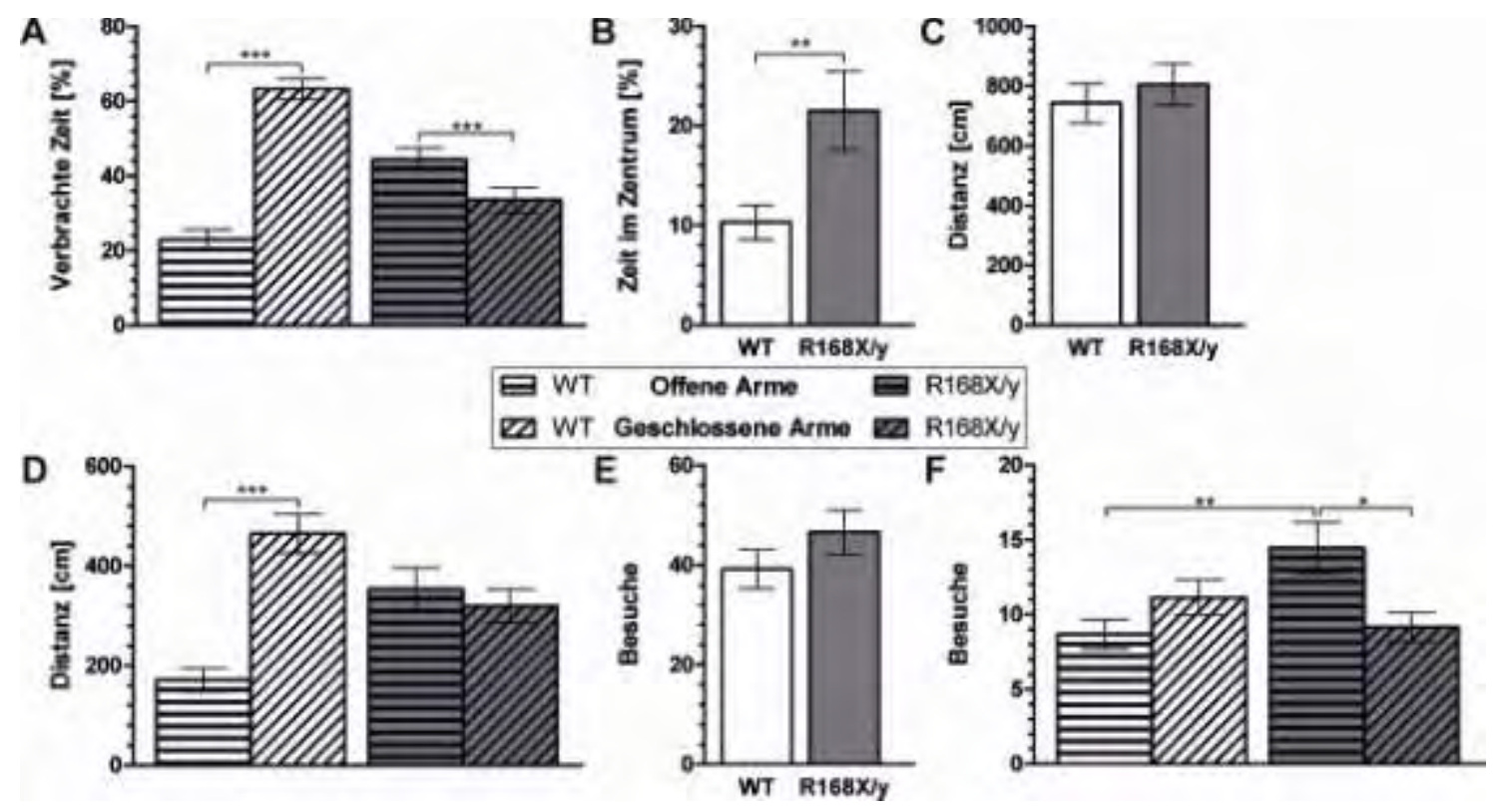

Abbildung 9: Untersuchung des Angstverhaltens männlicher Mäuse mittels des Elevated Plus Maze- (A, C-F) und des Open Field-Experiments (B). A: Gesunde Tiere (WT) hielten sich signifikant öfter in den geschlossenen Armen auf. $\mathrm{MeCP2}^{\mathrm{R} 168 \mathrm{X} / \mathrm{y}}$ hingegen hielten sich signifikant öfter in den offenen Armen der Apparatur auf. B: Das in Abb. 6 A gezeigte abnormale Angstverhalten von $\mathrm{MeCP}^{\mathrm{R} 168 \mathrm{X} / \mathrm{y}}$-Tieren konnte im Open FieldExperiment bestätigt werden. Hier verbrachten die $\mathrm{MeCP2}^{\mathrm{R168X} / \mathrm{y}}$-Tiere signifikant mehr Zeit im Zentrum als $\mathrm{MeCP2}^{\mathrm{WT} / \mathrm{y}}$ Tiere. C: Die zurückgelegte Distanz während des Versuchs ist bei $\mathrm{MeCP2}^{\mathrm{R} 168 \mathrm{X} / \mathrm{y}}$-Tieren leicht erhöht, weist jedoch keine statistische Signifikanz auf. D: Die zurückgelegten Strecken in den geschlossenen Armen ist bei $\mathrm{MeCP}^{\mathrm{WT} / \mathrm{y}}$-Tieren im Vergleich zu der zurückgelegten Strecke in den offenen Armen signifi- 
kant erhöht. In $\mathrm{MeCP2}^{\mathrm{R} 168 \mathrm{x} / \mathrm{y}}$-Tieren sind die zurückgelegten Strecken in offenen und geschlossenen Armen vergleichbar, wobei die zurückgelegte Distanz in den offenen Armen leicht erhöht ist. E: Die Gesamtzahl der Besuche in alle Bereiche der Arena ist in MeCP2 ${ }^{\mathrm{R168}}{ }^{-1}-$ Tieren leicht erhöht. F: Die Zahl der Besuche in die geschlossenen Arme im Vergleich zu der Zahl in offene Arme ist bei MeCP2 ${ }^{\mathrm{WT} / \mathrm{y}}$-Tieren leicht erhöht.

Im Gegensatz zu betroffenen männlichen Mäusen hielten sich weibliche heterozygote Tiere $(n=23) 60,28 \% \pm 4,13$ der Zeit in den geschlossenen Armen und nur 24,11\% $\pm 4,49$ der Zeit in den offenen Armen der Apparatur auf. Diesen signifikanten Unterschied ( $\mathrm{p}<0,001$ Kruskal-Wallis Test mit Dunn's Posttest) zeigten auch gesunde weibliche Tiere $(\mathrm{n}=33)$ die sich 59,24\% $\% 2,81$ der Zeit in den geschlossenen Armen und nur 19,78\% $\% 2,14$ der Zeit in den offenen Armen der Apparatur aufhielten $(\mathrm{p}<0,001$ Kruskal-Wallis Test mit Dunn's Posttest; Abbildung 10A). Während des Open FieldExperiments hielten sich MeCP2 ${ }^{\mathrm{R} 168 \mathrm{X} / \mathrm{x}}$-Mäuse tendenziell eher weniger im Zentrum der Arena auf $\left(\mathrm{t}_{\mathrm{WT}}=4,99 \% \pm 1,08, \mathrm{t}_{\mathrm{R} 168 \mathrm{X} / \mathrm{x}}=3,38 \% \pm 0,47\right)$, jedoch ohne einen signifikanten Unterschied zu erreichen ( $\mathrm{p}=$ 0,8546 Mann-Whitney Test; Abbildung 10B). Während des Elevated Plus Maze-Experiments legten gesunde Tiere mit 770,70 cm $\pm 32,20$ eine signifikant höhere Distanz zurück als heterozygote Weibchen $(632,70 \mathrm{~cm} \pm 44,10 ; \mathrm{p}=$ 0,0123 zweiseitiger ungepaarter t-Test; Abbildung 10C). Die zurückgelegten Distanzen in den geschlossenen Armen waren sowohl bei gesunden Tieren $\left(\mathrm{s}_{\text {offene Arme }}=150,60 \mathrm{~cm}\right.$ $\pm 17,97, \mathrm{~s}_{\text {geschlossene Arme }}=462,30 \mathrm{~cm} \pm 24,11 ; \mathrm{p}<0,001$ Kruskal-Wallis Test mit Dunn's Posttest) wie auch bei heterozygoten Tieren $\left(s_{\text {offene Arme }}=142,90 \mathrm{~cm} \pm 21,65, \mathrm{~s}_{\text {geschlossene }}\right.$ Arme $=375,20 \mathrm{~cm} \pm 38,37 ; \mathrm{p}<0,001$ Kruskal-Wallis Test mit Dunn's Posttest) signifikant erhöht (Abbildung 10D). Heterozygote Weibchen absolvierten während des gesamten Experiments mehr Besuche in alle Bereiche, dieser Unterschied erreichte aber kein signifikantes Niveau (WT= 36,48 $\pm 2,00 ; R 168 X / x=30,91 \pm 2,20 ; p=0,0713$ zweiseitiger ungepaarter t-Test; Abbildung 10E). Tiere beider Genotypen besuchten die geschlossenen Arme signifikant häufiger als die offenen Arme $\left(\mathrm{WT}_{\text {offene Arme }}=7,12 \pm 0,57\right.$, $\mathrm{WT}_{\text {geschlossene Arme }}=11,91 \pm 0,83 ; \mathrm{p}<0,001$ einfach ANOVA mit Bonferroni's Posttest; $\mathrm{R} 168 \mathrm{X}_{\text {offene }} \mathrm{Arme}=6,44 \pm 0,60, \mathrm{R} 168 \mathrm{X} / \mathrm{X}_{\text {geschlossene }} \mathrm{Arme}=9,57 \pm 0,87 ; \mathrm{p}<0,05$ einfache ANOVA mit Bonferroni’s Posttest; Abbildung 10F). 


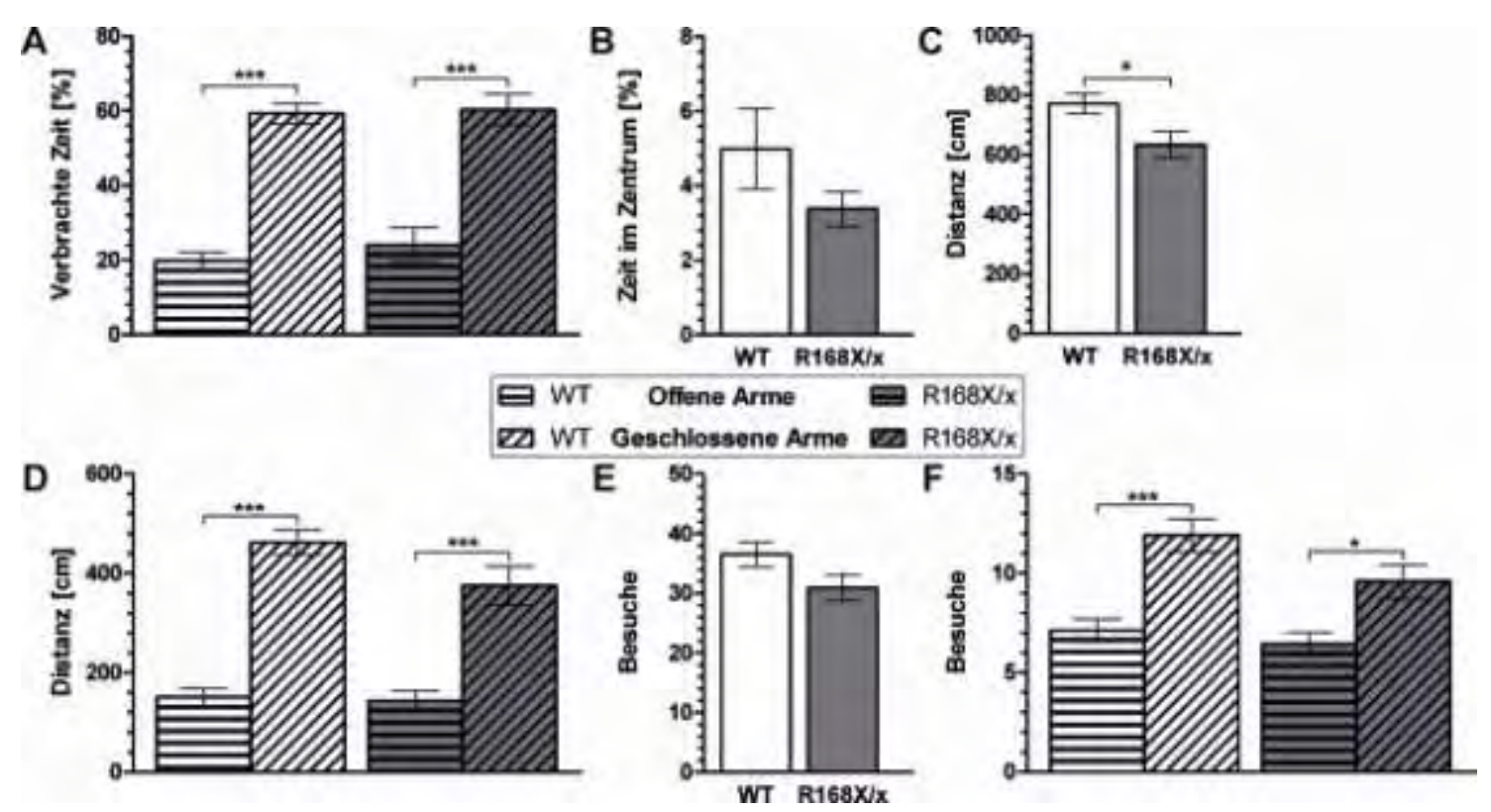

Abbildung 10: Untersuchung des Angstverhaltens weiblicher Mäuse mittels des Elevated Plus Maze- (A, C-F) und des Open Field-Experiments (B). A: Heterozygote (R168X/x) und gesunde (WT) Tiere verbrachten signifikant mehr Zeit in den geschlossenen Armen als in den offenen Armen. B: Während des Open Field-Versuchs hielten sich gesunde Tiere länger im Zentrum der Apparatur auf als R168X/x-Weibchen. C: Heterozygote Weibchen legten im Elevated Plus Maze-Experiment eine geringere Distanz zurück als gleichalte gesunde Tiere. D: Die zurückgelegte Distanz in den geschlossenen Armen war bei Tieren beider Genotypen signifikant erhöht. Die Distanz in den offenen Armen war dabei vergleichbar, während die Distanz in den geschlossenen Armen bei heterozygoten Weibchen leicht reduziert war (nicht signifikant). E: Die Zahl aller Besuche während des Experiments war in heterozygoten Tieren im Vergleich zu gesunden Tieren leicht reduziert. F: Die Zahl der Besuche in die geschlossenen Arme war bei Tieren beider Genotypen signifikant erhöht. Hetero-zygote Tiere besuchten die geschlossenen Arme jedoch weniger häufig als gesunde Tiere. 


\subsection{Experimentelle Therapien des Rett Syndroms}

Den zweiten zentralen Teil dieser Arbeit stellte die Therapie von MeCP2 ${ }^{\mathrm{R} 168 \mathrm{X}}$-Mäusen mit Hilfe experimenteller Methoden dar. Untersucht wurden die Möglichkeiten der „Stop-Codon Readthrough-Therapie“ und der Knochenmarktransplantation. Für die Behandlung der Mäuse mit Aminoglykosiden und PTC124 wurden nur männliche Tiere $\left(\mathrm{MeCP} 2^{\mathrm{WT} / \mathrm{y}}\right.$ und $\mathrm{MeCP} 2^{\mathrm{R} 168 \mathrm{X} / \mathrm{y}}$ ) verwendet, während für die Knochenmarktransplantation sowohl männliche $\left(\mathrm{MeCP} 2^{\mathrm{WT} / \mathrm{y}}\right.$ und $\left.\mathrm{MeCP} 2^{\mathrm{R} 168 \mathrm{X} / \mathrm{y}}\right)$ als auch weibliche $\left(\mathrm{MeCP} 2^{\mathrm{WT}}\right.$ und $\left.\mathrm{MeCP} 2^{\mathrm{R} 168 \mathrm{X} / \mathrm{x}}\right)$ Mäuse verwendet wurden.

\subsubsection{Stop-Codon Readthrough-Therapie in vitro}

\subsubsection{Stop-Codon Readthrough-Therapie an MECP2-3xFlag-c.502C $>T$ transifizierten HeLa Zellen}

Zunächst wurde die Readthrough-Aktivität der Aminoglykoside Gentamicin, Geneticin (G418) und Neomycin, deren strukturverwandten synthetischen Komponenten NB54, NB84 und NB124 und des niedermolekularen Stoffes PTC124 in der Zellkultur untersucht. Gentamicin, Geneticin, NB54 und NB84 wurden bereits in früheren Arbeiten eingesetzt ${ }^{94,95}$. Die HeLa-Zellen wurden mit $2 \mu \mathrm{g}$ des Konstrukts pN3-Flag - MECP2 c.502C $>T$ transfiziert und für 24 Stunden behandelt (siehe Tabelle 6). Anschließend wurden die Zellen lysiert und sowohl das endogene MeCP2 als auch das ReadthroughProdukt N3-Flag-MeCP2 ${ }^{\mathrm{R} 168 \mathrm{X}}$ mittels eines C-terminalen Antikörpers im Western Blot nachgewiesen (Abbildung 11).

Die Readthrough-Produkte waren durch eine Erhöhung der molekularen Masse, um etwa 3 kDa, aufgrund der drei N-terminal gelegenen Flag-Tags des Vektors und einer dadurch höher laufenden Bande im Western Blot sicher zu identifizieren. Die Behandlung mit Gentamicin und Neomycin führten nur zu einer geringen Menge eines Readthrough-Produkts. Die Behandlung mit Geneticin und den NB-Komponenten war dagegen deutlich effektiver, am effektivsten waren dabei die Behandlungen NB124. 
Tabelle 6: Substanzen, Konzentrationen und Lösungsmittel der eingesetzten Substanzen für die Behandlung von transifizierten HeLa-Zellen und $\mathrm{MeCP}^{\mathrm{R} 168 \mathrm{X} / \mathrm{y}}$-Fibroblasten.

\begin{tabular}{|c|c|c|}
\hline Substanz & Konzentration $[\boldsymbol{\mu g} / \mathbf{m l}]$ & Lösungsmittel \\
\hline Gentamicin & 800 & PBS \\
\hline G418 & 100 & PBS \\
\hline Neomycin & 800 & PBS \\
\hline NB54 & 800 & PBS \\
\hline NB84 & 800 & PBS \\
\hline NB124 & 800 & PBS \\
\hline PTC124 & 10 & DMSO \\
\hline
\end{tabular}

Die Behandlung mit PTC124 führte nicht zu einem im Western Blot nachweisbaren Readthrough-Produkt (Abbildung 11). Die negativen Auswirkungen von DMSO auf das Zellwachstum verhinderten höhere Dosierungen von PTC124, welches nur in $100 \%$ DMSO löslich war.

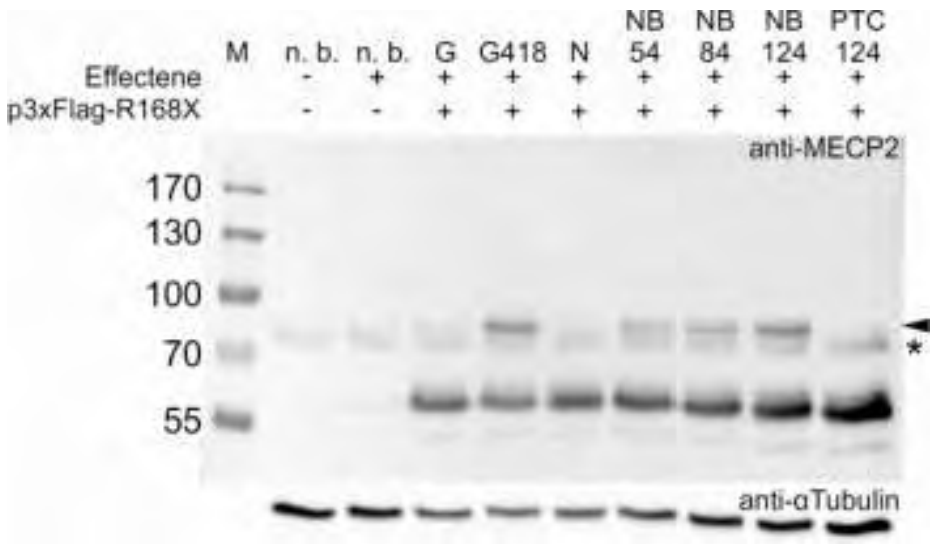

Abbildung 11: Immunologischer Nachweis von endogenem MeCP2 und dem Readthrough-Produkts p3N-FlagMeCP2 $^{\mathrm{R} 168 \mathrm{X}}$ mittels eines C-terminalen anti-MeCP2 Antiköpers. Der Western Blot zeigt transfizierte HeLaZellen nach 24 stündiger Behandlung mit Gentamicin (G), Geneticin (G418), Neomycin (N), NB54, NB84, NB124 und PTC124. Readthrough-Produkte sind nach Behandlung mit Gentamicin, G418, NB54, NB84 und NB124 aufgrund des höheren Molekulargewichts erkennbar (Pfeilspitze). Als Kontrolle dienten nichttransfizierte mit und ohne „Effectene“ behandelt (n. b.). Das Sternchen zeigt das endogene MeCP2 und die Pfeilspitze das Readthrough-Produkt an. M steht für den Marker.

\subsubsection{Stop-Codon Readthrough-Therapie an Fibroblasten männlicher MeCP2 ${ }^{\text {R168X }}$-Mäuse}

Um zu überprüfen ob die in HeLa-Zellen getesteten Substanzen auch in nicht transfizierten Zellen effektiv sind, wurden von männlichen $\mathrm{MeCP} 2^{\text {WT/y }}$ und $\mathrm{MeCP} 2^{\mathrm{R} 168 \mathrm{X} / \mathrm{y}}-$ Tieren Fibroblastenkulturen angelegt. Nach der fünftägigen Behandlung der Zellen mit den in Tabelle 6 aufgeführten Substanzen wurden die Proteinlysate mit- 
tels eines C-terminalen Antikörpers gegen MeCP2 im Western Blot auf das Vorkommen eines MeCP2 Proteins voller Länge untersucht. Ein Readthrough-Produkt konnte nach der Behandlung der Zellen mit allen Aminoglykosiden, aber nicht nach der Behandlung mit PTC124 nachgewiesen werden. Wie in den Experimenten mit transfizierten HeLa-Zellen, war der Readthrough durch Geneticin und NB124 besonders effektiv (Abbildung 12).

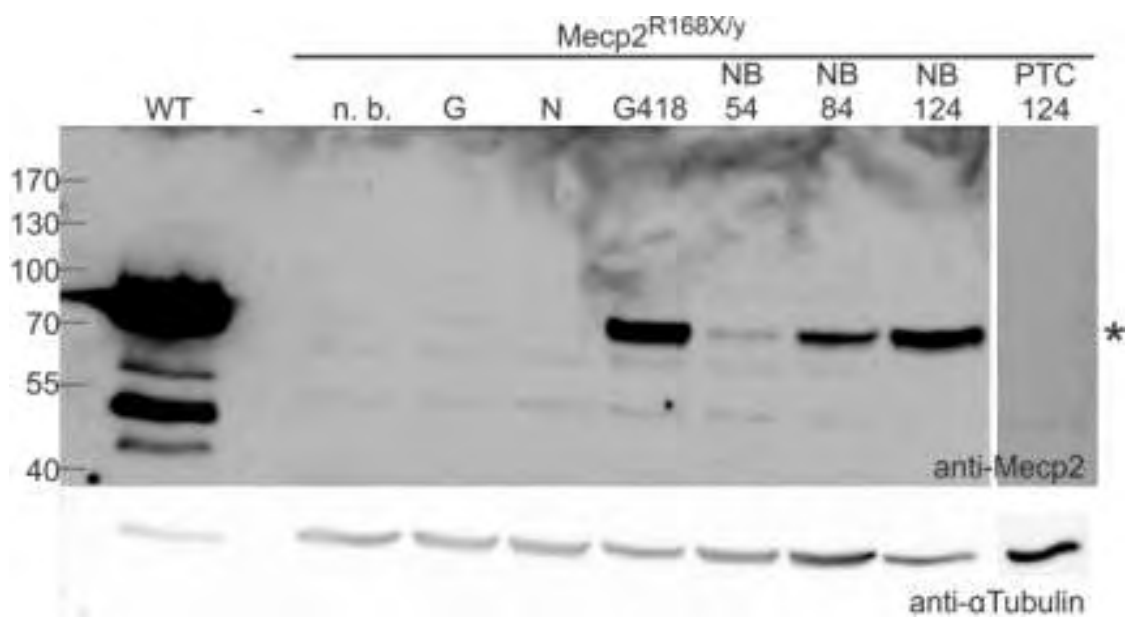

Abbildung 12: Immunologischer Nachweis von endogenem MeCP2 mittels eines C-terminalen anti-MeCP2Antiköpers. Ein MeCP2-Protein voller Länge konnte nach fünftägiger Behandlung mit Gentamicin, G418, NB54, NB84 und NB124 nachgewiesen werden. Als Kontrollen dienten Zellen gesunder Tiere (WT) und nichtbehandelter R168X/y Tiere (n. b.). Das Sternchen gibt das Readthrough-Produkt/ MeCP2an.

\subsubsection{Readthrough-Therapie in vivo}

Gentamicin, NB54, NB84, NB124 und PTC124 wurden nach dem erfolgreichen Nachweis ihrer Wirksamkeit in vitro in Tierexperimenten auf ihre Wirksamkeit in vivo untersucht. Geneticin, welches in der Zellkultur sehr effektiv war, konnte aufgrund seiner hohen Nephro- und Ototoxizität nicht für Tierversuche verwendet werden. Für jede Substanz und jede Dosierung wurden jeweils 3 Mäuse behandelt.

\subsubsection{Behandlung von $\mathrm{MeCP2}^{\mathrm{R} 168 \mathrm{X} / \mathrm{y}}$-Mäusen mit Gentamicin}

Zur in vivo Therapie männlicher MeCP2 $2^{\mathrm{R} 168 \mathrm{X}}$-Mäuse wurde zunächst Gentamicin eingesetzt, da diese Substanz als Antibiotikum zugelassen ist und und für die ReadthroughTherapie bereits erfolgreich an anderen Krankheitsmodellen getestet wurde ${ }^{88,89,146-148}$. In sechs aufeinander folgenden Experimenten wurden Mäuse mit steigenden Gentamicin-Konzentrationen behandelt (Tabelle 7). 
Tabelle 7: Auflistung der Experimente der Gentamicinbehandlung von $\mathrm{MeCP}^{\mathrm{R} 168 \mathrm{X} / \mathrm{y}}{ }_{-}$Mäusen. Die Verabreichung von Gentamicin erfolgte über subkutane (s.c.) und intraperitoneale (i.p.) Injektionen oder über subkutan implantierte osmotische Pumpen der Firma ALZET $^{\circledR}$ (ALZET).

\begin{tabular}{|c|c|c|}
\hline Experiment & $\begin{array}{c}\text { Konzentration } \\
{[\mathbf{m g} / \mathbf{k g} / \text { Tag] }}\end{array}$ & $\begin{array}{c}\text { Dauer des Experiments } \\
\text { [Tagen] }\end{array}$ \\
\hline 1 s.c. & 35 & 14 \\
\hline 2 s.c. & 35 & 28 \\
\hline 3 (ALZET) & 35 & 28 \\
\hline 4 i.p. & 100 & 14 \\
\hline 5 i.p. & 400 & 1 \\
\hline 6 i.p. & $2 \times 200$ & 14 \\
\hline
\end{tabular}

Als erstes wurden drei Tiere mit einer täglichen Injektion von $35 \mathrm{mg}$ Gentamicin/ kg / Tag für 14 Tage behandelt (Tabelle 7 Experiment 1). Dabei konnte in keinem der behandelten Tiere ein MeCP2-Protein voller Länge detektiert werden (Abbildung 13G und H). Um eine Anreicherung des MeCP2-Proteins voller Länge zu ermöglichen wurde die Behandlungsdauer bei gleicher Dosis auf 28 Tage verlängert, führte jedoch ebenfalls nicht zu einem detektierbaren MeCP2-Protein (Tabelle 7 Experiment 2). Auch die Verwendung subkutan implantierter osmotischer Pumpen der Firma ALZET ${ }^{\circledR}$ führte bei gleicher Behandlungsdauer und gleicher Dosierung zu keinem MeCP2-Protein voller Länge (Tabelle 7 Experiment 3 (ALZET)). Eine weitere Anhebung der Dosis auf 100 mg Gentamicin/ kg / Tag (Tabelle 7 Experiment 4) zeigte ebenfalls kein detektierbares MeCP2-Protein. Die weitere Steigerung der Dosis (400 mg Gentamicin/ kg / Tag (Tabelle 7 Experiment 5)) nahe der $\mathrm{LD}_{50}$-Dosis (430 mg Gentamicin/ kg/ Tag) führte bei allen Tieren zu akuten toxischen Symptomen und alle Tiere verstarben in den ersten acht Stunden nach der Injektion. Bei Teilung dieser Dosis auf zwei Injektionen pro Tag konnten die Tiere für 14 Tage behandelt werden (Tabelle 7 Experiment 6). Es konnte jedoch auch nach dieser hochdosierten Behandlung kein MeCP2-Protein nachgewiesen werden (Abbildung 13K und L). 

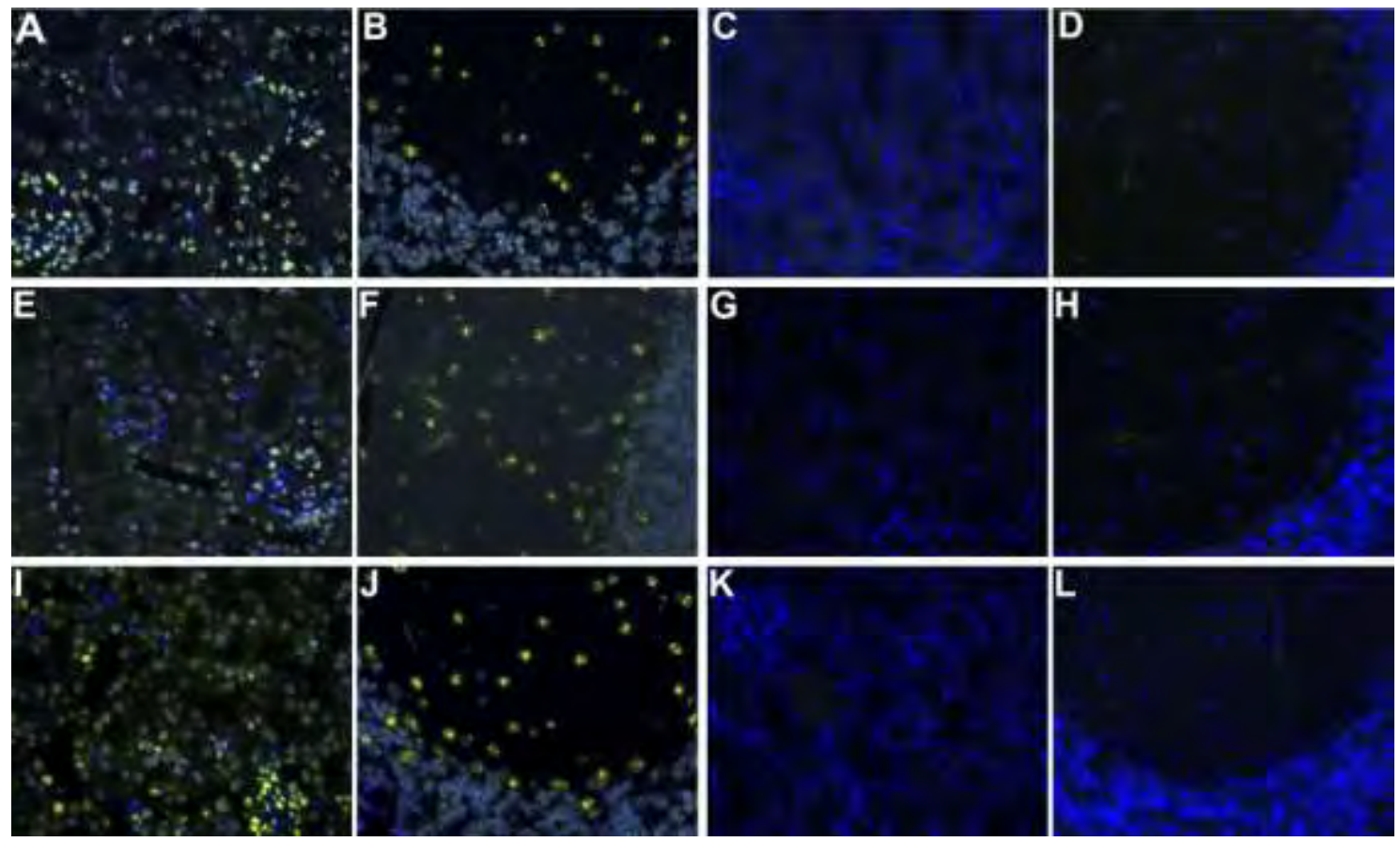

Abbildung 13: Representative Immunofluoreszenzfärbung gegen MeCP2 in Nieren und Kleinhirnen gesunder $(\mathrm{A}, \mathrm{B}, \mathrm{E}, \mathrm{F}, \mathrm{I}$ und $\mathrm{J})$ und $\mathrm{MeCP2}{ }^{\mathrm{R} 168 \mathrm{X} / \mathrm{y}}$-Mäuse $(\mathrm{C}, \mathrm{D}, \mathrm{G}, \mathrm{H}, \mathrm{K}$ und $\mathrm{L})$ von unbehandelten Tieren $(\mathrm{A}-\mathrm{D})$ und aus den Experimenten $1(E-H)$ und 5 (I - L). A-D: Färbung von MeCP2in Nieren (A und C) und Kleinhirnen (B und D) von unbehandelten Tieren. E-H: Färbung von MeCP2 in Nieren (E unf G) und Kleinhirnen (F und H) von, mit $35 \mathrm{mg}$ Gentamicin/ kg/ Tag, behandelten Tieren. I-L: Färbung von Gentamicin in Nieren (E unf G) und Kleinhirnen (F und H) von, 2x $200 \mathrm{mg}$ Gentamicin/ kg/ Tag, behandelten Tieren mit. MeCP2 ist in gelb und Kerne in blau gefärbt (DAPI). Alle Bilder wurden in 400-facher Vergrößerung aufgenommen.

Um die intrazelluläre Aufnahme von Gentamicin nach der Injektion sicher zu stellen, wurden sowohl in Nieren wie auch in Kleinhirnen behandelter Tiere die

Gentamicinaufnahme durch eine Immunfluoreszenzfärbung untersucht. Diese Fluoreszenzfärbung zeigte eine dosisabhängige Aufnahme von Gentamicin in den Nieren von $\mathrm{MeCP} 2^{\mathrm{WT} / \mathrm{y}}$ und $\mathrm{MeCP} 2^{\mathrm{R} 168 \mathrm{X} / \mathrm{y}}$-Mäusen (Abbildung 14A, E, I und C, G, K). Auch in

Purkinje-Zellen im Cerebellum von Mäusen die mit 2x 200 mg Gentamicin /kg / Tag behandelt wurden, konnte eine geringe Aufnahme von Gentamicin nachgewiesen werden (Abbildung 14J und L). 

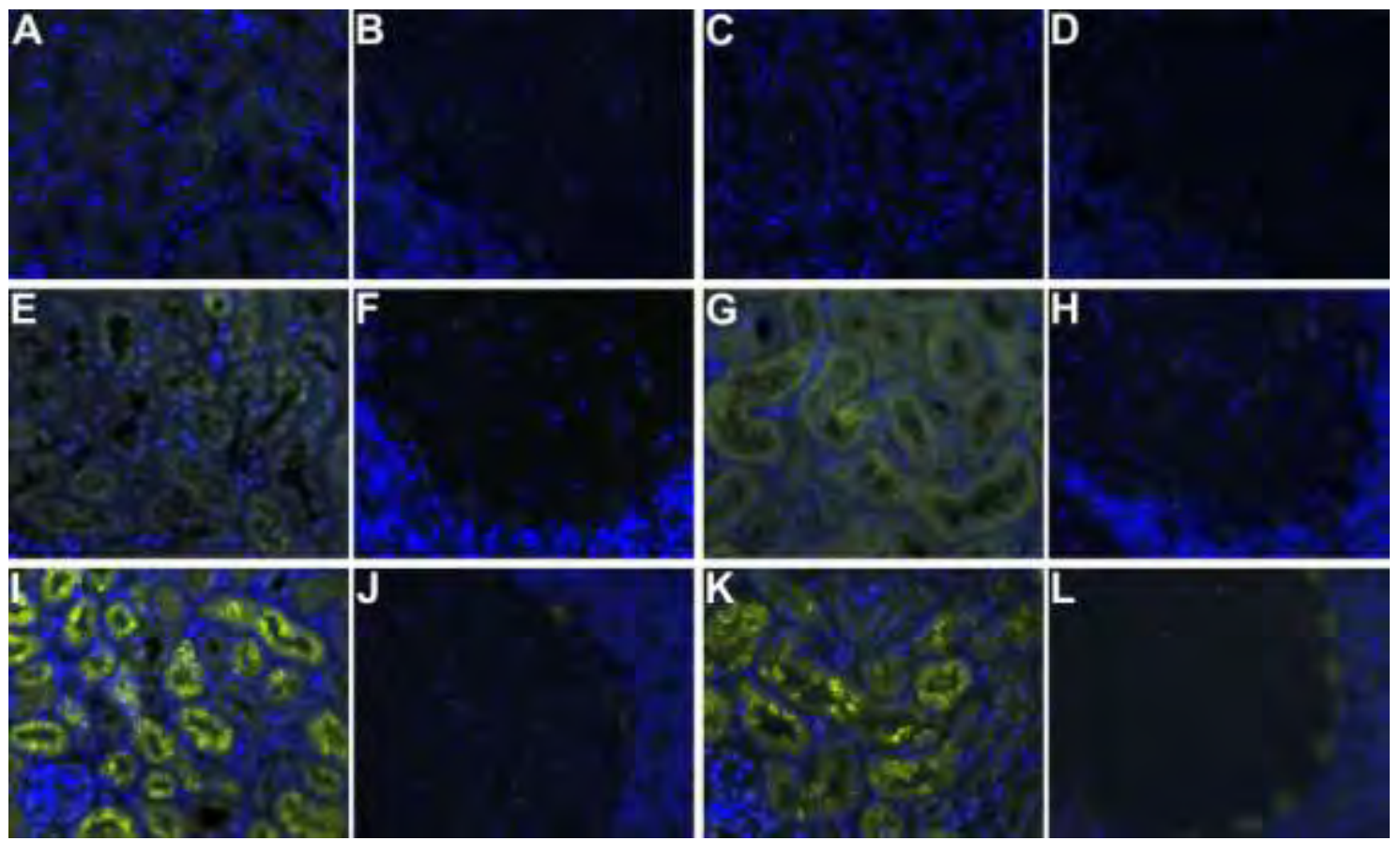

Abbildung 14: Immunofluoreszenzfärbung gegen Gentamicin in Nieren und Kleinhirnen gesunder (A, B, E, F, $I$ und $\mathrm{J}$ ) und $\mathrm{MeCP}^{\mathrm{R} 168 \mathrm{X} / \mathrm{y}}$-Tiere $(\mathrm{C}, \mathrm{D}, \mathrm{G}, \mathrm{H}, \mathrm{K}$ und $\mathrm{L})$. A-D: Färbung von Gentamicin in Nieren (A und C) und Kleinhirnen (B und D) von unbehandelten Tieren zeigt kein Signal. E-H: Die Färbung von Gentamicin in Nieren ( $E$ unf $G$ ) und Kleinhirnen (F und $H)$ von, mit 35 mg Gentamicin/ kg/ Tag, behandelten Tieren zeigt eine deutliche Aufnahem von Gentamicin in den Nieren. I-L: Färbung von Gentamicin in Nieren (E unf G) und Kleinhirnen ( $F$ und $H$ ) von, mit $2 \times 200$ mg Gentamicin/ kg/ Tag, behandelten Tieren zeigt eine deutlich erhöhte Aufnahme von Gentamicin in den Nieren. Purkinje-Zellen behandelter Tiere zeigen ebenfalls eine leichte Aufnahme von Gentamicin. Gentamicin ist in gelb und Kerne in blau gefärbt (DAPI). Alle Bilder wurden in 400-facher Vergrößerung aufgenommen.

\subsubsection{Behandlung von $\mathrm{MeCP} 2^{\mathrm{R} 168 \mathrm{X} / \mathrm{y}}$-Mäusen mit NB-Komponenten}

Als nächstes wurden die synthetischen Aminoglykosid-Derivate NB54, NB84 und $\mathrm{NB} 124$ in $\mathrm{MeCP} 2^{\mathrm{R} 168 \mathrm{X} / \mathrm{y}}$-Mäusen getestet. In den insgesamt elf durchgeführten Experimenten wurden die Dosierungen systematisch angehoben und die Behandlungszeiträume zur Vermeidung toxischer Nebeneffekte angepasst (Tabelle 8).

Tabelle 8: Auflistung der Experimente zur Behandlung von $\mathrm{MeCP}^{\mathrm{R} 168 \mathrm{X} y}$-Mäusen mit den synthetischen Aminoglykosiden NB54, NB84 und NB124. Mit Ausnahme der Experimente 1 bis 3 wurden alle Substanzen durch intraperitoneale (i.p.) Injektionen verabreicht. Die Verabreichung der Substanzen erfolgte in Experimente 1 über eine subkutane Injektion (s.c.) und in den Experimenten 2 und 3 über subkutan implantierte osmotische Pumpen der Firma ALZET ${ }^{\circledR}$.

\begin{tabular}{|c|c|c|c|}
\hline Experiment & Komponente & $\begin{array}{c}\text { Konzentration } \\
{[\mathrm{mg} / \mathrm{kg} / \mathrm{Tag}]}\end{array}$ & $\begin{array}{c}\text { Dauer des Experiments } \\
\text { [Tagen] }\end{array}$ \\
\hline 1 s.c. & \multirow{4}{*}{ NB54 } & 35 & 7 \\
\hline 2 (ALZET) & & 35 & 14 \\
\hline 3 (ALZET) & & 35 & 28 \\
\hline 4 i.p. & & 45 & 14 \\
\hline
\end{tabular}




\begin{tabular}{|c|c|c|c|}
\hline Experiment & Komponente & $\begin{array}{c}\text { Konzentration } \\
{[\mathrm{mg} / \mathrm{kg} / \text { Tag] }}\end{array}$ & $\begin{array}{c}\text { Dauer des Experiments } \\
\text { [Tagen] }\end{array}$ \\
\hline 5 i.p. & \multirow{5}{*}{ NB84 } & 35 & 7 \\
\hline 6 i.p. & & 60 & 5 \\
\hline 7 i.p. & & 60 & 14 \\
\hline 8 i.p. & & 120 & 7 \\
\hline 9 i.p. & & 240 & 14 \\
\hline 10 i.p. & \multirow{2}{*}{ NB124 } & 120 & 28 \\
\hline 11 i.p. & & 450 & 14 \\
\hline
\end{tabular}

Wie nach den Behandlungen mit Gentamicin konnte in keinem der in Tabelle 8 aufgeführten Experimente ein MeCP2-Signal im Gewebe mittels Western Blot (Abbildung 15) und Imunofluoreszenzfärbung (Abbildung 16A bis E und G bis K) detektiert werden.

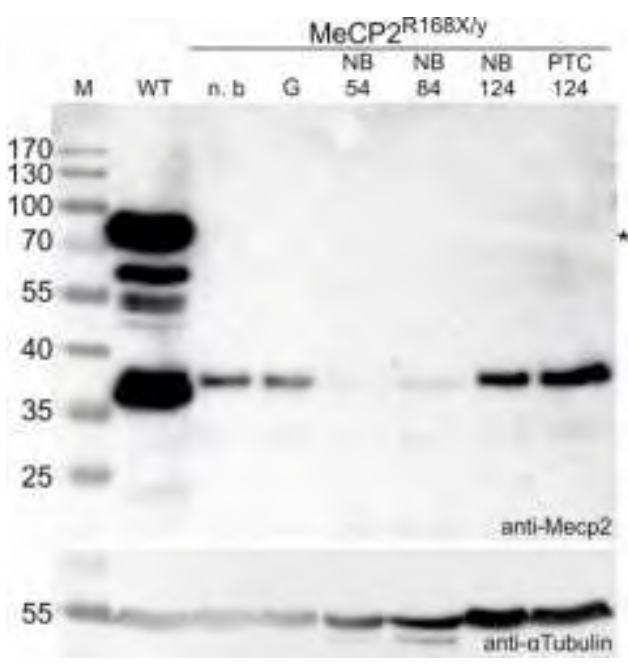

Abbildung 15: Western Blot gegen MeCP2 von gesunden (WT), nicht-behandelter (n. b.) und mit den jeweils höchsten Dosierung behandelten Mäusen MeCP2 ${ }^{\mathrm{R} 168 \mathrm{X} / \mathrm{y}}-$ Mäuse. In gesunden Tieren (WT) ist ein starkes MeCP2 Signal bei etwa $75 \mathrm{kDa}$ zu erkennen (Sternchen). Dieses fehlt sowohl bei unbehandelten (n. b.), mit $2 x$ $200 \mathrm{mg}$ Gentamicin/ kg/ Tag (G), 45 mg NB54/ kg/ Tag, 240 mg NB84/ kg/ Tag, 450 mg NB124/ kg/ Tag und 60 mg PTC124/ kg/ Tag behandelten MeCP2 ${ }^{\text {R168X }}$-Tieren. Pro Spur wurden $40 \mu$ Gesamtprotein geladen. Tubulin diente als Ladekontrolle. „M“ steht für Marker. 

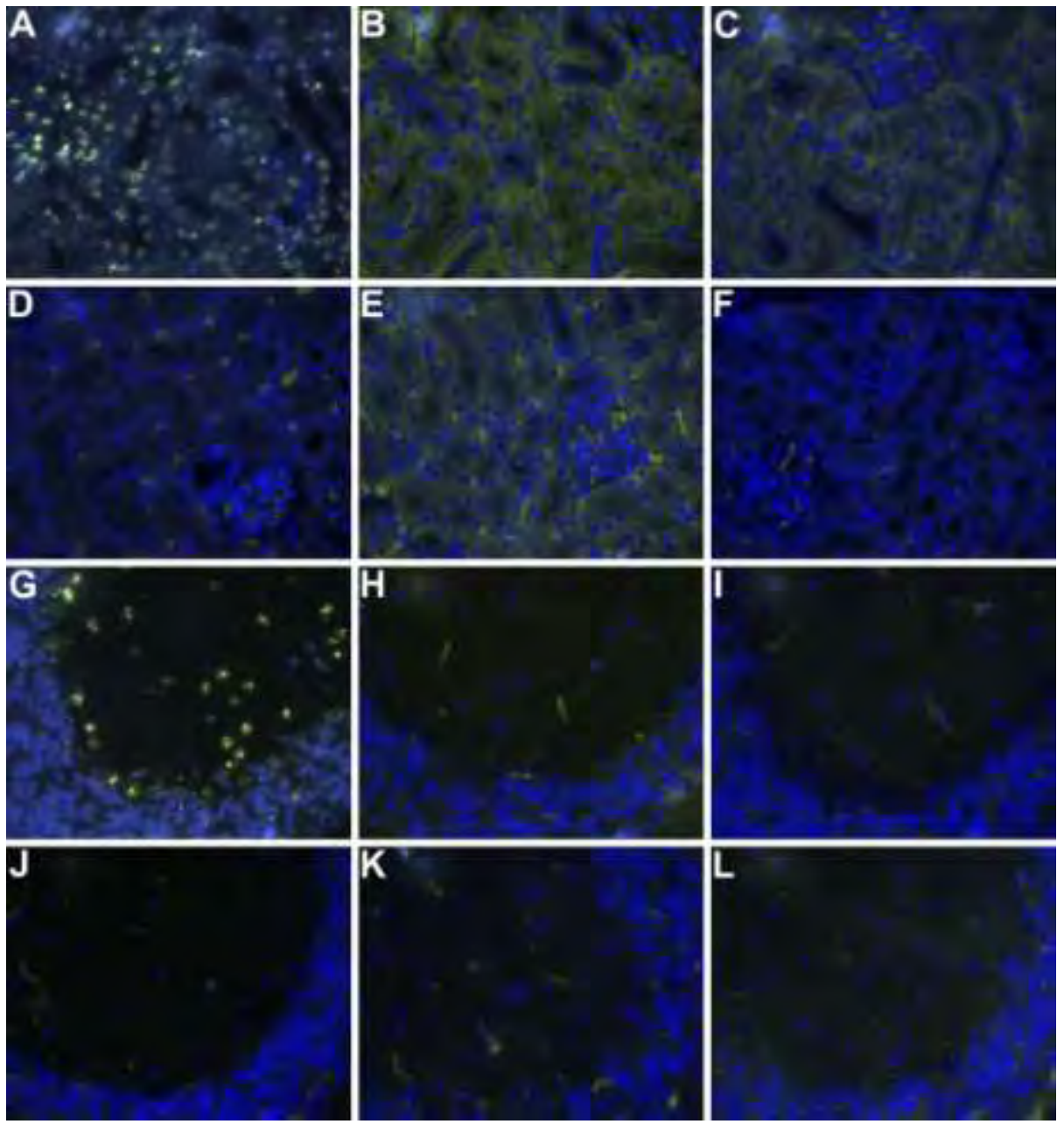

Abbildung 16: Immunofluoreszenz gegen MeCP2 in Nieren (A bis F) und Kleinhirnen ( $G$ bis $L)$ unbehandelter Tiere (A, B, G und $\mathrm{H}$ ) und Tiere die mit den höchsten Dosierungen der benutzten Komponenten (C bis F und I bis L). Ein starkes Signal der MeCP2-Färbung ist in unbehandelten MeCP2 ${ }^{\mathrm{WT}}$-Mäusen (A und G) zu sehen. Weder in unbehandelte $\mathrm{MeCP2}^{\mathrm{R} 168 \mathrm{X} / \mathrm{y}}$-Mäusen $(\mathrm{B}$ und $\mathrm{H})$ noch in Mäusen die mit $45 \mathrm{mg} \mathrm{NB54/} \mathrm{kg/} \mathrm{Tag} \mathrm{(C} \mathrm{und}$

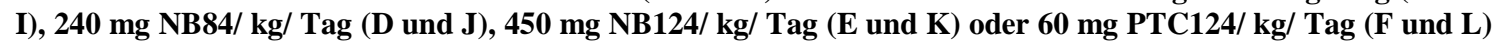
behandelt wurden, konnte MeCP2 nachgewiesen werden. MeCP2 ist in gelb und Zellkerne in blau gefärbt (DAPI). Alle Bilder wurden in 400-facher Vergrößerung aufgenommen.

\subsubsection{Behandlung von $\mathrm{MeCP2}^{\mathrm{R} 168 \mathrm{X} / \mathrm{y}}$-Mäusen mit PTC124}

Da PTC124 in verschiedenen anderen Krankheitsmodellen und klinischen Studien erfolgreich eingesetzt werden konnte, wurden auch männliche $\mathrm{MeCP} 2^{\mathrm{R} 168 \mathrm{X}}$-Mäuse mit dieser Substanz behandelt, obwohl bei in vitro Versuchen kein MeCP2 Protein voller Länge detektiert werden konnte ${ }^{106,119,149-151}$. Die 14-tägige Behandlung mit einer täglichen intraperitonealen Injektionen von 60 mg PTC124/ kg führte, wie bei den Behandlungen mit Gentamicin oder den NB-Komponenten, weder im Gehirn noch in einem somatischen Gewebe zu einem MeCP2-Protein voller Länge (Abbildung 15 und Abbildung $16 \mathrm{~F}$ und $\mathrm{L})$. 


\subsubsection{Behandlung von männlichen $\mathrm{MeCP}^{\mathrm{R} 168 \mathrm{X}}$-Mäusen mit Neomycin}

Tiere, die eine Knochenmarktransplantation erhielten, wurden mit Neomycin behandelt, um Infektionen durch das geschwächte Immunsystem zu vermeiden. Um auszuschlieBen, dass die dreiwöchige Neomycinbehandlung $\mathrm{zu}$ einem MeCP2-ReadthroughProdukt führt, welches die Ergebnisse beeinflussen könnte, wurden drei MeCP2 ${ }^{\mathrm{R} 168 \mathrm{X} / \mathrm{y}}$ und zwei gesunde Mäuse mit 2,03 mg Neomycin/ ml Trinkwasser ad libitum für drei Wochen behandelt. Die Analyse von Nieren (Abbildung 17A) und Gehirnen (Abbildung 17B) der Tiere mittels eines C-terminalen Antikörpers gegen MeCP2 zeigte in keinem der behandelten MeCP2 ${ }^{\mathrm{R} 168 \mathrm{X}}$-Männchen ein MeCP2-Signal.
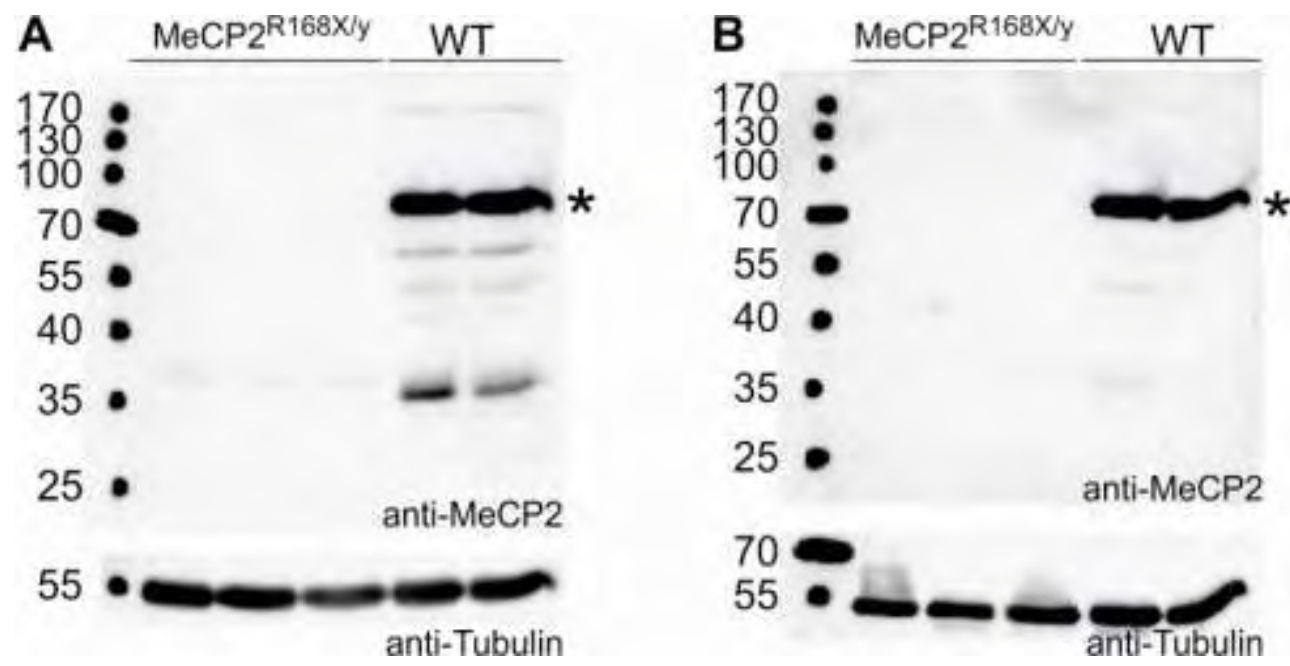

Abbildung 17: Western Blot gegen die C-terminale Region von MeCP2 bei Neomycin-behandelten Tieren. A: Western Blot gegen MeCP2 von Nierenlysaten zeigte kein detektierbares MeCP2-Signal in behandelten Männchen. B: Western Blot gegen MeCP2 von Hirnlysaten zeigte kein detektierbares MeCP2-Signal in behandelten Männchen. Das Sternchen markiert die MeCP2-Bande.

\subsubsection{Knochenmarktransplantation bei MeCP2 ${ }^{\mathrm{R} 168 \mathrm{X}}$-Mäusen}

Die Grundlage für die Knochenmarktransplantation von Mäusen mit Rett Syndrom war die Publikation von Noël Derecki aus dem Jahr 2012, in der eine weitgehende Heilung der Tiere durch eine Knochenmarktransplantation nach einer Ganzkörperbestrahlung beschrieben wurde ${ }^{135}$. Erklärt wurde der Effekt durch einen Austausch „defekter““ Mikroglia, die nicht in der Lage waren Zellrückständen verstorbener Zellen zu phagozytieren.

$29 \mathrm{MeCP} 2^{\mathrm{R} 168 \mathrm{X} / \mathrm{y}}$-und acht MeCP2 $2^{\mathrm{R} 168 \mathrm{X} / \mathrm{x}}$-Mäuse erhielten das Knochenmark gesunder Tiere (WT $\rightarrow$ R168X/y bzw. WT $\rightarrow$ R168X/x). Als Kontrollen dienten 15 $\mathrm{MeCP} 2^{\mathrm{R} 168 \mathrm{X} / \mathrm{y}}-$ Mäuse, die das Knochenmark symptomatischer MeCP2 $2^{\mathrm{R} 168 \mathrm{X} / \mathrm{y}}-$ Tiere erhielten $(\mathrm{R} 168 \mathrm{X} / \mathrm{y} \rightarrow \mathrm{R} 168 \mathrm{X} / \mathrm{y})$ und 19 gesunde männliche bzw. 14 weibliche Tiere, 
denen das Knochenmark gesunder Tiere transplantiert wurde (jeweils WT $\rightarrow$ WT). Als Bestrahlungskontrolle dienten zwei gesunde Männchen, die nach der Bestrahlung keine Knochenmarktransplantation erhielten. Diese Tiere verstarben 21 und 26 Tage nach der Bestrahlung.

Die Transplantation des Knochenmarks erfolgte bei allen Tieren im Alter von 28 bis 30 Tagen durch eine Injektion in das retrobulbäre Venengeflecht. Acht von 29 Tieren der Gruppe WT $\rightarrow$ R168X/y und vier Tiere der Gruppe R168X/y $\rightarrow$ R168X/y wurden aus den Analysen ausgeschlossen, da diese während der ersten drei Wochen nach der Transplantation wahrscheinlich an einer Infektion verstarben. Organschäden und Tumore konnten durch eine Sektion als Todesursache bei diesen Tieren ausgeschlossen werden.

\subsubsection{Rekonstitutionsanalyse des Knochenmarks bei $\mathrm{MeCP}^{\mathrm{R} 168 \mathrm{X}}$-Mäusen nach Knochenmarktransplantation}

Die Überprüfung der Rekonstitution des Knochenmarks durch die Spenderzellen erfolgte mittels FACS-Analyse aus Proben des peripheren Bluts fünf Wochen nach der Transplantation. Zu diesem Zeitpunkt ist die Rekonstitution des Knochenmarks anhand von myeloiden (z.B. neutrophile Granulozyten $\left(\mathrm{GR} 1^{+}\right)$) und lymphatischer Zellen $\left(\mathrm{CD} 4^{+}\right.$ und $\mathrm{CD}^{+}$) nachweisbar ${ }^{152}$. Getestet wurden elf WT $\rightarrow$ WT und fünf WT $\rightarrow$ R168X/y Tiere. Die geringe Anzahl ist auf den krankheitsbedingten schlechten Allgemeinzustand der Tiere zurückzuführen. Die Populationen der rekonstituierten GR-1 ${ }^{+}$neutropilen Zellen bestand sowohl bei WT $\rightarrow$ WT-Tieren $\left(\mathrm{WT} \rightarrow \mathrm{WT}_{\mathrm{CD} 45.1^{+}}=94,72 \% \pm 2,28\right.$, WT $\rightarrow$

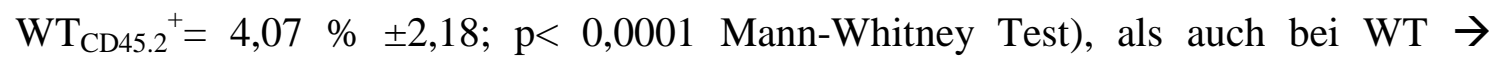
$\mathrm{R} 168 \mathrm{X} / \mathrm{y}\left(\mathrm{WT} \rightarrow \mathrm{R} 168 \mathrm{X} / \mathrm{y}_{\mathrm{CD} 45.1^{+}}=90,13 \% \pm 4,26, \mathrm{WT} \rightarrow \mathrm{R} 168 \mathrm{X} / \mathrm{y}_{\mathrm{CD} 45.2^{+}}=7,78 \%\right.$ $\pm 3,67$; $=0,0079$ Mann-Whitney Test; Abbildung 18A) zu über $90 \%$ aus CD45.1 ${ }^{+}$ Spenderzellen. Der Anteil rekonstitutierter $\mathrm{CD}^{+} \mathrm{T}_{\mathrm{H}^{-}}$Zellen erreichte in beiden Gruppen mindestens $60 \%$, es konnte jedoch nur für WT $\rightarrow$ WT Tiere eine signifikante Veränderung nachgewiesen werden $\left(\mathrm{WT} \rightarrow \mathrm{WT}_{\mathrm{CD} 45.1}{ }^{+}=69,69 \% \pm 1,82, \mathrm{WT} \rightarrow \mathrm{WT}_{\mathrm{CD} 45.2}{ }^{+}=\right.$ $25,01 \% \pm 2,60 ; \mathrm{p}<0,001$ Mann-Whitney-Test und WT $\rightarrow \mathrm{R} 168 \mathrm{X} / \mathrm{y}_{\mathrm{CD} 45.1^{+}}=65,85 \%$ $\pm 2,66, \mathrm{WT} \rightarrow \mathrm{R} 168 \mathrm{X} / \mathrm{y}_{\mathrm{CD} 45.2^{+}}{ }^{+} 33,08 \% \pm 2,46 ; \mathrm{p}=0,2222$ Mann-Whitney Test). Bei der Analyse der Rekonstitution der $\mathrm{CD}^{+}$zytotoxischen T-Zellen konnte ebenfalls nur bei $\mathrm{WT} \rightarrow \mathrm{WT}$ Tieren eine signifikante Anreicherung von CD45.1 $1^{+}$Zellen gefunden wer$\operatorname{den}\left(\mathrm{WT} \rightarrow \mathrm{WT}_{\mathrm{CD} 45.1}{ }^{+}=63,10 \% \pm 1,75, \mathrm{WT} \rightarrow \mathrm{WT}_{\mathrm{CD} 45.2^{+}=32,36 \% \pm 2,82 ; \mathrm{p}<0,0001}\right.$ Mann-Whitney Test; WT $\rightarrow \mathrm{R} 168 \mathrm{X} / \mathrm{y}_{\mathrm{CD} 45.1}{ }^{+}=58,46 \% \pm 9,04, \mathrm{WT} \rightarrow \mathrm{R} 168 \mathrm{X} / \mathrm{y}_{\mathrm{CD} 45.2}{ }^{+}=$ 40,64 \% $\pm 8,97 ; \mathrm{p}=0,5476$ Mann-Whitney Test; Abbildung 18A). 
Aus diesen Analysen geht hervor, dass die Rekonstitution des Knochenmarks durch die Transplantation von CD45.1 ${ }^{+}$-Spenderzellen erfolgreich war.
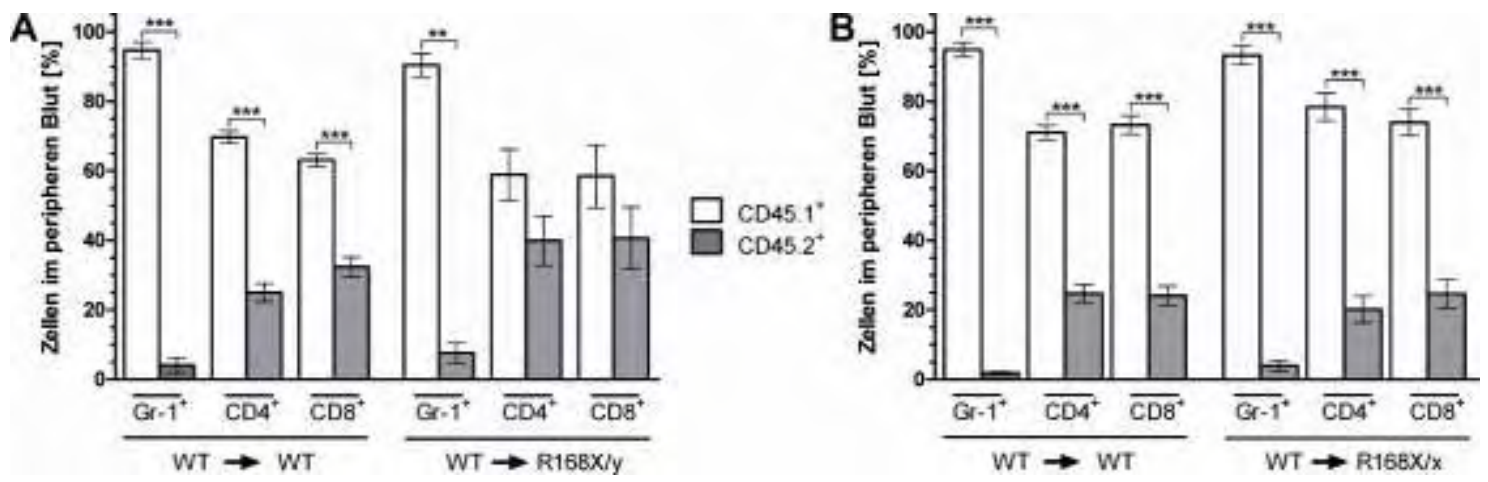

Abbildung 18: Analyse der Rekonstitution von neutrophilen Granulozyten, $\mathbf{T}_{\mathrm{H}}$-Lymphozyten und zytotoxischen T-Zellen nach Knochenmarktransplantation des peripheren Blutes von WT $\rightarrow$ WT $\left(\mathrm{MeCP2}^{+/ \mathrm{y}} \mathrm{bzw}\right.$. $\left.\mathrm{MeCP}^{+/+}\right)$, WT $\rightarrow \mathrm{R} 168 \mathrm{X} / \mathrm{y}$ und WT $\rightarrow \mathrm{R} 168 X / \mathrm{x}$ Tieren. A: Anzahl rekonstituierter Spender-(CD45.1 $\left.{ }^{+}\right)$und Empfängerzellen $\left(\mathrm{CD}^{25.2^{+}}\right)$nach Knochenmarktransplantation in männlichen Mäusen (WT $\rightarrow$ WT und WT $\rightarrow$ R168X/y). B: Anzahl rekonstituierter Spender-(CD45.1 $\left.{ }^{+}\right)$und Empfängerzellen $\left(C D 45.2^{+}\right)$nach Knochenmarktransplantation in weibliche Mäuse (WT $\rightarrow$ WT und WT $\rightarrow$ R168X/x).

Die Rekonstitution des Knochenmarks weiblicher Tiere (Abbildung 18B, $\mathrm{n}_{\mathrm{WT}} \rightarrow \mathrm{wT}=13$, $\left.\mathrm{n}_{\mathrm{WT}} \rightarrow \mathrm{R} 168 \mathrm{X} / \mathrm{x}=8\right)$ zeigte ebenfalls eine signifikant erhöhte Population an CD45.1 ${ }^{+}$ neutrophilen Granulozyten, sowohl bei WT $\rightarrow \mathrm{WT}\left(\mathrm{WT} \rightarrow \mathrm{WT}_{\mathrm{CD} 45.1}{ }^{+}=94,89 \% \pm 2,19\right.$, $\mathrm{WT} \rightarrow \mathrm{WT}_{\mathrm{CD} 45.2}{ }^{+}=1,91 \% \pm 0,40 ; \mathrm{p}<0,0001$ Mann-Whitney Test), als auch auch bei WT $\rightarrow \mathrm{R} 168 \mathrm{X} / \mathrm{x}$ Tieren $\left(\mathrm{WT} \quad \rightarrow \quad \mathrm{R} 168 \mathrm{X} / \mathrm{x}_{\mathrm{CD} 45.1^{+}=90,48} \% \quad \pm 3,32, \quad \mathrm{WT} \quad \rightarrow\right.$ $\mathrm{R} 168 \mathrm{X} / \mathrm{x}_{\mathrm{CD} 45.2}{ }^{+}=7,65 \% \pm 2,84 ; \mathrm{p}=0,0002$ Mann-Whitney Test; Abbildung 18B). Die Zahl der rekonstituierten $\mathrm{CD}^{+}{ }^{+}$und $\mathrm{CD}^{+} \mathrm{T}$-Zellen lag in beiden Gruppen bei mindestens $70 \%$ und erreichte somit eine deutlich höhere Population als die männlicher Mäuse (Abbildung 18B). Hieraus ergaben sich sowohl für $\mathrm{CD}^{+} \mathrm{T}_{\mathrm{H}^{-}}$Helferzellen (WT $\rightarrow$ $\mathrm{WT}_{\mathrm{CD} 45.1}{ }^{+}=71,05 \% \pm 2,05, \mathrm{WT} \rightarrow \mathrm{WT}_{\mathrm{CD} 45.2}{ }^{+}=24,76 \% \pm 2,60 ; \mathrm{p}<0,0001$ MannWhitney Test und WT $\rightarrow \mathrm{R} 168 \mathrm{X} / \mathrm{x}_{\mathrm{CD} 45.1}{ }^{+}=78,41 \% \pm 3,95, \mathrm{WT} \rightarrow \mathrm{R} 168 \mathrm{X} / \mathrm{x}_{\mathrm{CD} 45.2}{ }^{+}=$ 20,15\% $\% 3,83 ; \mathrm{p}=0,0009$ Mann-Whitney Test), als auch für $\mathrm{CD}^{+}$zytotoxische $\mathrm{T}$ Zellen $\left(\mathrm{WT} \rightarrow \mathrm{WT}_{\mathrm{CD} 45.1^{+}}{ }^{+}=73,27 \% \pm 2,68, \mathrm{WT} \rightarrow \mathrm{WT}_{\mathrm{CD} 45.2^{+}=24,13 \% \pm 2,80 ; \mathrm{p}<}\right.$ 0,0001 Mann-Whitney Test und WT $\rightarrow \mathrm{R} 168 \mathrm{X} / \mathrm{x}_{\mathrm{CD} 45.1}{ }^{+}=74,01 \% \pm 3,84, \mathrm{WT} \rightarrow$

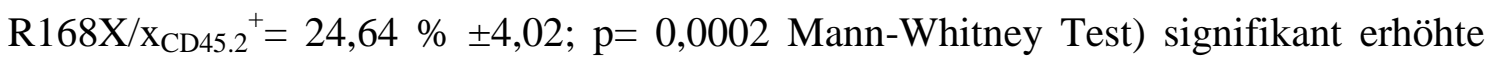
Populationen an CD $45.1^{+}$-Spenderzellen.

Die Analysen des peripheren Bluts weiblicher Tiere deutet ebenfalls eine erfolgreiche Rekonstitution des Knochenmarks nach einer Ganzkörperbestrahlung an. 


\title{
3.2.3.2 Untersuchung der Auswirkung der Knochenmarktransplantation auf männliche $\mathrm{MeCP2}^{\mathrm{R168X}}$-Mäuse
}

Gesunde Tiere, denen Knochenmark gesunder Tiere transplantiert wurde (WT $\rightarrow$ WT), zeigten wie unbehandelte gesunde Tiere (WT) keine Verminderung der mittleren Überlebenswahrscheinlichkeit (Abbildung 19, schwarze Linie). Unbehandelte MeCP2 $2^{\mathrm{R} 168 \mathrm{X}}$ Männchen wiesen während des Versuchs eine mittlere Überlebenswahrscheinlichkeit von 73 Tagen auf (Abbildung 19, orange Linie). MeCP2 ${ }^{\mathrm{R} 168 \mathrm{X}}-\mathrm{Männchen} \mathrm{denen} \mathrm{gesun-}$ des Knochenmark transplantiert wurde (WT $\rightarrow$ R168X/y) zeigten eine leichte Verringerung der mittleren Überlebenswahrscheinlichkeit auf 69 Tage (Abbildung 19, grüne Linie). Tiere denen zur Kontrolle der Prozedur Knochenmark von MeCP2 $2^{\text {R168X/y }}-$ Tieren transplantiert wurde, zeigten ebenfalls eine leichte Verringerung der mittleren Überlebenswahrscheinlichkeit auf 68 Tagen (Abbildung 19, rote Linie).

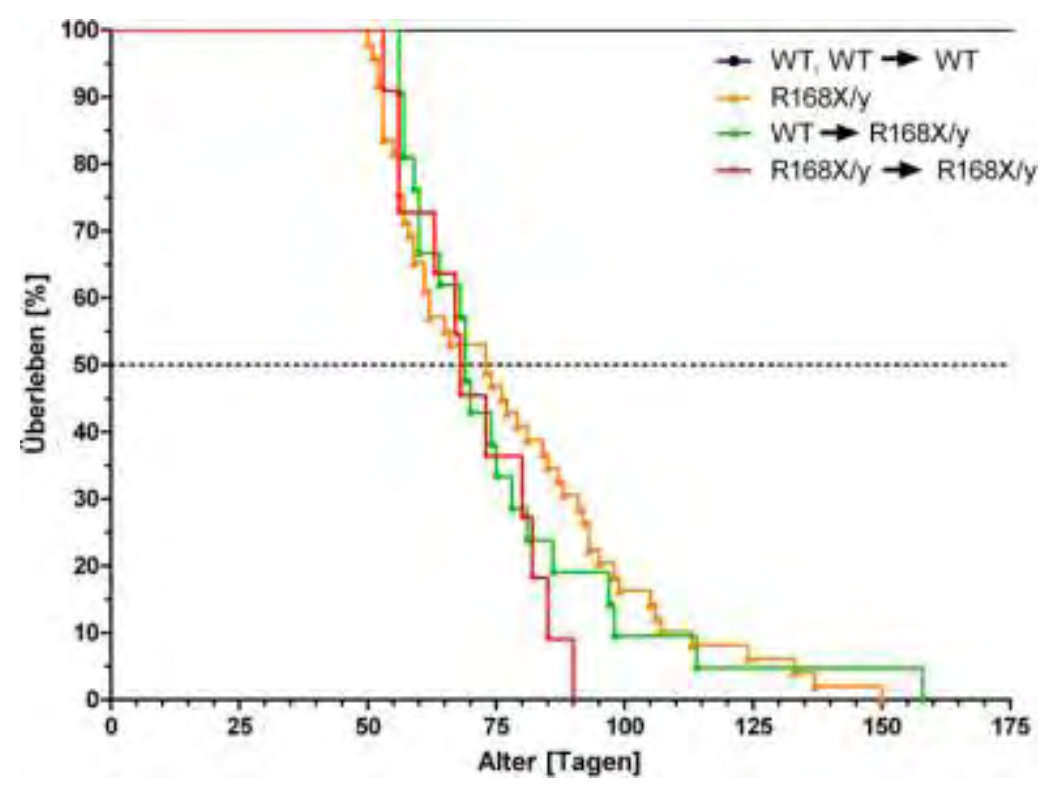

\begin{abstract}
Abbildung 19: Mittlere Überlebensrate männlicher Tiere ohne Knochenmarktransplantation (WT und R168X/y) und nach Transplantation von gesundem Knochenamark (WT $\rightarrow$ WT , WT $\rightarrow$ R168X/y) und $\mathrm{MeCP2}^{\mathrm{R} 168 \mathrm{X} / \mathrm{y}}$ Knochenmark $(\mathrm{R} 168 \mathrm{X} / \mathrm{y} \rightarrow \mathrm{R} 168 \mathrm{X} / \mathrm{y})$. Die gestrichelte Linie markiert die mittlere Überlebenswahrswahrscheinlichkeit.

Das Körpergewicht der Tiere reduzierte sich nach der Transplantation (Woche 4) sowohl bei gesunden (WT $\rightarrow$ WT; Abbildung 20A) als auch bei MeCP2 $2^{\mathrm{R} 168 \mathrm{X} / \mathrm{y}}-$ Tieren $(\mathrm{WT} \rightarrow \mathrm{R} 168 X / \mathrm{y}$ und R168X/y $\rightarrow$ R168X/y; Abbildung 20B) gegenüber den jeweiligen nicht-transplantierten

Kontrolltieren.
\end{abstract}



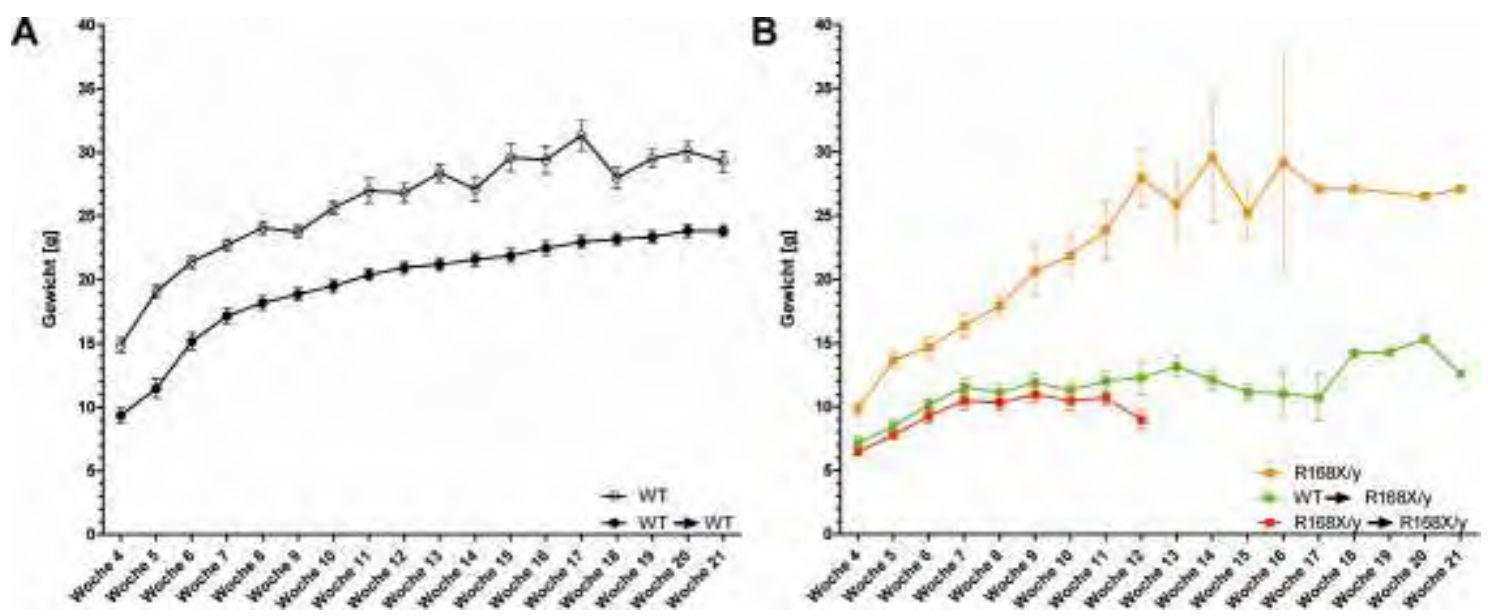

Abbildung 20: Änderung des Köpergewichts von gesunden (A) und $\mathrm{MeCP2}^{\mathrm{R} 168 \mathrm{X} / \mathrm{y}}$-Mäusen (B) nach einer Knochenmarktransplantation. A: WT $\rightarrow$ WT-Mäuse zeigen eine deutliche Verringerung des Körpergewichts im Vergleich zu nicht-behandelten Mäusen (WT). B: Sowohl WT $\rightarrow$ R168X/y-als auch R168X/y $\rightarrow$ R168X/yMäuse zeigen eine deutliche Reduzierung des Körpergewichts nach einer Knochenmarktransplantation im Vergleich zu nicht-behandelten Mäusen (R168X/y).

MeCP2-defiziente männliche Tiere wiesen nach der Transplantation gegenüber unbehandelten Tieren ein signifikant früheres Auftreten eines Tremors und dem hindlimb clasping, ab einem alter von 35 Tage, auf (Tabelle 9).

Tabelle 9: Das Auftreten von Tremoren und dem hindlimb clasping bei WT $\rightarrow \mathrm{MeCP}^{\mathrm{R} 168 \mathrm{X} / \mathrm{y}}-\mathrm{Mäusen}$. Die pWerte wurden mit dem Mann-Whitney Test (*) bzw. einen zweiseitigen ungepaarten t-Test (**) jeweils gegenüber nicht-transplantierten Tieren (3.1.1) ermittelt. Alle Werte sind als Mittelwert mit dem Standardfehler des Mittelwerts (SEM) angegeben. „Min/Max“ gibt den ersten (Min) bzw. den letzten (Max) Tag der beobachtetetn Symptome an.

\begin{tabular}{|c|c|c|c|}
\hline $\mathrm{WT} \rightarrow \mathrm{MeCP} 2^{\mathrm{R} 168 \mathrm{X} / \mathrm{y}}$ & Mittelwert $\pm \mathrm{SEM}$ & $\mathrm{Min} / \mathrm{Max}$ & $\mathrm{p}$-Wert \\
\hline Tremore & $39,50 \pm 1,02$ & $35,75 / 46$ & $0,0354^{*}$ \\
\hline Hindlimb clasping & $37,641,04$ & $35 / 45$ & $0,0024 * *$ \\
\hline
\end{tabular}

Aufgrund der beobachteten Schwächung transplantierter männlicher $\mathrm{MeCP} 2^{\mathrm{R} 168 \mathrm{X}}$ Mäuse konnten mit diesen Tieren keine Verhaltensuntersuchungen durchgeführt werden.

Die Untersuchungen transplantierter $\mathrm{MeCP} 2^{\mathrm{R} 168 \mathrm{X}}$-Männchen zeigen, dass eine Knochenmarktransplantation zu keiner Verlängerung der durchschnittlichen Überlebensdauer führt.

\subsubsection{Analyse der MHC-I und MHC-II Expression und Messung der Phagozytosefähigkeit von $\mathrm{MeCP2} 2^{\mathrm{R} 168 \mathrm{X} / \mathrm{y}}$ Mikroglia in vitro}

Um eine Aussage über die Beteiligung der MeCP2 ${ }^{\mathrm{R} 168 \mathrm{X}}$-Mikroglia treffen zu können, wurden diese auf ihre immunologische Reaktion nach externen Stimuli getestet. Hierdurch soll untersucht werden, ob MeCP2-defiziente Mikroglia Fehlregulationen bei der 
Immunantwort und der Phagozytose aufweisen.

Um dies zu untersuchen, wurden die Expressionniveaus von MHC-I und MHC-II nach Zugabe von Lipopolysacchariden (LPS) bzw. Interferon- $\gamma($ IFN $\gamma)$ gemessen. Das Signal der mittleren Fluoreszenzintensität (MFI) wurde für jeden Genotyp auf die MediumKontrolle ohne LPS bzw. INF $\gamma$ normalisiert. Dabei zeigte sich eine signifikant erhöhte Expression von MHC-I in MeCP2 ${ }^{\mathrm{R} 168 \mathrm{X} / \mathrm{y}}$-Mikroglia gegenüber Mikroglia gesunder Tiere $\left(\right.$ MHC- $\mathrm{I}_{\mathrm{WT}}=554,10 \pm 35,79$, MHC-I $\mathrm{I}_{\mathrm{R} 168 \mathrm{X} / \mathrm{y}}=820,90 \pm 84,80 ; \mathrm{p}=0,0286$ Mann-Whitney Test; Abbildung 21A). Die Expression von MHC-II zeigte in beiden Gruppen eine vergleichbare Expression $\left(\mathrm{MHC}-\mathrm{II}_{\mathrm{WT}}=1464 \pm 27,07, \mathrm{MHC}-\mathrm{II}_{\mathrm{R} 168 \mathrm{X} / \mathrm{y}}=1291 \pm 13,96\right.$, Abbildung 21B). Die Anzahl an phagozytierenden Zellen, gemessen an der Anzahl Myelinpositiver Zellen, war zwischen MeCP2 ${ }^{\mathrm{R} 168 \mathrm{X}}-(62,70 \pm 4,16)$ und wildtypischen-Mikroglia $(58,18 \pm 6,59)$ unverändert (Abbildung 21C).
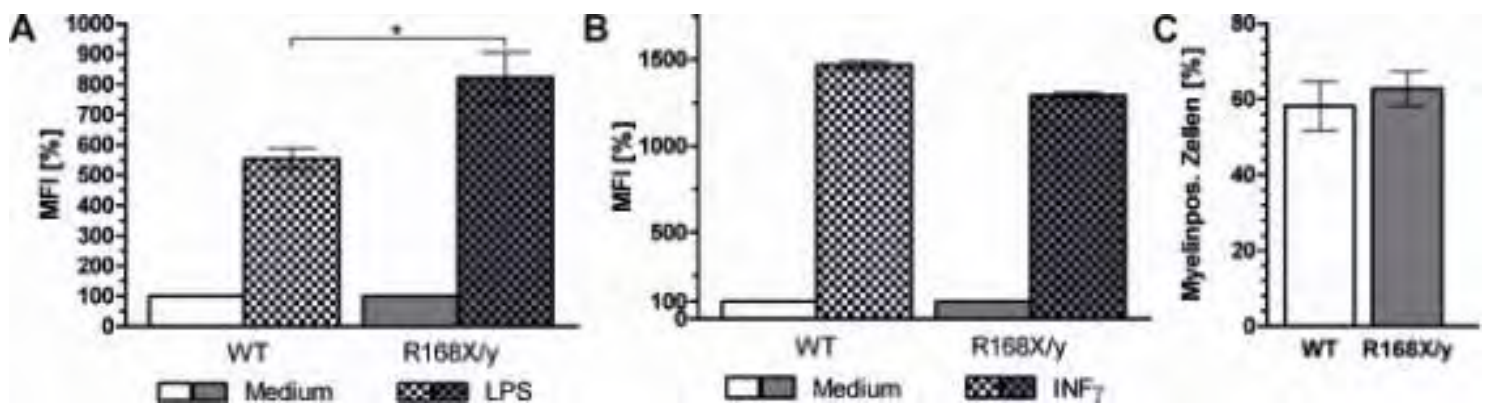

Abbildung 21: Expression von MHC-I und MHC-II nach Stimulation mit LPS (A) bzw. INFy (B) und Phagozytoseaktivität von $\mathrm{MeCP2}^{\mathrm{R} 168 \mathrm{X}}$-Mikroglia (C). Mediumkontrollen und die Stimulation mit INF $\gamma$ wurden in Duplikaten angefertigt, die Stimulation mit LPS und die Untersuchung der Myelinphagozytose konnten in jeweils 4 Proben durchgeführt werden A: Die relative Expression von MHC-I nach Stimulation mit LPS zeigt eine deutliche Erhöhung der mittleren Fluoreszenzintensität in $\mathrm{MeCP2}^{\mathrm{R} 168 \mathrm{x}}$-Mikroglia. B: Die relative Expression von MHC-II nach Stimulation mit INFy ist in $\mathrm{MeCP2}^{\mathrm{R} 168 \mathrm{x}}$-Mikroglia geringfügig verringert. C: Die Zahl Myelin-poitiver Zellen ist bei wildtypischen und MeCP2 ${ }^{\mathrm{R} 168 \mathrm{X} / \mathrm{y}}$-Mikroglia unverändert.

\subsubsection{Indirekter Nachweis der Phagozytoseaktivität männlicher $\mathrm{MeCP2}^{\mathrm{R} 168 \mathrm{x}}$ - Mikroglia durch Elektronenmikroskopie in vivo}

Da die in Punkt 3.2.3.3 beschriebenen Untersuchung der Phagozytoseaktivität in vitro um ein artifizielles System darstellt, wurde eine mögliche Anreicherung von verbliebenem Zellmaterial abgestorbener Zellen im Gehirn von gesunden und $\mathrm{MeCP} 2^{\mathrm{R} 168 \mathrm{X}}$ Mäusen mittels Elektronenmikroskopie untersucht. Hierfür wurde auf Schnitten des Hippocampus (Abbildung 22) und des Corpus callosum (Abbildung 23) degenerierte bzw. nicht als intakt zu identifizierende Neurone gezählt. Aufgrund von Fixierungsschwierigkeiten der hippocampalen Region der MeCP2 ${ }^{\mathrm{R} 168 \mathrm{X}}$-Mäuse, konnten für diese Region nur zwei Tiere (14 Bilder) ausgewertet werden. Alle übrigen Gruppen bestanden aus drei Tieren pro Genotyp bzw. 21 Bildern. Die Anzahl degenerierter Zellen waren im 
Corpus callosum zwischen beiden Gruppen vergleichbar (Abbildung 24A, WT= 1,24 $\pm 0,27, \mathrm{R} 168 \mathrm{X} / \mathrm{y}=1,19 \pm 0,24 ; \mathrm{p}=0,8978$ zweiseitiger ungepaarter t-Test). In der molekularen Schicht des Gyrus dentatus, des Hippocampus, konnte bei MeCP2 $2^{\mathrm{R} 168 \mathrm{X} / \mathrm{y}_{-}}$ Mäusen eine leicht verringerte Anzahl verstorbener Neuronen gezählt werden, jedoch ohne ein signifikantes Niveau zu erreichen $(\mathrm{WT}=1,00 \pm 0,49, \mathrm{R} 168 \mathrm{X} / \mathrm{y}=0,43 \pm 0,22 ; \mathrm{p}=$ 0,2980 Mann-Whitney Test; Abbildung 24B). 


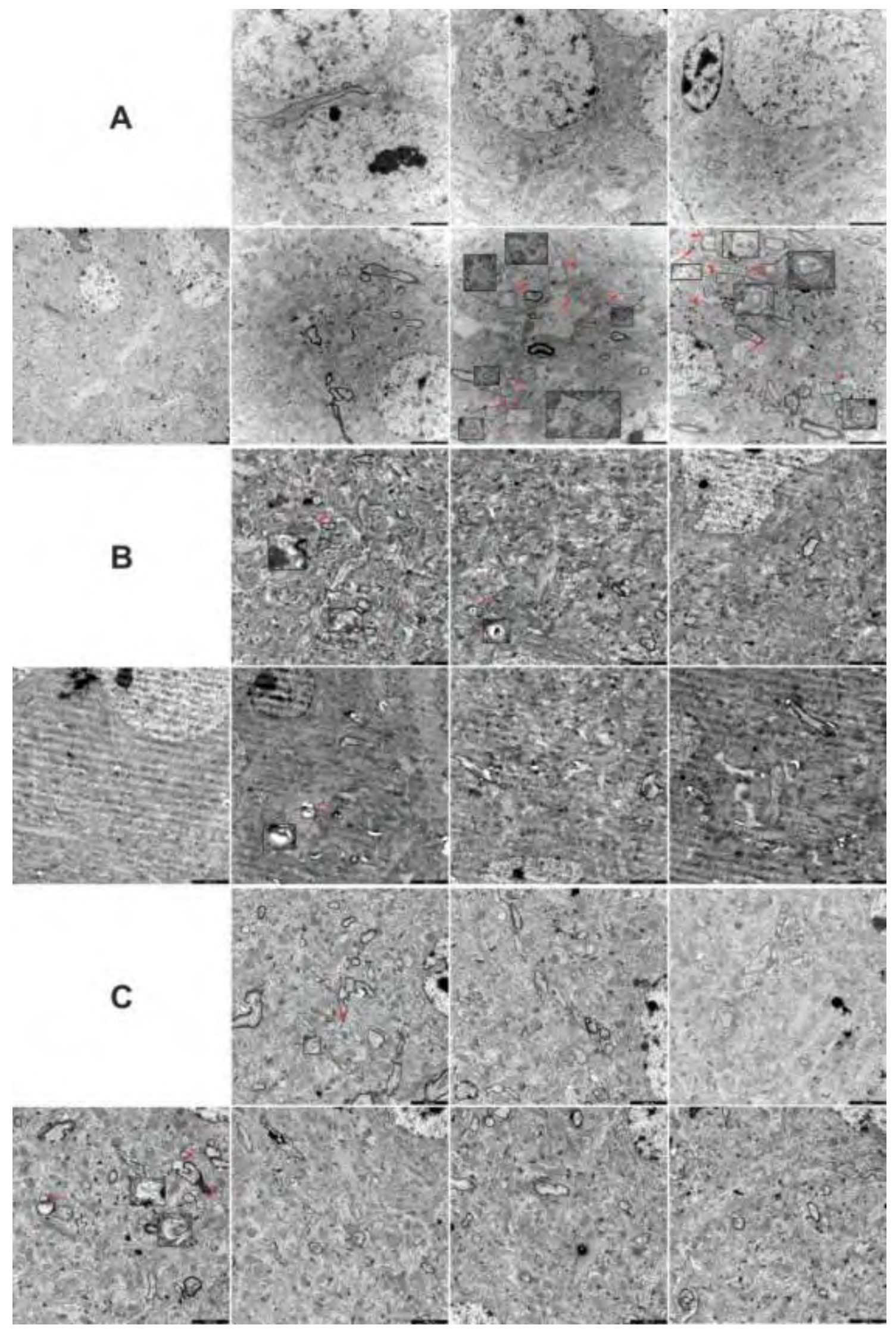




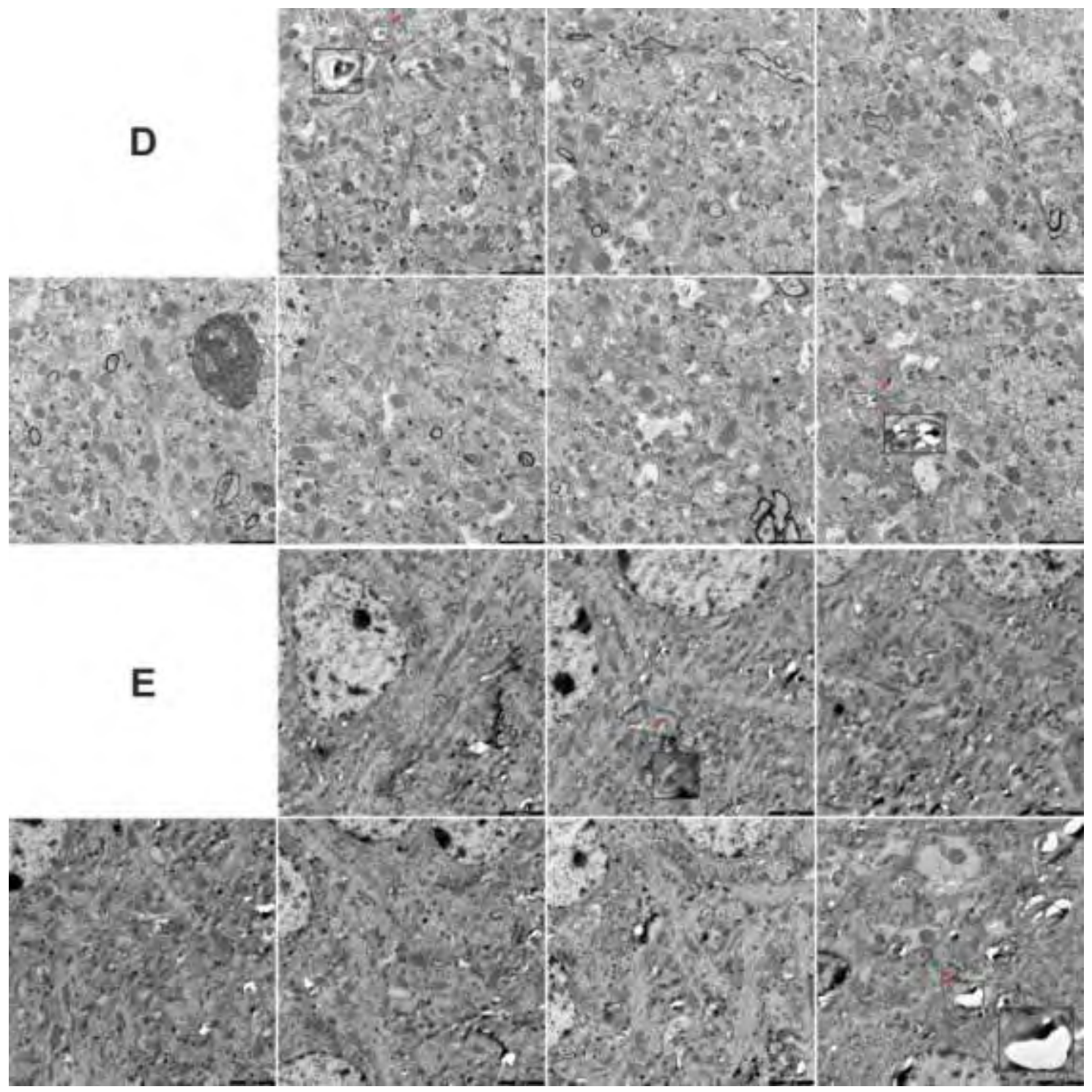

Abbildung 22: Auswertung der elektronenmikroskopischen Aufnahmen des Hippocampus männlicher Mäuse. A-C: Darstellung der ausgewerteten Bilder des Hippocampus gesunder Tiere. D-E: Darstellung der Bilder des Hippocampus mänlicher $\mathrm{MeCP2}^{\mathrm{R} 168 \mathrm{X}}$-Mäuse. Rote Pfeilspitzen zeigen für die auswertung relevante Strukturen. 


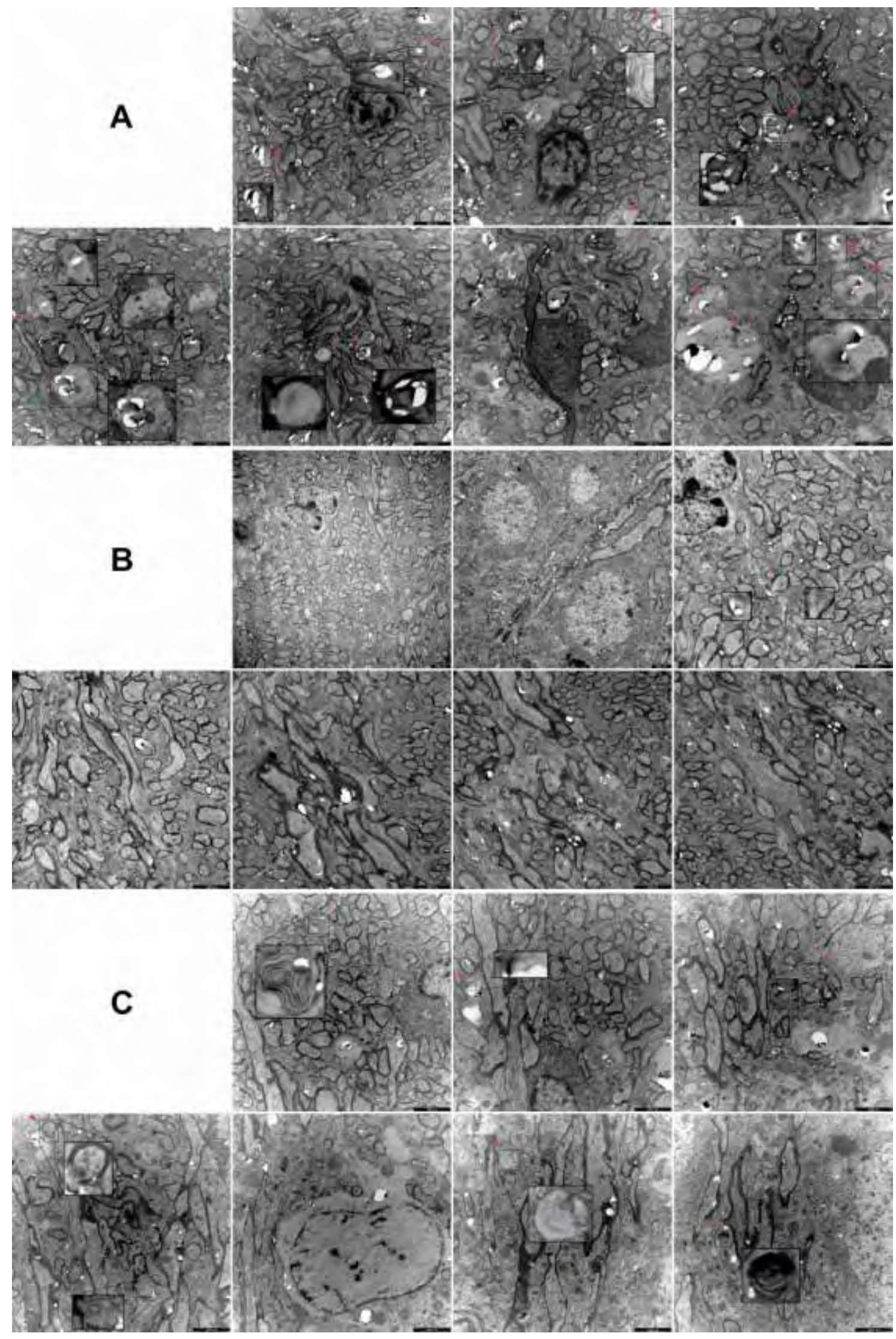




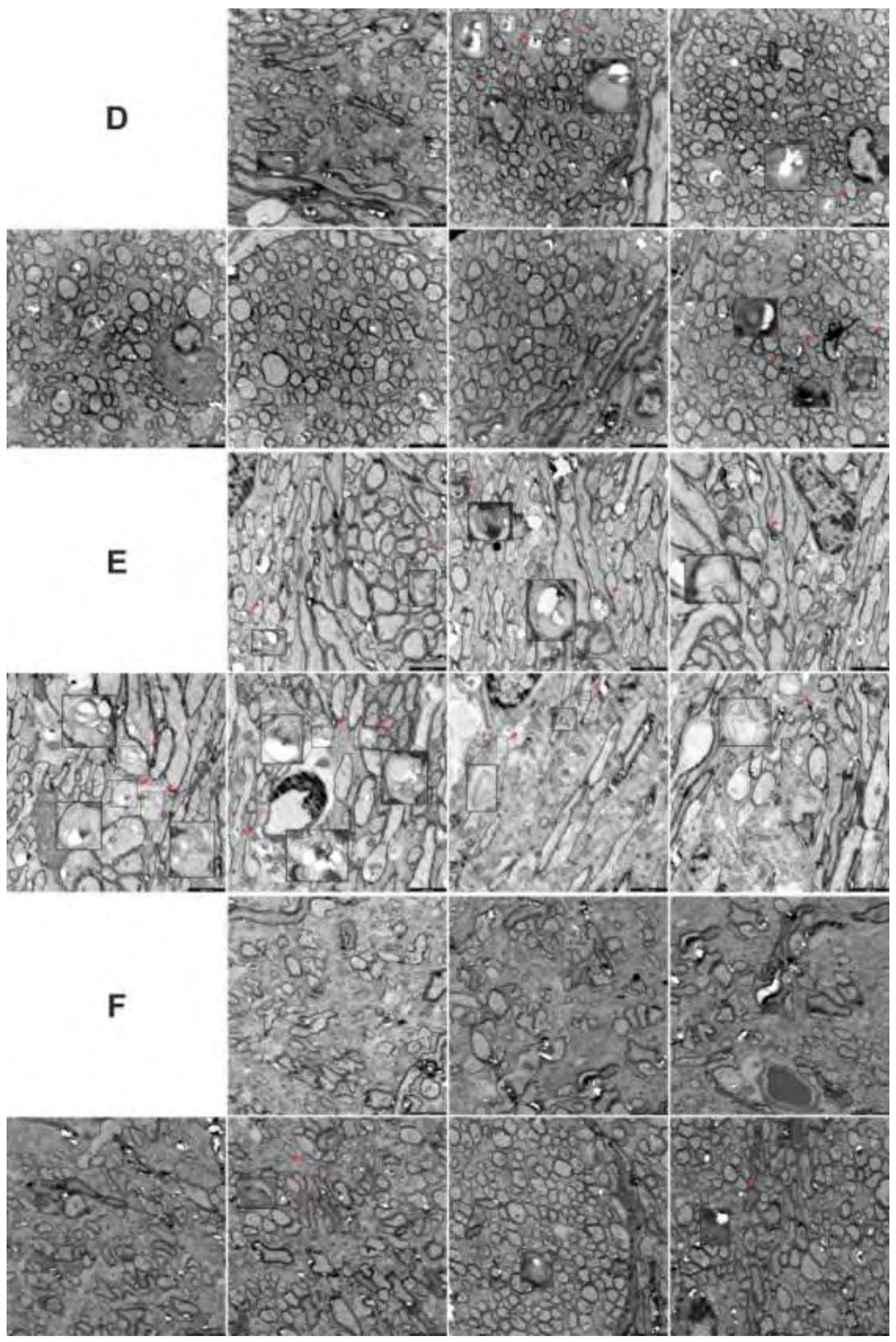

Abbildung 23: Auswertung der elektronenmikroskopischen Aufnahmen der Corpus callosum Region männlicher Mäuse. A-C: Darstellung der ausgewerteten Bilder des Corpus callosum gesunder Mäuse. D-F: Darstellung der Bilder des Corpus callosum mänlicher $\mathrm{MeCP2}^{\mathrm{R} 168 \mathrm{X}}$-Mäuse. Rote Pfeilspitzen zeigen für die auswertung relevante Strukturen. 
Die hier gewonnen Daten bestätigen die in vitro ermittelten Ergebnisse und bekräftigen somit die Annahme eines normalen Phagozytose der MeCP2 $2^{\mathrm{R} 168 \mathrm{X}}-$ Mikroglia in vivo.
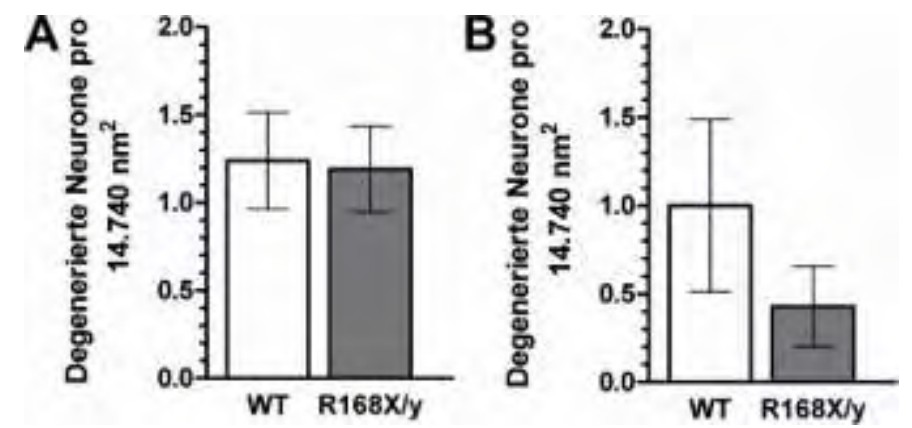

Abbildung 24: Die Auszählung der Zellreste degenerierter Neurone pro $14.740 \mathbf{n m}^{2}$, auf elektronenmikroskopischen Aufnahmen. A: Die Anzahl degenerierter Neurone im Corpus callosum ist in beiden Genotypen nahezu identisch. B: Die Anzahl degenerierter Neurone im Hippocampus ist bei MeCP2 $^{\text {R168X }}$-Männchen leicht verringert, erreicht jedoch keine signifikante Differenz.

\subsubsection{Untersuchung der Auswirkung der Knochenmarktransplantation auf weibliche $\mathrm{MeCP2}^{\mathrm{R168X}}$-Mäuse}

Während der Versuchsdauer konnte bei allen Tieren, transplantiert und nichttransplantiert, eine Zunahme des Körpergewichts beobachtet werden. Einzig WT $\rightarrow$ WT-Tiere zeigten während des Untersuchungszeitraums eine leichte Verringerung des Körpergewichts während der Monate eins bis vier ( $\mathrm{p}<0,001$ zweifache ANOVA mit Bonferroni's Posttest), acht ( $\mathrm{p}<0,05$ zweifache ANOVA mit Bonferroni's Posttest) und neun ( $\mathrm{p}<0,01$ zweifache ANOVA mit Bonferroni's Posttest) (Tabelle 10 und Abbildung 25). 
Tabelle 10: Körpergewicht [g] transplantierter und nicht-transplantierter weiblicher $\mathrm{MeCP2}^{\mathrm{R} 168 \mathrm{X}}$-Tiere. Alle Werte sind als Mittelwert (MW) \pm Standardfehler des Mittelwertes (SEM) angegeben.

\begin{tabular}{|c|c|c|c|c|c|c|c|c|}
\hline \multirow{2}{*}{$\begin{array}{c}\text { Alter } \\
\text { Monaten] }\end{array}$} & \multicolumn{2}{|c|}{ WT } & \multicolumn{2}{c}{ R168X/x } & \multicolumn{2}{c|}{ WT $\rightarrow$ WT } & \multicolumn{2}{c|}{ WT $\rightarrow$ R168X/x } \\
\cline { 2 - 9 } & MW \pm SEM & $\mathbf{n}$ & MW \pm SEM & $\mathbf{n}$ & MW \pm SEM & $\mathbf{n}$ & MW \pm SEM & $\mathbf{n}$ \\
\hline $\mathbf{1}$ & $13,44 \pm 0,93$ & 8 & $14,31 \pm 0,98$ & 6 & $8,74 \pm 0,51$ & 14 & $12,13 \pm 1,38$ & 8 \\
\hline $\mathbf{2}$ & $18,25 \pm 0,30$ & 17 & $16,41 \pm 0,46$ & 15 & $14,29 \pm 0,35$ & 14 & $14,89 \pm 0,94$ & 8 \\
\hline $\mathbf{3}$ & $20,11 \pm 0,30$ & 20 & $18,41 \pm 0,56$ & 18 & $16,40 \pm 0,41$ & 14 & $17,21 \pm 0,83$ & 8 \\
\hline $\mathbf{4}$ & $21,65 \pm 0,25$ & 13 & $20,30 \pm 0,47$ & 16 & $17,92 \pm 0,48$ & 14 & $18,83 \pm 0,77$ & 6 \\
\hline $\mathbf{5}$ & $22,75 \pm 0,37$ & 16 & $21,88 \pm 0,60$ & 16 & $20,08 \pm 0,47$ & 8 & $20,74 \pm 0,87$ & 4 \\
\hline $\mathbf{6}$ & $24,55 \pm 0,54$ & 17 & $23,76 \pm 1,00$ & 11 & $21,56 \pm 1,13$ & 2 & $25,03 \pm 1,11$ & 4 \\
\hline $\mathbf{7}$ & $26,29 \pm 0,69$ & 13 & $24,71 \pm 1,33$ & 11 & $22,05 \pm 0,05$ & 2 & $26,75 \pm 1,63$ & 4 \\
\hline $\mathbf{8}$ & $27,09 \pm 0,71$ & 12 & $26,68 \pm 1,46$ & 9 & $21,95 \pm 0,35$ & 2 & $26,03 \pm 1,52$ & 4 \\
\hline $\mathbf{9}$ & $27,91 \pm 0,73$ & 10 & $27,66 \pm 1,34$ & 7 & $21,80 \pm 0,00$ & 2 & $26,68 \pm 1,47$ & 4 \\
\hline
\end{tabular}

Alle Tiere wurden in einem Alter von 9 Monaten (8 Monate nach der Transplantation) einer Verhaltensanalyse unterzogen, um zu ermitteln welche Auswirkungen die Knochenmarktransplantation auf die Tiere hatte.

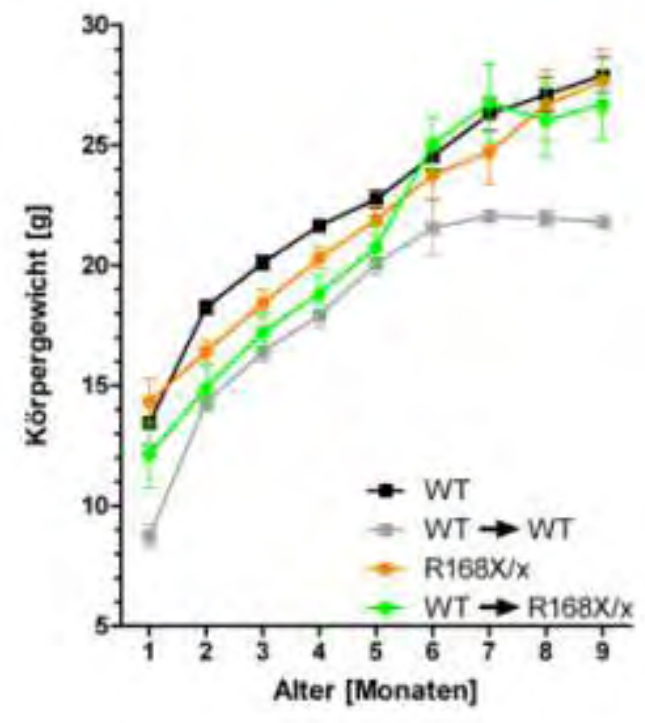

Abbildung 25: Das Körpergewicht [g] weiblicher Tiere ohne Knochenmarktransplantation (WT und R168X/x) und nach Knochenmarktransplantation (WT $\rightarrow$ WT und WT $\rightarrow$ R168X/x). 


\subsubsection{Nestbauverhalten weiblicher $\mathrm{MeCP}^{\mathrm{R} 168 \mathrm{x}}$-Mäuse nach Knochenmark- transplantation}

Die Knochenmarktransplantation führte bei transplantierten $\mathrm{MeCP} 2^{\mathrm{R} 168 \mathrm{X}}-$ Weibchen nach 24 Stunden zu einer verringerten Komplexität der angefertigten Nester mit einer mittleren Nestqualität von 1 (Spanne: 0 bis 2) im Vergleich zu nicht-transplantierten $\mathrm{MeCP} 2^{\mathrm{R} 168 \mathrm{X}}-$ Weibchen (mittlere Nestqualität= 2, Spanne: 0 bis 4; p>0,05 KruskalWallis Test mit Dunn's Posttest). Im Gegensatz zu nicht-transplantierten heterozygoten Weibchen, die in der Lage waren nach 48 Stunden eine mittlere Nestqualität von 3 (Spanne: 0 bis 5) zu erreichen, verbesserte sich die mittlere Nestqualität bei transplantierten heterozygoten Weibchen nicht (mittlere Nestqualität $=1$, Spanne: 0 bis $4 ; p>0,05$ Kruskal-Wallis Test mit Dunn's Posttest; Abbildung 26). Bei gesunden Tieren führte die Transplantation zu einer leichten Erhöhung der mittleren Nestqualität nach 48 Stunden von 3 auf 4 (Spanne: 1 bis 5; p>0,05 Kruskal-Wallis Test mit Dunn's Posttest; Abbildung 26).

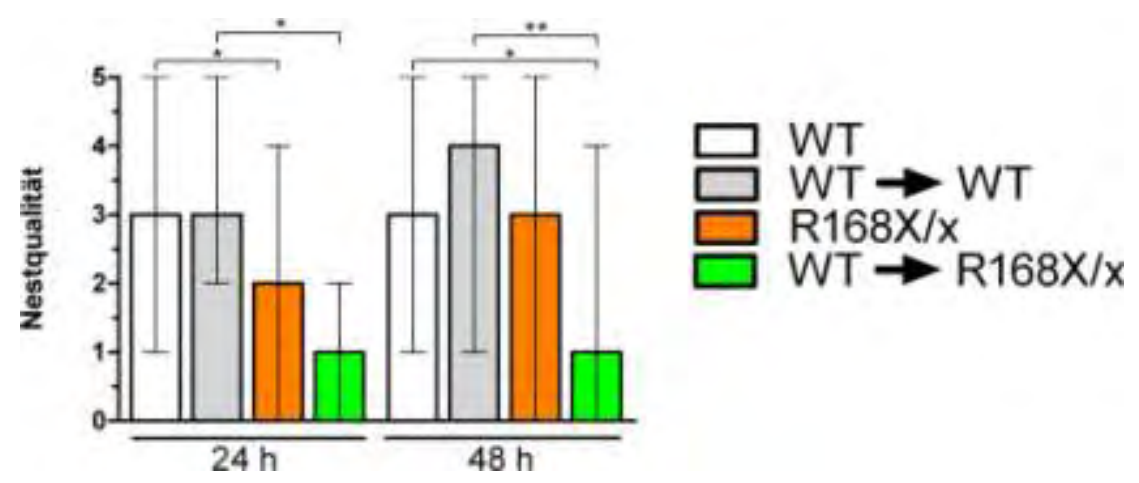

Abbildung 26: Untersuchung des Nestbauverhaltens (transplantierter (WT $\rightarrow$ WT, WT $\rightarrow$ R168X/x) und nicht-transplantierter Tiere (WT, R168X/x) nach 24 und 48 Stunden. Die Werte sind als Median mit Minima und Maxima angegeben.

\subsubsection{Atmung und Lungenfunktion weiblicher $\mathrm{MeCP2}^{\mathrm{R} 168 \mathrm{X}}$-Mäuse nach Kno- chenmarktransplantation}

Im Vergleich zu nicht-transplantierten MeCP2 ${ }^{\mathrm{R} 168 \mathrm{X}}$-Mäusen (R168X/x: n= 10, Apnoen $>1$ s/ vier Minuten=0,60 $\pm 0,27$ ) verringerten sich die Zahl auftretender Apnoen bei transplantierten $\mathrm{MeCP} 2^{\mathrm{R} 168 \mathrm{X}}$-Mäusen, jedoch ohne ein signifikantes Niveau zu erreichen $(\mathrm{WT} \rightarrow \mathrm{R} 168 X / \mathrm{x}: \mathrm{n}=5$, Apnoen $>1 \mathrm{~s} /$ vier Minuten=0,40 $\pm 0,40 ; \mathrm{p}>0,05$ KruskalWallis Test mit Dunn's Posttest; Abbildung 27A). Dieser Effekt konnte ebenfalls bei gesunden transplantierten Tieren beobachtet werden (WT: Apnoen $>1 \mathrm{~s} /$ vier Minuten= $0,70 \pm 0,52 ; \mathrm{WT} \rightarrow \mathrm{WT}:$ Apnoen $>1 \mathrm{~s} /$ vier Minuten=0,20 $\pm 0,20 ;$ Abbildung 27A). Die Atemfrequenz weiblicher $\mathrm{MeCP} 2^{\mathrm{R} 168 \mathrm{X}}$-Mäuse zeigte keine Unterschiede zwischen 
heterozygoten transplantierten und nicht-transplantierten Tieren $(\mathrm{R} 168 \mathrm{X} / \mathrm{x}=6,54 \mathrm{~Hz}$ $\pm 0,37 ; \mathrm{WT} \rightarrow \mathrm{R} 168 \mathrm{X} / \mathrm{x}=6,36 \mathrm{~Hz} \pm 0,67 ; \mathrm{p}>0,05$ Kruskal-Wallis Test mit Dunn’s Posttest) und gesunden transplantierten und nicht-transplantierten Tieren (WT=7,33 Hz $\pm 0,34 ; \mathrm{WT} \rightarrow \mathrm{WT}=6,66 \mathrm{~Hz} \pm 0,38 ; \mathrm{p}>0,05$ Kruskal-Wallis Test mit Dunn's Posttest, Abbildung

Wie auch die Atemfrequenz blieb die Regelmäßigkeit der Atmung nach der Transplantation in beiden Behandlungsgruppen unverändert (IrrScore ${ }_{\mathrm{WT}} \rightarrow \mathrm{wT}_{\mathrm{W}}=0,32 \pm 0,01$; IrrScore $_{\mathrm{WT}} \rightarrow \mathrm{R} 168 \mathrm{X} / \mathrm{x}=0,33 \pm 0,04$; jeweils $\mathrm{p}>0,05$ Kruskal-Wallis Test mit Dunn's Posttest, verglichen mit den jeweiligen unbehandelten Kontrollen; Abbildung 27C).
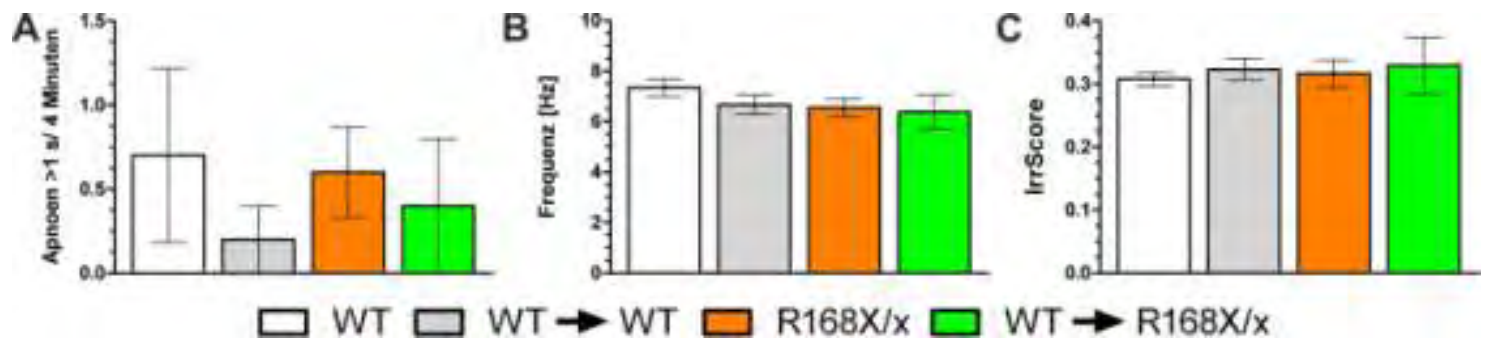

Abbildung 27: Untersuchung der Atmung transplantierter (WT $\rightarrow$ WT, WT $\rightarrow$ R168X/x) und nichttransplantierter Mäuse (WT, R168X/x). A: Anzahl auftretender Apnoen pro vier Minuten mit einer minimalen Dauer von einer Sekunde. B: Analyse der Atemfrequenz transplantierter und nicht-transplantierter Tiere. C: Darstellung des „IrrScores“ als Maß der Reglmäßigkeit der Atmung.

\subsubsection{Lokomotorische Aktivität weiblicher $\mathrm{MeCP}^{\mathrm{R} 168 \mathrm{X}}$-Mäuse nach Knochen- marktransplantation}

Bei MeCP2 $2^{\mathrm{R} 168 \mathrm{X}}$-Weibchen führte die Knochenmarktransplantation $\left(\mathrm{n}_{\mathrm{WT}} \rightarrow{ }_{\mathrm{R} 168 \mathrm{X} / \mathrm{x}}=8\right)$ zu einer signifikant reduzierten Durchschnittsgeschwindigkeit gegenüber nichttransplantierten Tieren ( $\mathrm{v}_{\mathrm{WT}} \rightarrow \mathrm{R} 168 \mathrm{X} / \mathrm{x}=2,19 \mathrm{~cm} / \mathrm{s} \pm 0,21$ vs. $\mathrm{v}_{\mathrm{R} 168 \mathrm{X} / \mathrm{x}}=3,37 \mathrm{~cm} / \mathrm{s} \pm 0,24$; $\mathrm{p}<0,05$, einfache ANOVA mit Bonferroni’s Posttest; Abbildung 28A). Die Verringerung der durchschnittlichen Bewegungsgeschwindigkeit resultierte bei den transplantierten heterozygoten Weibchen in einer signifikant kürzeren zurückgelegten Distanz

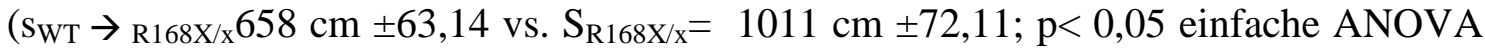
mit Bonferroni’s Posttest; Abbildung 27B) und einer signifikant verringerten Anzahl an Besuchen in alle Quadranten der Apparatur (Besuche ${ }_{\mathrm{WT}} \rightarrow \mathrm{R} 168 \mathrm{X} / \mathrm{x}=57,63 \pm 11,03$ vs. Besuche $_{\mathrm{R} 168 \mathrm{X} / \mathrm{x}}=90,09 \pm 6,73 ; \mathrm{p}<0,05$ einfache ANOVA mit Bonferroni's Posttest; Abbildung

Gesunde Tiere wurden durch die Transplantation $\left(\mathrm{n}_{\mathrm{WT}} \rightarrow \mathrm{wT}=14\right)$ weder in ihrer Geschwindigkeit $\left(\mathrm{v}_{\mathrm{WT}}=3,36 \mathrm{~cm} / \mathrm{s} \pm 0,18\right.$ vs. $\mathrm{v}_{\mathrm{WT}} \rightarrow \mathrm{wT}=3,27 \mathrm{~cm} / \mathrm{s} \pm, 024 ; \mathrm{p}>0,05$ einfache ANOVA mit Bonferroni's Posttest; Abbildung 28A), der zurückgelegten Distanz ( $\mathrm{s}_{\mathrm{WT}}=$ $1008 \mathrm{~cm} \pm 55,51$ vs. $\mathrm{s}_{\mathrm{WT}} \rightarrow \mathrm{wT}=981,10 \mathrm{~cm} \pm 72,60 ; \mathrm{p}>0,05$ einfache ANOVA mit 
Bonferroni's Posttest; Abbildung 28B) oder der Anzahl an Besuchen in einzelne Bereiche der Apparatur beeinträchtigt $\left(\right.$ Besuche $_{\mathrm{WT}}=80,85 \pm 3,78$, Besuche $_{\mathrm{WT}} \rightarrow \mathrm{wT}_{\mathrm{wT}}=81,71$ $\pm 10,37$; p> 0,05 einfache ANOVA mit Bonferroni's Posttest; Abbildung 28C).
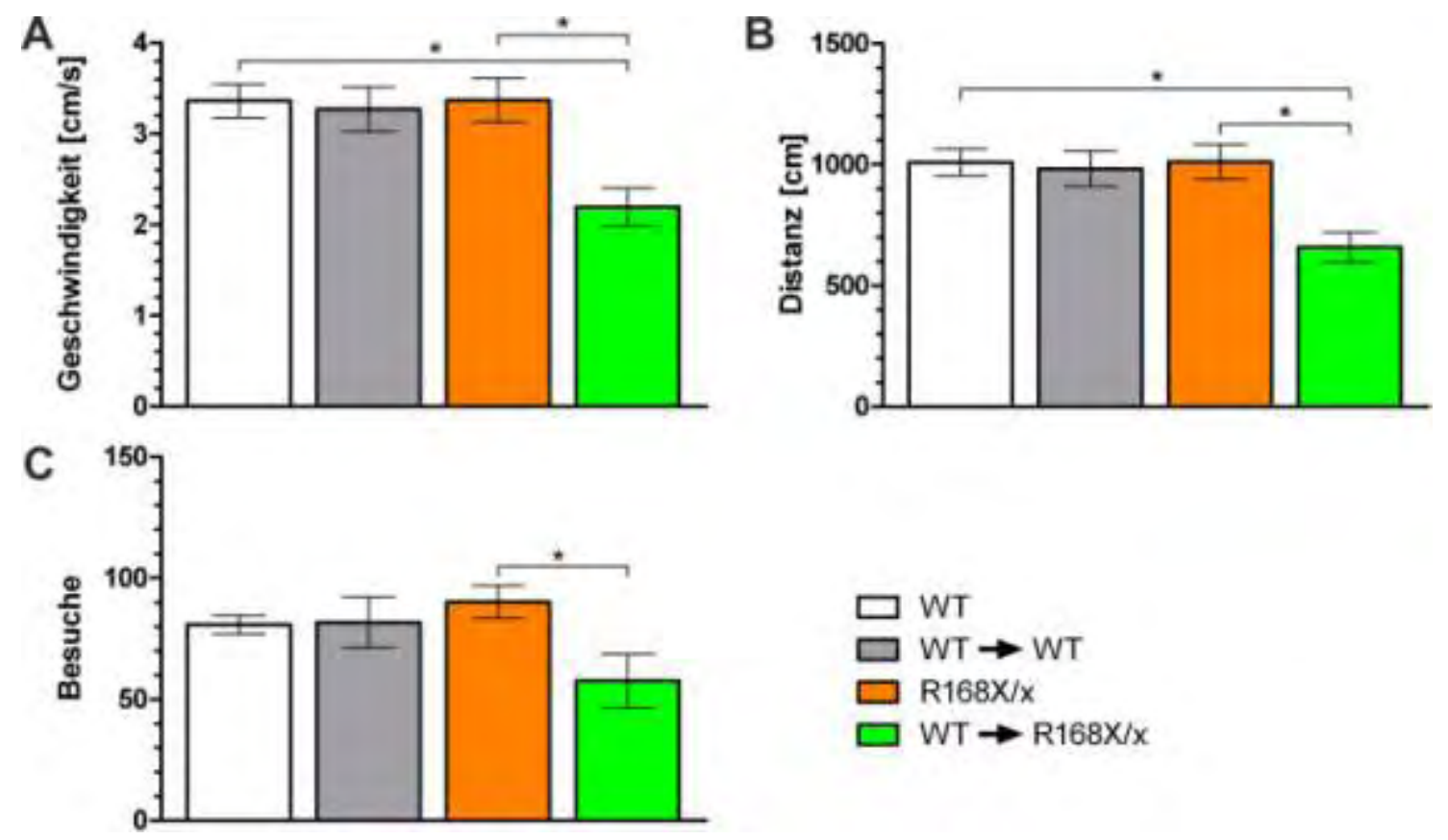

Abbildung 28: Untersuchung des lokomotorischen Aktivität knochenmaktransplantierter $\mathrm{MeCP2}^{\mathrm{R} 168 \mathrm{X}}$ Weibchen. A: Die durchschnittliche Geschwindigkeit war während des Versuchs bei WT $\rightarrow$ R168X/x Mäusen stark vermindert. B: Die zurückgelegte Distanz war zwischschen WT, WT $\rightarrow$ WT und R168X/x Weibchen vergleichbar. WT $\rightarrow \mathrm{R} 168 X / \mathrm{x}$ Weibchen legten in der gleichen Zeit deutlich kürzere Distanz zurück. C: Die Zahl der Besuche während des Open Field-Experiements zeigte ebenfalls ein deutlich Reduzierung bei WT $\rightarrow$ $\mathbf{R 1 6 8 X} / \mathbf{x}$ Weibchen, während die anderen Gruppen vergleichbare Besuche absolvierten.

\subsubsection{Motorische Koordination und motorisches Lernen weiblicher $\mathrm{MeCP2}^{\mathrm{R} 168 \mathrm{X}}$-Mäuse nach Knochenmarktransplantation}

Die Knochenmarktransplantation führte bei heterozygoten Tieren zu keiner Veränderung der motorischen Koordination gegenüber nicht transplantierten Tieren ( $p>0,05$ Kruskal-Wallis Test mit Dunn's Posttest, Tabelle 11 und Abbildung 29A). Transplantierte heterozygote Weibchen wiesen eine den nicht-transplantierten Tieren vergleichbare Steigerung der Verweildauer auf der Apparatur zwischen den ersten beiden Trainingsphasen auf, jedoch ohne ein signifikantes Niveau zu erreichen ( $p>0,05$ KruskalWallis Test mit Dunn's Posttest, Tabelle 11 und Abbildung 29A). Transplantierte gesunde Tiere wiesen verglichen mit nicht-transplantierten Tieren eine leicht verbesserte, nicht signifikante, motorische Koordination nach dem ersten Training auf und steigerten sich nachfolgend weniger stark zum zweiten Training ( $p>0,05$ Kruskal-Wallis Test mit Dunn's Posttest, Tabelle 11 und Abbildung 29A). 
Tabelle 11: Durchschnittliche Zeit während der vier Trainingsintervalle, die sich transplantierte und nichttransplantierte Weibchen auf dem Rotarod halten konnten. Alle Werte sind als Mittelwert mit dem Standardfehler des Mittelwerts angegeben.

\begin{tabular}{|c|c|c|c|c|}
\hline Training & WT & WT $\rightarrow$ WT & $\mathbf{R 1 6 8 X / x}$ & WT $\rightarrow \mathbf{R 1 6 8 X / \mathbf { x }}$ \\
\hline 1 & $104,50 \mathrm{~s} \pm 14,30$ & $135,30 \mathrm{~s} \pm 20,96$ & $39,40 \mathrm{~s} \pm 12,23$ & $52,89 \mathrm{~s} \pm 27,89$ \\
\hline 2 & $164,10 \mathrm{~s} \pm 7,38$ & $180,00 \mathrm{~s} \pm 0,00$ & $145,30 \mathrm{~s} \pm 13,20$ & $151,60 \mathrm{~s} \pm 21,52$ \\
\hline 3 & $175,00 \mathrm{~s} \pm 5,07$ & $169,60 \mathrm{~s} \pm 10,36$ & $160,10 \mathrm{~s} \pm 9,82$ & $158,20 \mathrm{~s} \pm 21,83$ \\
\hline 4 & $173,10 \mathrm{~s} \pm 5,30$ & $180,00 \mathrm{~s} \pm 0,00$ & $163,20 \mathrm{~s} \pm 9,46$ & $155,20 \mathrm{~s} \pm 17,97$ \\
\hline
\end{tabular}

Bei der Analyse der motorischen Koordination, bei gleichbleibender Beschleunigung, konnte bei keiner Behandlungsgruppe ein signifikanter Unterschied zu den Kontrollgruppen im Hinblick auf die Verweildauer auf der Apparatur oder die maximale Geschwindigkeit ermittelt werden ( $\mathrm{p}>0,05$ Kruskal-Wallis Test mit Dunn's Posttest; Tabelle 12 und Abbildung 29B und C).

Tabelle 12: Wertetabelle des Rotarodexperiments bei gleichmäßiger Beschleunigung nach Knochenmarktransplantation. Alle Werte sind als Mittelwert mit dem Standardfehler des Mittelwerts angegeben.

\begin{tabular}{|c|c|c|c|c|}
\hline Parameter & WT & WT $\rightarrow$ WT & $\mathbf{R 1 6 8 X / \mathbf { x }}$ & WT $\rightarrow \mathbf{R 1 6 8 X} / \mathbf{x}$ \\
\hline Zeit [s] & $66,09 \mathrm{~s} \pm 1,90$ & $70,60 \mathrm{~s} \pm 2,50$ & $55,05 \mathrm{~s} \pm 2,42$ & $48,95 \mathrm{~s} \pm 4,39$ \\
\hline $\begin{array}{c}\text { Geschwindig- } \\
\text { keit [rpm] }\end{array}$ & $17,92 \pm 0,37$ & $18,80 \pm 0,57$ & $15,78 \pm 0,47$ & $14,58 \pm 0,85$ \\
\hline
\end{tabular}
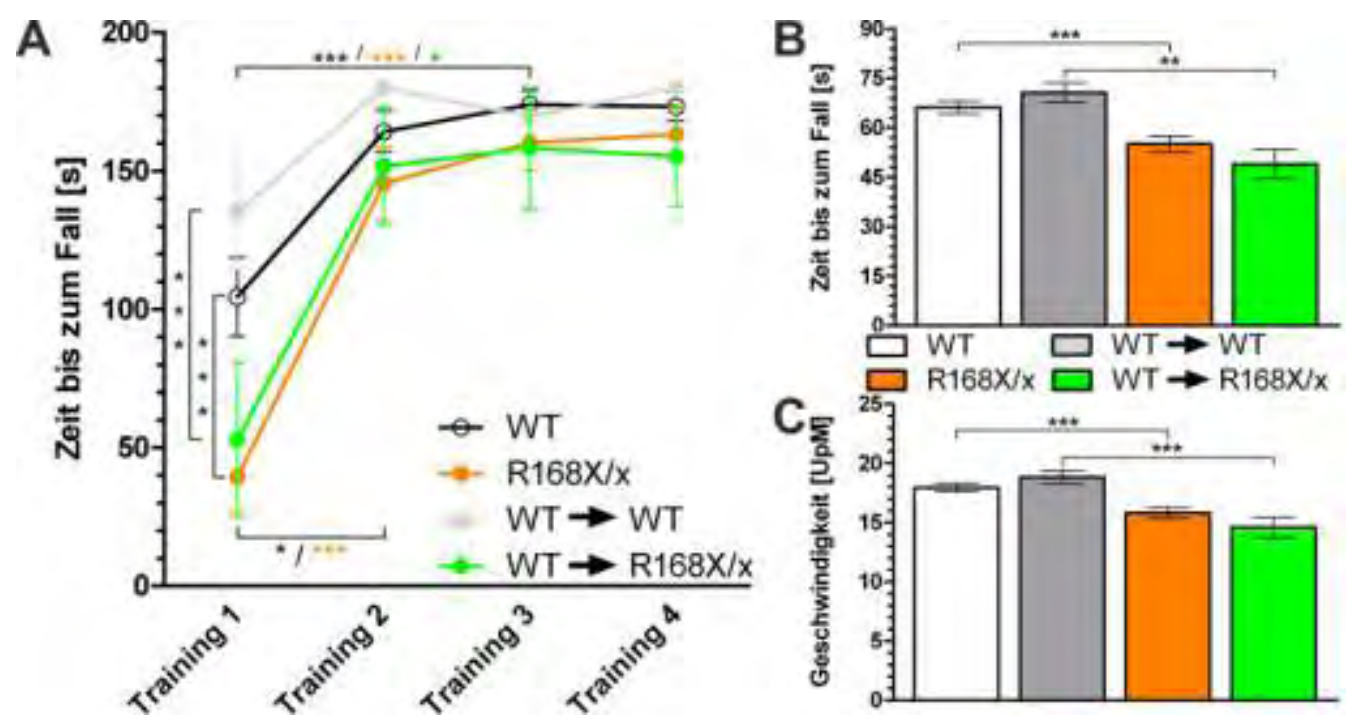

Abbildung 29: Untersuchung motorischer Fähigkeiten und des motorischen Lernens bei weibchlichen Mäusen mit und ohne Knochenmarktransplantation. A: Untersuchung der motorischen Lernfähigkeit bei nichttransplantierten und transplantierten Weibchen auf dem Rotarod bei gleichbleibender Geschwindigkeit von zehn Umdrehungen pro Minute. Angegeben ist die Zeit bis zum Fall der Tiere von Apparatur. B: Die durchschnittliche Zeit die sich die Tiere auf dem beschleunigtem Rotarod halten konnten. C: Die durchschnittliche Maximalgeschwindigkeit der rotierenden Walze, bei der die Tiere von der Apparatur fielen. 


\subsubsection{Untersuchung des Angstverhaltens weiblicher $\mathrm{MeCP2}^{\mathrm{R} 168 \mathrm{X}}$-Mäuse nach Knochenmarktransplantation}

Die Knochenmarktransplantation führte bei heterozygoten und gesunden Weibchen zu einer Steigerung des Angstverhaltens, gemessen an einer verringerten Aufenthaltsdauer im Zentrum des Open Fields, gegenüber nicht-transplantierten Kontrolltieren ( $\mathrm{t}_{\mathrm{WT}} \rightarrow$ $\mathrm{R} 168 \mathrm{X} / \mathrm{x}=1,55 \% \pm 0,63$ vs. $\mathrm{t}_{\mathrm{R} 168 \mathrm{X} / \mathrm{x}}=3,38 \% \pm 0,47$ und $\mathrm{t}_{\mathrm{WT}}=4,98 \% \pm 1,08$ vs. $\mathrm{t}_{\mathrm{WT}} \rightarrow \mathrm{wT}=$ $3,73 \% \pm 0,98$; jeweils p> 0,05 Kruskal-Wallis Test mit Dunn's Posttest; Abbildung 30A). Diese Ergebnisse konnten durch das Elevated Plus Maze-Experiment nicht bestätigt werden. Hier zeigten transplantierte heterozygote Weibchen ein verringertes Angstverhalten gegenüber nicht-transplantierten Tieren, gemessen am Vergleich der Aufenthaltsdauer in den offenen und geschlossenen Armen der Apparatur (p>0,05 KruskalWallis Test mit Dunn's Posttest; Tabelle 13 und Abbildung 30B).
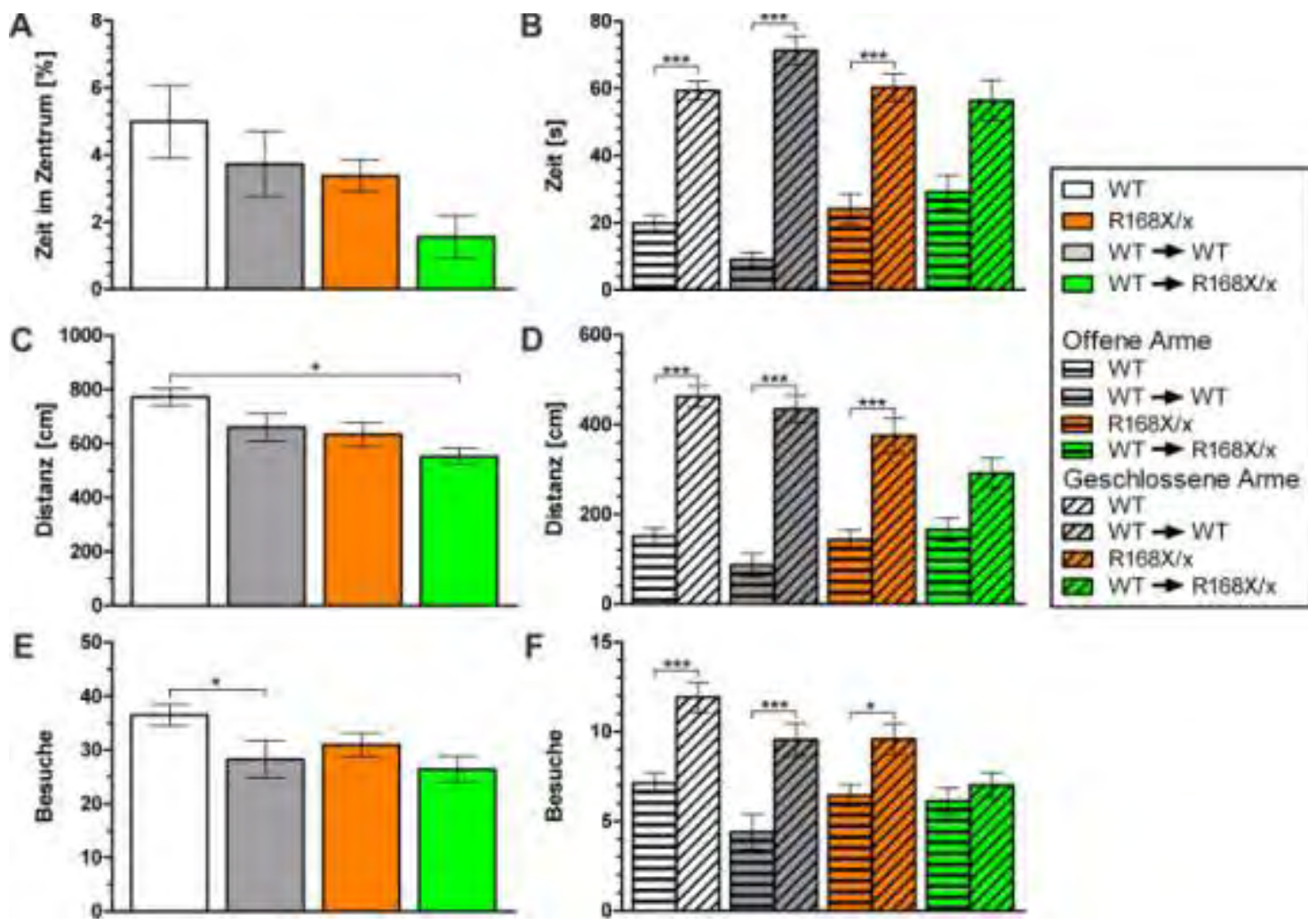

Abbildung 30: Untersuchung des Angstverhaltens nach Knochenmarktransplantation in der Elevated Plus Maze und im Open Field. A: Die verbrachte Zeit in offenen und geschlossenen Armen der Elevated Plus Maze. B: Die Zeit die die Weibchen im Zentrum des Open Fields verbrachten. C: Die gesamte zurückgelegte Strecke während des Elevates Plus Maze Experiments. D: Die zurückgelegten Distanzen in den offenen und geschlossen Armen der Elevated Plus Maze. E: Die Gesamtzahl der Besuche weiblicher Tiere in allen Regionen der Arena. F: Die Anzahl der Besuche in offenen und geschlossenen Armen der Arena.

Transplantierte gesunde Tiere zeigten in diesem Versuch ein unverändertes Angstverhalten ( $\mathrm{p}<0,05$ Kruskal-Wallis Test mit Dunn's Posttest; Tabelle 13 und Abbildung 30B). 
Die Durchschnittlich zurückgelegte Gesamtdistanz war bei Versuchstieren beider Gruppen nach Transplantation leicht verringert (Abbildung 30C - D und Tabelle 14).

Tabelle 13: Aufenthaltsdauer der Tiere in offenen und geschlossenen Armen der Elevated Plus Maze nach Knochenmarktransplantation. Alle Werte sind als Mittelwert mit Standardfehler des Mittelwertes angegeben.

\begin{tabular}{|c|c|c|}
\hline \multirow{2}{*}{ Gruppe } & \multicolumn{2}{|c|}{ Aufenthaltsdauer [\%] in } \\
& Offenen Armen & Geschlossenen Armen \\
\hline WT & $19,78 \pm 2,41$ & $59,24 \pm 2,81$ \\
\hline WT $\rightarrow$ WT & $8,98 \pm 2,17$ & $71,23 \pm 4,19$ \\
\hline R168X/x & $24,11 \pm 4,49$ & $60,28 \pm 4,13$ \\
\hline WT $\rightarrow$ R168X/x & $29,15 \pm 4,97$ & $56,28 \pm 6,07$ \\
\hline
\end{tabular}

Tabelle 14: Übersicht der zurückgelegten Distanzen gesamt und in offenen bzw. geschlossenen Armen der Apparatur nach Knochenmarktrasnplantation. Alle Werte sind als Mittelwert mit Standardfehler des Mittelwertes angegeben. p-Werte zwischen den Distanzen in offenen und geschlossenen Armen wurden mittels Kruskal-Wallis Test und Dunn's Posttest ermittelt.

\begin{tabular}{|c|c|c|c|c|}
\hline Gruppe & $\begin{array}{c}\text { Gesamtdistanz } \\
{[\mathbf{c m}]}\end{array}$ & $\begin{array}{c}\text { Offene Arme } \\
{[\mathbf{c m}]}\end{array}$ & $\begin{array}{c}\text { Geschlossene } \\
\text { Arme }[\mathbf{c m}]\end{array}$ & $\begin{array}{c}\text { p-Wert } \\
\text { offen vs. } \\
\text { geschlossen }\end{array}$ \\
\hline WT & $770,70 \pm 32,20$ & $150,60 \pm 17,97$ & $462,30 \pm 24,11$ & $<0,001$ \\
\hline WT $\rightarrow$ WT & $659,40 \pm 54,42$ & $86,47 \pm 26,62$ & $434,30 \pm 30,87$ & $<0,001$ \\
\hline $\mathrm{R} 168 X / x$ & $632,70 \pm 44,10$ & $142,90 \pm 21,65$ & $375,20 \pm 38,37$ & $<0,001$ \\
\hline $\mathrm{WT} \rightarrow \mathrm{R} 168 \mathrm{X} / \mathrm{x}$ & $552,00 \pm 28,95$ & $165,40 \pm 25,72$ & $291,40 \pm 33,46$ & $>0,05$ \\
\hline
\end{tabular}

Während des gesamten Experiments führten transplantierte Tiere beider Gruppen, verglichen mit nicht-transplantierten Tieren, eine leicht reduzierte Anzahl an Besuchen durch. Lediglich transplantierte gesunde Tiere wiesen eine signifikante Verringerung der Besuche auf (WT vs. WT $\rightarrow$ WT p $<0,05$ Kruskal-Wallis Test mit Dunn's Posttest; Abbildung 30E und Tabelle 15). Transplantierte heterozygote Weibchen zeigten eine leichte Verringerung der Besuche der geschlossenen und offenen Arme der Apparatur (Abbildung 30F und Tabelle 15). 
Tabelle 15: Anzahl der Besuche transplantierter und nicht-transplantierter Tiere gesamt und in offene bzw. geschlossene Arme der Apparatur. Alle Werte sind als Mittelwert mit Standardfehler des Mittelwertes angegeben. Die p-Werte wurden mittels Kruskal-Wallis Test und Dunn's Posttest ermittelt.

\begin{tabular}{|c|c||c|c|c|}
\hline \multirow{2}{*}{ Gruppe } & Gesamt & $\begin{array}{c}\text { Offene } \\
\text { Arme }\end{array}$ & Geschlossene Arme & $\begin{array}{c}\text { p-Wert } \\
\text { offen vs. } \\
\text { geschlos- }\end{array}$ \\
\hline $\mathrm{WT}$ & $770,70 \pm 32,20$ & $150,60 \pm 17,97$ & $462,30 \pm 24,11$ & $<0,001$ \\
\hline $\mathrm{WT} \rightarrow \mathrm{WT}$ & $659,40 \pm 54,42$ & $86,47 \pm 26,62$ & $434,30 \pm 30,87$ & $<0,001$ \\
\hline $\mathrm{R} 168 \mathrm{X} / \mathrm{x}$ & $632,70 \pm 44,10$ & $142,90 \pm 21,65$ & $375,20 \pm 38,37$ & $<0,001$ \\
\hline $\mathrm{WT} \rightarrow \mathrm{R} 168 \mathrm{X} / \mathrm{x}$ & $552,00 \pm 28,95$ & $165,40 \pm 25,72$ & $291,40 \pm 33,46$ & $>0,05$ \\
\hline
\end{tabular}

Die Ergebnisse zeigen, dass eine Knochenmarktransplantation an heterozygoten $\mathrm{MeCP} 2^{\mathrm{R} 168 \mathrm{X}}$-Weibchen zu Beeinträchtigungen des Nestbaus (3.2.3.6), der motorischen Fähigkeiten (3.2.3.8), des Angstverhaltens (3.2.3.10) und einem vermehrten Auftreten langer Apnoen (3.2.3.7) führt.

\section{Diskussion}

Obwohl sowohl das MECP2 Gen wie auch seine Beteiligung an der Entstehung des Rett Syndroms seit den neunziger Jahren bekannt ist, konnte die genaue Funktion von MeCP2 bis heute nicht vollständig geklärt werden ${ }^{5}$. Bisher konnten 12 Mausmodelle für das Rett Syndrome etabliert werden, von denen die Mehrheit kein Mecp2-Allel mit einer der häufigsten humanen $M E C P 2-$ Mutationen trägt ${ }^{81}$. Ein Ziel dieser Arbeit war es daher die Mauslinie MeCP2 $2^{\mathrm{R} 168 \mathrm{X}}$ verhaltensbiologisch zu charakterisieren. R168X ist die beim Rett Syndrom am häufigsten gefundene Nonsense-Mutation und die am zweithäufigsten nachgewiesene Mutation im MECP2 Gen.

Ein weiteres Ziel dieser Arbeit war es MeCP2 $2^{\mathrm{R} 168 \mathrm{X}}$-Mäuse mittels experimenteller Therapien zu behandeln. Hierfür standen zwei verschiedene Ansätze zur Verfügung: 1. Die „Stop-Codon Readthrough-Therapie“ mit natürlichen und synthetischen Aminoglykosiden sowie der niedermolekularen Substanz PTC124. Da bei etwa $35 \%$ aller Rett Syndrom Patienten Nonsense-Mutationen ursächlich für die Erkrankung sind, würde diese Therapie für viele Patienten in Frage kommen. Es wurden neue Aminoglykosid-Derivate und niedermolekulare Substanzen in vitro auf ihre Wirksamkeit hin untersucht und anschließend zusammen mit klinisch etablierten Aminoglykosiden in vivo getestet. 
2. Die experimentelle Therapie des Rett Syndroms durch eine Knochenmarktransplantation nach einer Ganzkörperbestrahlung. Dieser therapeutische Ansatz basiert auf der Arbeit von Noël Derecki ${ }^{135}$, in der die Hypothese aufgestellt wurde, dass eine verminderte Phagozytoseaktivität MeCP2-defizienter Mikroglia ursächlich für das Rett Syndrom ist und dass eine Knochenmarktransplantation nach einer Ganzkörperbestrahlung zu einer drastischen Linderung der Symptome bei MeCP2 knockout Mäusen führt. Da eine Knochenmarktransplantation mit einer erheblichen Mortalität und Letalität einhergeht, war es notwendig diese Arbeiten zu bestätigen bevor eine solche Behandlung bei Patienten mit Rett Syndrom eingesetzt wird.

\subsection{Die Charakterisierung des MeCP2R168X-Mausmodells}

Für die verhaltensbiologische Charakterisierung wurden sowohl männliche als auch weibliche Tiere untersucht. Die hier verwendeten Experimente und Parameter wurden gewählt, da diese weit verbreitet und standardisiert sind.

Es konnte gezeigt werden, dass männliche $\mathrm{MeCP} 2^{\mathrm{R} 168 \mathrm{X}}$-Mäuse weder ein verkürztes Protein noch ein vollständiges MeCP2-Protein exprimieren ${ }^{95}$. In allen Mauslinien mit einem kompletten Verlust der MeCP2-Funktion weisen männliche Nachkommen eine stark verminderte Lebenserwartung auf und die Hälfte verstirbt bevor sie die 12. Lebenswoche erreicht ${ }^{71,73,74,76,82}$. Übereinstimmend mit diesen Ergebnissen verstirbt auch in der hier untersuchten Linie die Hälfte der untersuchten Tiere bevor sie die 12. Lebenswoche erreicht. Während sich die mittlere Überlebenswahrscheinlichkeit weitestgehend unabhängig vom genetischen Hintergrund manifestiert, ist dies für das Körpergewicht bei Mäusen nicht der Fall ${ }^{81}$. Mäuse mit dem genetischen Hintergrund C57BL6/J, inklusive der hier vorgestellten Linie, weisen ein reduziertes Körpergewicht auf ${ }^{71,74,80,153}$. Tiere im genetischen Hintergrund SVJ129 weisen dagegen häufig ein erhöhtes Körpergewicht auf ${ }^{73}, 75$. Wie bei anderen Mausmodellen des Rett Syndroms ist bei Tieren der Linie MeCP2 $2^{\mathrm{R} 168 \mathrm{X}}$ die postnatale Entwicklung anfänglich normal, gefolgt vom Auftreten Rett-ähnlicher Symptome wie Tremor, hindlimb clasping und einer fortschreitenden Inaktivität beginnend mit einem Alter von 27 Tagen. Der Tremor und das hindlimb clasping ähneln dabei den dystonen Bewegungsstörungen und stereotypen Bewegungen, die bei Patienten des Rett Syndroms beschrieben wurden $^{71,73-77,80,81,153}$. 
Da bei Patienten mit Rett Syndrom die motorische Koordination gestört ist, wurden $\mathrm{MeCP} 2^{\mathrm{R} 168 \mathrm{X}}$-Mäuse im Rotarod-Experiment getestet. Sowohl männliche als auch weibliche $\mathrm{MeCP} 2^{\mathrm{R} 168 \mathrm{X}}$-Mäuse zeigten eine verminderte motorische Leistung. Diese Art der Störung ist in fast allen Mauslinien zu finden, denen ein funktionelles MeCP2-Protein fehlt $^{67,74,77,80,81,154-156}$. Tiere beider Geschlechter zeigten während der vier Trainingsphasen einen starken Anstieg in Ihrer Leistung, was auf eine gewisse Fähigkeit im Bereich des motorischen Lernens schließen lässt. Dies wurde auch in anderen MeCP2Mausmodellen beobachtet ${ }^{67,80,154}$. Die allgemeine lokomotorische Aktivität der $\mathrm{MeCP} 2^{\mathrm{R} 168 \mathrm{X}}$-Tiere wurde mit Hilfe des Open Field-Experiments untersucht. Wie auch bei anderen Mauslinien des Rett Syndroms zeigte sich bei MeCP2 ${ }^{\mathrm{R} 168 \mathrm{X}}$-Männchen eine Verringerung der durchschnittlichen Bewegungsgeschwindigkeit und der zurückgelegten Distanz.

Mäuse beider Geschlechter errichten Nester um einen Schutz für die Aufzucht des Nachwuchses und vor Umwelteinflüssen wie Temperaturschwankungen und Jägern gewährleisten zu können ${ }^{140,144}$. Die Fähigkeit des Nestbaus hängt sowohl von motorischen und kognitiven Fähigkeiten als auch von hormonellen Veränderungen $a b^{140,} 157$. Die hier getesteten $\mathrm{MeCP} 2^{\mathrm{R} 168 \mathrm{X}}$-Männchen zeigten eine signifikante Beeinträchtigung bei der Errichtung komplexer Nester. Ein gestörtes Nestbauverhalten ist auch bei anderen MeCP2-Mausmodellen zu finden ${ }^{154,156,158-160 .}$

Während des Open Field-Experiments verbrachten $\mathrm{MeCP} 2^{\mathrm{R} 168 \mathrm{X}}-$ Männchen gegenüber gesunden Tieren eine deutlich längere Zeit im Zentrum der Apparatur, was auf ein reduziertes Angstverhalten hindeuten kann. Darauf deuten auch die Experimente im Elevated Plus Maze hin. Hier zeigten die Tiere eine verlängerte Aufenthaltsdauer in den offenen Armen und eine häufigere Anzahl an Besuchen der offen Arme. Ein Einfluss der beeinträchtigten motorischen Fähigkeiten auf das Ergebnis ist unwahrscheinlich, da die durchschnittlichen Geschwindigkeit, die zurückgelegte Distanz und die Gesamtzahl der Besuche vergleichbar mit gesunden Tieren war.

Ein häufiges Merkmal von Rett Syndrom Patienten sind Atemstörungen und Hyperventilation gefolgt von Apnoen, die während der aktiven Phase der Patienten auftreten ${ }^{161}$, 162. Wie auch bei anderen Mausmodellen des Rett Syndroms beschrieben, weisen die $\mathrm{MeCP} 2^{\mathrm{R} 168 \mathrm{X}}$-Männchen eine deutlich geringere Atemfrequenz und eine unregelmäßige Atmung auf, die von langen Apnoen begleitet wurden ${ }^{81,163-166 .}$ 
Obwohl das Rett Syndrom fast ausschließlich Frauen betrifft, wird der Großteil der Forschung an männlichen Mäusen durchgeführt. Ausschlaggebend hierfür ist, dass die Symptome früher auftreten und sich schwerer und konstanter entwickeln. Im Gegensatz $\mathrm{zu}$ männlichen $\mathrm{MeCP} 2^{\mathrm{R} 168 \mathrm{X}}$-Tieren zeigten weibliche $\mathrm{MeCP} 2^{\mathrm{R} 168 \mathrm{X}}$-Mäuse weder eine Verringerung des Körpergewichts, noch der Lebenserwartung. Sowohl der Tremor als auch das hindlimb clasping manifestierten sich jedoch häufiger in weiblichen Tieren und traten nur wenig später als bei männlichen Tieren auf. Bei den Untersuchungen der motorischen Fähigkeiten konnte nur eine leicht verringerte Leistung der motorischen Koordination ermittelt werden, während die lokomotorische Aktivität unverändert blieb. Hierbei muss beachtet werden, dass in dieser Arbeit nur ein kurzer Open Field-Versuch durchgeführt wurde. Da eine neue Umgebung die motorische Aktivität positiv beeinflussen kann, ist nicht auszuschließen, dass ein längerer Open Field-Versuch motorische Beeinträchtigungen weiblicher $\mathrm{MeCP} 2^{\mathrm{R} 168 \mathrm{X}}$-Tiere aufzeigen könnte. Die Errichtung komplexer Nester erfolgte bei $\mathrm{MeCP} 2^{\mathrm{R} 168 \mathrm{X}}$-Weibchen verzögert, erreichte jedoch nach 48 Stunden die gleiche mittlere Qualität wie die Nester gesunder Tiere. Weibliche Tiere anderer MeCP2-Mauslinien zeigen hingegen eine starke Beeinträchtigung bei der Errichtung komplexer Nester ${ }^{160,167}$. Weibliche $\mathrm{MeCP} 2^{\mathrm{R} 168 \mathrm{X}}$-Tiere zeigten in keinem der hier durchgeführten Experimente eine Veränderung in ihrem Angst-ähnlichen Verhalten. Auch die Atmung, die bei anderen MeCP2-Mauslinien als abnorm beschrieben wurde, zeigte bei weiblichen $\mathrm{MeCP} 2^{\mathrm{R} 168 \mathrm{X}}$-Tieren keine Veränderungen im Vergleich zu gesunden Tieren ${ }^{168-171}$.

In einer kürzlich erschienen Arbeit wurde eine andere Mauslinie verhaltensbiologisch charakterisiert, die ebenfalls die R168X-Mutation aufweist ${ }^{77}$. Bei der Generierung dieser Linie wurde eine BspHI-Restriktionstelle in den kodierenden Bereich nach Mecp2 c.502 eingefügt. Hierdurch entstanden zwei neue Missense-Mutationen (E169D und Q170S) und eine neue Nonsense-Mutation (K171X). Durch die Anwesenheit dieser neuen Nonsense-Mutation ist diese Mauslinie für die Erforschung der Stop-Codon Readthrough-Therapie ungeeignet, da dass Readthrough-Produkt kein funktionelles $\mathrm{MeCP} 2$ Protein darstellen würde. Desweiteren wurde die MeCP2 ${ }^{\mathrm{R} 168 \mathrm{XBspHI}}$-Linie in einem anderen genetischen Hintergrund gezüchtet (C57BL/6 x 129S6/SvEV Tac) und weist ein verkürztes MeCP2 Protein auf ${ }^{76}$. Die Expression gleicher Mecp2-Allele kann dabei in verschiedenen genetischen Hintergründen zu stark veränderten phänotypischen Ausprägungen führen ${ }^{81}$. Trotz dieser genetischen Unterschiede verhalten sich die männchlichen Tiere beider Linien in Bezug auf die Lebenserwartung, das Körperge- 
wicht, motorische Funktionen und das Angstverhalten ähnlich ${ }^{77,}{ }^{172}$. Weibliche Tiere zeigten lediglich bei der Untersuchung der motorischen Koordination und des Angstverhaltens vergleichbare Ergebnisse in beiden Studien. Die von Schaevitz untersuchten $\mathrm{MeCP} 2^{\mathrm{R} 168 \mathrm{XBspHI}}$-Weibchen wiesen außerdem ein vermindertes Körpergewicht und eine abnormale Atmung mit einer erhöhten Anzahl auftretender Apnoen, einer irreguläreren Atmung und einer verlangsamten Atemfrequenz auf ${ }^{77}$. Weibchen der hier untersuchten Linie $\mathrm{MeCP} 2^{\mathrm{R} 168 \mathrm{X}}$ wiesen in keinem dieser Punkte eine Veränderung verglichen mit gesunden Tieren auf.

\subsection{Experimentelle Therapien des Rett Syndroms}

Durch die Re-Expression von MeCP2 in Neuronen symptomatischer MeCP2 knockout Mäuse zeigten Guy und Kollegen 2007, dass die Symptome des Rett Syndroms reversibel sind ${ }^{82}$. Trotz dieser Ergebnisse gibt es bisher keine kausale Therapie für das Rett Syndrom. Es sind verschiedene Therapieansätze publiziert worden, die versuchen die verlorene MeCP2-Funktion an verschiedenen Stellen zu ersetzten. Obwohl einige dieser Therapieansätze im Tiermodell vielversprechende Ergebnisse lieferten, zeigte keines der verwendeten Medikamente in klinischen Studien eine nachweisbare Wirkung ${ }^{173}$. Auch eine virusvermitteltelte Gentherapie bei MeCP2 knockout Mäusen zeigte eine deutliche Linderung der Symptomatik der Tiere ${ }^{156,174-176}$. Versuche zur Gentherapie bei Patienten mit Rett Syndrom gibt es bisher nicht. Zwei weitere experimentelle Therapiemethoden, die ihren Fokus auf die Behebung des MeCP2-Mangels richten, sind die „Stop-Codon Readthrough-Therapie“ ${ }^{\text {(85 }}$ und eine Knochenmarktransplantation nach einer Ganzkörperbestrahlung ${ }^{135}$. Beide wurden in dieser Arbeit auf ihren therapeutischen Nutzen für das Rett Syndrom untersucht.

\subsubsection{Die Stop-Codon Readthrough-Therapie beim Rett Syn- drom}

In früheren Arbeiten konnte gezeigt werden, dass Gentamicin und Geneticin einen erfolgreichen Readthrough in HeLa-Zellen, die mit Konstrukten der häufigsten MeCP2Nonsense-Mutationen transfiziert wurden, initiieren konnten ${ }^{94}$. Auch in Fibroblasten männlicher $\mathrm{MeCP} 2^{\mathrm{R} 168 \mathrm{X}}$-Mäuse konnte der Readhtrough der MeCP2 ${ }^{\mathrm{R} 168 \mathrm{X}}$-Mutation mit Gentamicin, NB54 und NB84 gezeigt werden ${ }^{95}$. Bei den Substanzen NB54 und NB84 handelt es sich um synthetische Aminoglykoside die speziell für den Readthrough von 
Nonsense-Mutationen hergestellt wurden. Im Vergleich zu ihren Grundsubstanzen, Paromomycin und Gentamicin, weisen diese Substanzen eine deutlich höhere Readthrough-Effizienz bei geringerer Toxizität auf ${ }^{100-102}$. Bei der Erprobung dieser Substanzen in vivo sollte auch die neuste NB-Komponente, NB124, und die niedermolekulare Substanz PTC124 in die Versuche eingeschlossen werden. Hierfür wurden die in vitro Experimente an transfizierten HeLa-Zellen und männlichen $\mathrm{MeCP} 2^{\mathrm{R} 168 \mathrm{X}}$ Fibroblasten mit NB124 und PTC124 wiederholt ${ }^{103}$. Übereinstimmend mit früheren Ergebnissen, in denen NB84 eine höhere Readthrough-Effizienz gegenüber NB54 zeigte, konnte auch bei NB124 eine weitere Zunahme der Readthrough-Effizienz in beiden in vitro-Experimenten ermittelt werden. NB124 erreichte dabei eine mit Geneticin vergleichbare Readthrough-Effizienz. Aufgrund der hohen Nephro- und Ototoxizität von Geneticin war es jedoch nicht möglich dieses in in vivo Experimenten zu verwenden ${ }^{108}$. Eine Behandlung mit PTC124 führte weder in transfizierten HeLa-Zellen noch in männlichen $\mathrm{MeCP} 2^{\mathrm{R} 168 \mathrm{X}}$-Fibroblasten zu einem MeCP2-Protein voller Länge. Trotz der negativen Ergebnisse in vitro wurde PTC124 für in vivo-Experimente eingesetzt, da dieses in klinischen Studien bei der Behandlung durch Nonsense-Mutationen verursachter genetischer Erkrankungen vielversprechende Ergebnisse und eine gute Verträglichkeit gezeigt hat $^{151}$.

Das eigentliche Ziel dieser Therapie war eine Verlängerung der Überlebenspanne, eine Verbesserung der motorischen Fähigkeiten und der Atmung männlicher $\mathrm{MeCP}^{\mathrm{R} 168 \mathrm{X}}$. Mäuse. Zunächst war es jedoch wichtig, ein MeCP2-Protein voller Länge im Gehirn oder einem somatischen Gewebe als Nachweis eines erfolgreichen Readthroughs zu detektieren. Aufgrund der Vielzahl möglicher Dosierungen, Applikationswegen und Therapiezeiträumen wurden die ersten Experimente den Arbeiten von Elisabeth R. Barton-Davis und Ming Du, für die Readthrough-Therapien an Mausmodellen für die Muskeldystrophie des Typs Duchenne bzw. der zystischen Fibrose, nachempfunden ${ }^{88,89}$. Da nach der vierzehntägigen Behandlung mit einer täglichen, intraperitonealen Injektion mit $35 \mathrm{mg}$ Gentamicin/ kg bei keinem der behandelten Tiere ein MeCP2-Protein voller Länge detektiert werden konnte, wurde die Behandlungsdauer auf 28 Tage bei gleicher Dosierung verlängert, um eine Akkumulation des Readthrough-Produkts zu ermöglichen. Dabei wurden sowohl tägliche subkutane Injektionen als auch subkutan implantierte osmotische Pumpen verwendet. Jedoch konnte auch in diesen Versuchen kein MeCP2-Protein voller Länge nachgewiesen werden. Auch nach weiteren Steigerungen der Dosierung bis auf 400 mg Gentamicin/ kg/ Tag, nahe der LD $_{50}$-Dosis, konnte kein 
MeCP2-Protein detektiert werden. Als nächstes wurden die synthetischen Aminoglykoside NB54, NB84 und NB124, welche sich in den in vitro-Experimenten deutlich effektiver als Gentamicin erwiesen, in steigenden Konzentrationen und PTC124 in vivo getestet. Wieder konnte in keinem der Experimente ein MeCP2-Protein detektiert werden.

Für das Hurler Syndrom, der Muskeldystrophie des Typs Duchenne und die zystische Fibrose konnte gezeigt werden, dass der Aminoglykosid-vermittelte Readthrough jeweils zu einem Protein voller Länge führte. Daher stellte sich die Frage, warum diese Art der Behandlung bei dem MeCP2 ${ }^{\mathrm{R} 168 \mathrm{X}}$-Mausmodell für das Rett Syndrom nicht erfolgreich war? Der Mechanismus des „Stop-Codon vermittelten mRNS-Abbaus“ (Nonsense-mediated mRNA decay; kurz NMD) könnte dazu führen, dass nicht ausreichend mRNS für den Readthrough zu Verfügung steht. Das ist aus zwei Gründen unwahrscheinlich: Zum einen weisen männliche $\mathrm{MeCP} 2^{\mathrm{R} 168 \mathrm{X}}$-Mäuse, wie bereits in einer früheren Publikation beschrieben, eine normale Menge an Mecp2-Transkripten im Gehirn und anderen Organen auf ${ }^{95}$. Zum anderen führen Nonsense-Mutationen die das letzte Exon betreffen, wie die MeCP2 $2^{\mathrm{R} 168 \mathrm{X}}$-Mutation, in der Regel nicht zum Abbau der mRNS ${ }^{13,}$ 177, 178. Eine weitere Erklärung wäre, dass die Aminoglykoside nicht in die Zelle gelangen. Um diese Möglichkeit auszuschließen, wurden Immunfluoreszenzfärbungen Gentamicinbehandelter Tiere durchgeführt, die eine deutliche, dosisabhängige Aufnahme von Gentamicin in zeigten. Die plausibelste Erklärung warum die Aminoglykoside in den in vivo Experimenten keine Wirksamkeit zeigten, ist, dass die Konzentration der Aminoglykoside in den Zellkulturexperimenten um ein Vielfaches höher war als in den in vivo-Versuchen. Die resultierende Menge von Readthrough-Produkten könnte damit unterhalb der Nachweisgrenze gewesen sein. Auch die großen unstrukturierten Anteile des MeCP2-Proteins könnten, im Gegensatz zu den stark strukturierten Proteinen CFTR und Dystrophin ${ }^{179}$, zu einem reduzierten Readthrough durch eine erhöhte Instabilität nach dem Einbau einer alternativen Aminosäure beitragen. Experimente an Lymphozyten von Rett Patientinnen zeigen zudem, dass eine Langzeitbehandlung mit einer für Menschen tolerierbaren Dosis keinen Readthrough initiieren kann ${ }^{96} .2006$ stellten Ming Du und Kollegen fest, dass die empfohlene humane Erhaltungsdosis von 5 mg/ kg/ Tag bei Mäusen zu einer dem Menschen vergleichbaren maximal erlaubten Bergkonzentration im Serum führt ${ }^{180}$. In den hier beschriebenen Experimenten wurden $\mathrm{MeCP} 2^{\mathrm{R} 168 \mathrm{X}}$ Mäuse mit bis zu 400 mg/ kg/ Tag behandelt, was einer 80-fach höheren Dosis als der 
bei Menschen dauerhaft tolerierbaren Dosis entspricht. Trotz der hohen Dosierung konnten nur geringer Mengen Gentamicin die Blut-Hirn-Schranke durchdringen, wohingegen die Mengen in den durch Aminoglykoside meist gefährdeten Organen, den Nieren, um ein vielfaches höher waren. Die Ergebnisse dieser Arbeiten deuten daher darauf hin, dass eine systemische Verabreichung von Gentamicin, NB54, NB84 und NB124 auch bei weiterer Optimierung der Dosis, der Behandlungsdauer und der Behandlungsintervalle keine geeignete therapeutische Option für das Rett Syndrom darstellt. Auch die Behandlung der Tiere mit PTC124 zeigte sich als nicht erfolgreiche Therapie in vitro und in vivo bei Dosierungen, die in Studien zur Behandlung der zystischen Fibrose erfolgreich eingesetzt wurden ${ }^{124}$. Dabei muss erwähnt werden, dass keine anderen Dosierungen getestet wurden und das dieser Arbeit und in der von Du und Kollegen genutzte PTC124 unterschiedliche Löslichkeit aufwiesen, da sie von unterschiedlichen Herrstellern stammten. Zukünftige Arbeiten werden sich daher auf die Erprobung neuer Readthrough-Komponenten und die intrathekale Injektion als Applikationsweg konzentrieren, um nephro- und ototoxizische Nebenwirkungen auf ein Minimum zu reduzieren.

\subsubsection{Knochenmarktransplantation bei MeCP2 ${ }^{\mathrm{R} 168 \mathrm{X}}$-Mäusen}

In einer 2012 erschienen Publikation wurde gezeigt, dass eine Knochenmarktransplantation nach einer Ganzkörperbestrahlung bei männlichen MeCP2 knockout Mäusen $\left(\mathrm{MeCP} 2^{\text {tm1.1Jae/y }}\right) \mathrm{zu}$ einer vollständigen Wiederherstellung einer zuvor gestörten mikrogliären Phagozytoseaktivität führt und die Tiere so vor dem neurologischen Verfall und vor allem dem frühen Versterben bewahrt ${ }^{135}$. Diese Ergebnisse führten zu einer klinischen Studie, die die Wirkung eine Knochenmarktransplantation bei männlicher Rett Syndrom Patienten untersuchen soll ${ }^{181}$. Da eine Knochenmarktransplantation mit erheblichen Risiken einhergeht ist die Bestätigung dieser Ergebnisse in verschiedenen MeCP2-Mausmodellen unerlässlich. Zu diesem Zweck wurde in dieser Arbeit die Knochenmarktransplantation an männlichen und weiblichen $\mathrm{MeCP} 2^{\mathrm{R} 168 \mathrm{X}}$-Mäusen durchgeführt.

Die Analyse des peripheren Bluts transplantierter Tiere ergab eine solide Rekonstitution neutrophiler Granulozyten und T-Zellen im Blut männlicher und weiblicher Tiere ${ }^{182}$. Obwohl bei männlichen $\mathrm{WT} \rightarrow \mathrm{MeCP} 2^{\mathrm{R} 168 \mathrm{X}}$-Tieren sowohl einen Tremor als auch das hindlimb clasping später auftraten als bei unbehandelten Tieren, konnte bei $\mathrm{WT} \rightarrow \mathrm{MeCP} 2^{\mathrm{R} 168 \mathrm{X}}$-Mäusen keine Verlängerung der Überlebensdauer festgestellt wer- 
den. Desweiteren zeigten transplantierte männliche Tiere eine drastische Verringerung des Körpergewichts nach der Knochenmarktransplantation und eine zunehmende Hypoaktivität, so dass die Untersuchung des Verhaltens männlicher transplantierter Tiere nicht durchgeführt werden konnte. Die Ergebnisse der Experimente stehen daher im Widerspruch zu den Ergebnissen der von Derecki publizierten Arbeit, in der transplantierte männliche Tiere eine signifikante Verlängerung der Überlebensdauer und ein stark erhöhtes Körpergewicht aufwiesen ${ }^{135}$.

Um die Beteiligung der Mikroglia, mit der von Derecki postulierten Hypothese der verringerten Phagozytoseaktivität bei der Pathogenese des Rett Syndroms genauer zu überprüfen, wurde die Phagozytose in vitro und in vivo untersucht. Um eine generelle Fehlregulation auszuschließen, wurden Mikroglia neonataler Mäuse isoliert und auf die Expression der Oberflächenmoleküle MHC-I und MHC-II hin untersucht. Dabei konnte beobachtet werden, dass $\mathrm{MeCP} 2^{\mathrm{R} 168 \mathrm{X}}$-Mikroglia eine deutlich erhöhte Expression des Oberflächenmoleküls MHC-I nach Stimulation mit Lipopolysacchariden aufwiesen. Die LPS-vermittelte Stimulierung der „Toll-like Rezeptoren“ kann dabei unter anderem eine Erhöhung der Phagozytoseaktivität bewirken ${ }^{183}$. Interessanterweise ergab die in vitro gemessene Phagozytose von fluoreszenzmarkieten Myelin jedoch keine Unterscherschiede zwischen Mikroglia gesunder und MeCP2-defizienter Mäuse. Auch die elektronenmikroskopische Untersuchung des Hippocampus und des Corpus callosum männlicher $\mathrm{MeCP} 2^{\mathrm{R} 168 \mathrm{X}}$-Mäuse zeigte keine erhöhten Ansammlungen zellulärer Überreste, wie es die Arbeit von Derecki und Kollegen vermuten lassen würde ${ }^{135}$. Die Ergebnisse dieser Arbeit deuten daher nicht darauf hin, dass der Verlust von MeCP2 zu einer Verringerung der mikrogliären Phagozytoseaktivität führt.

Da das Rett Syndrom fast ausschließlich Frauen betrifft, wurde die Knochenmarktransplantation zusätzlich an weiblichen $\mathrm{MeCP} 2^{\mathrm{R} 168 \mathrm{X}}$-Mäusen getestet. Die Knochenmarktransplantation und die Analyse des peripheren Blutes wurden analog zu den männlichen Tieren durchgeführt und zeigten ebenfalls eine solide Rekonstitution des Knochenmarks nach der Transplantation. Die Knochenmarktransplantation führte bei weiblichen Tieren weder zu einem verzögertem Auftreten der Tremore und dem hindlimb clasping, noch zu einer Veränderung des Körpergewichts. Da weibliche MeCP2 $2^{\mathrm{R} 168 \mathrm{X}}$ Mäuse keine verminderte Lebenserwartung aufwiesen und sich die Aktivität der Tiere durch die Knochenmarktransplantation nicht verringerte, konnte das Verhalten dieser Tiere untersucht werden. Die Untersuchungen der Mäuse im Open Field und auf dem 
Rotarod ergaben eine Verschlechterung der motorischen Fähigkeiten weiblicher $\mathrm{MeCP} 2^{\mathrm{R} 168 \mathrm{X}}$-Mäuse nach der Knochenmarktransplantation. Durch die Untersuchungen des Angstverhaltens im Open Field und in der Elevated Plus Maze konnten keine einstimmigen Ergebnisse ermittelt werden. So zeigte sich eine Verstärkung des Angstverhaltens im Open Field, wohingegen das Elevated Plus Maze-Experiment eine Verringerung des Angstverhaltens andeutet ${ }^{138}$. Aufgrund der verringerten Aktivität der transplantierten Tiere während des Elevated Plus Maze-Experiments kann eine motorische Beteiligung bei diesem Versuch nicht ausgeschlossen werden. Interessanterweise führte die Knochenmarktransplantation aus unbekannten Gründen zu einer Verringerung der Anzahl auftretender Apnoen bei Tieren beider Gruppen.

Da einzelne Tiermodelle individuelle Stärken und Schwächen aufweisen, profitieren vorklinische Studien von einer hohen Reproduzierbarkeit in verschiedenen Tiermodel$\operatorname{len}^{184}$. Aus diesem Grund wurde die Knochenmarktransplantation in Kooperation in weiteren Laboren an verschiedenen MeCP2-Mauslinien durchgeführt. Während sich die Gruppe von Andrew A. Piper (University of Iowa Carver College of Medicine, Iowa City, IA USA) auf die exakte Reproduktion der Arbeit von Derecki konzentrierte, legte die Gruppe von Antonio Bedalov (Clinical Research Division, Fred Hutchinson Cancer Research Center, Seattle, WA USA) den Fokus auf die Therapie mit einem neuen Mausmodell des Rett Syndroms. Jedoch konnte in keinem der durchgeführten Experimente die Beteiligung der Mikroglia an der Pathogenese des Rett Syndroms, noch eine erhöhte Überlebensdauer der transplantierten Tiere beobachtet werden ${ }^{185}$. Die Ergebnisse der verschiedenen Studien ergaben daher keine Hinweise dafür, dass eine Knochenmarktransplantation eine sinnvolle Therapie des Rett Syndroms darstellt. Für die Diskrepanz dieser Ergbenisse zu denen von Derecki et al. gibt es bisher keine Erklärung. 


\section{Zusammenfassung}

Für das Rett Syndrom, eine der häufigsten genetischen Ursachen für mentale Retardierung bei Frauen, gibt es bisher keine kausale Therapie, obwohl gentherapeutische Studien mit konditionellen knockout Mäusen gezeigt haben, dass es sich um eine therapierbare Erkrankung handelt. Um neue Therapien entwickeln zu können, werden Mausmodelle benötigt, die auf den beim Menschen am häufigsten gefundenen Mutation beruhen. In der vorliegenden Arbeit wurde ein Mausmodell mit der häufigsten humanen Nonsense-Mutation R168X im Mecp2 Gen charakterisiert. Mit Hilfe dieses Mausmodells wurden dann die Therapieansätze der „Stop-Codon Readthrough-Therapie“ und einer Knochenmarktransplantation auf ihre Wirksamkeit in vitro und in vivo untersucht.

Die Charakterisierung der Mauslinie zeigte, dass männliche $\mathrm{MeCP} 2^{\mathrm{R} 168 \mathrm{X}}$-Mäuse im Gegensatz zu anderen MeCP2-Mausmodellen kein verkürztes MeCP2 Protein exprimieren. Desweiteren weisen männliche $\mathrm{MeCP} 2^{\mathrm{R} 168 \mathrm{X}}$-Mäuse einen Phänotyp, inklusive der drastisch verkürzten Lebenspanne, auf, wie er bei bereits etablierten Mausmodellen für das Rett Syndrom beschrieben wurde. Dagegen zeigten weibliche, heterozygote $\mathrm{MeCP} 2^{\mathrm{R} 168 \mathrm{X}}$-Mäuse nur einen sehr mild ausgeprägten Phänotyp verglichen mit bereits etablierten MeCP2-Mauslinien.

Für die „Stop-Codon Readthrough-Therapie“ wurde die Effizienz der Aminoglykoside Geniticin, Gentamicin und Neomycin, der Komponenten NB54, NB84 und NB124, sowie der niedermolekularen Substanz PTC124 auf ihre Wirksamkeit bei der Induktion eines Readthroughs mit transfizierten HeLa-Zellen und MeCP2 $2^{\text {R168X/y }}$ Mausohrfibroblasten in vitro untersucht. Dabei zeigte sich eine deutliche Steigerung der Readthrough-Effizienz der NB-Komponenten, gemessen an der detektierbaren Menge an MeCP2, mit zunehmender Generation (NB54 $\rightarrow$ NB84 $\rightarrow$ NB124) und gegenüber dem klinisch angewandten Gentamicin. Während die Behandlung mit Neomycin zu einem minimalen Readthrough-Produkt führte, zeigte die Behandlung mit PTC124 keinen messbaren Readthrough.

Anschließend wurden männliche $\mathrm{MeCP} 2^{\mathrm{R} 168 \mathrm{X}}$-Mäuse mit den in vitro getesteten Substanzen, mit Ausnahme von Geniticin, behandelt. Die Expression eines MeCP2-Proteins voller Länge konnte durch keine der applizierten Substanzen induziert werden. Auch bei Behandlungen über einen längeren Zeitraum mit hohen Dosierungen, im Fall von Gentamicin nahe der $\mathrm{LD}_{50}$-Dosis und nachweisbarer intrazellulärer Aufnahme, konnte 
in den behandelten Tieren weder ein verkürztes noch ein MeCP2 Protein nativer Länge detektiert werden. Die Ergebnisse dieser Arbeit zeigen, dass für die „Stop-Codon Readthrough-Therapie“ für das Rett Syndrom neue Komponenten entwickelt werden oder andere Applikationswege gewählt werden müssen, da mit den derzeit verfügbaren Substanzen kein therapeutischer Erfolg erzielt werden kann.

Im letzten Teil dieser Arbeit wurde die Theorie einer gestörten Phagozytose MeCP2defizienter Mikroglia, sowie die Therapie von MeCP2-defizienten Mäusen durch eine Knochenmarktransplantation überprüft. Dabei konnte weder in vitro noch in vivo eine Veränderung der Phagozytoseaktivität der MeCP2-defizienten Mikroglia nachgewiesen werden, wie sie von Derecki und Kollegen publiziert wurde $^{185}$. Die Transplantation von gesundem Knochenmark führte bei männlichen $\mathrm{MeCP} 2^{\mathrm{R} 168 \mathrm{X}}$ Tieren zu keiner Verlängerung der Überlebensspanne oder einer allgemeinen Abmilderung der Symptomatik, wie sie ebenfalls von Derecki und Kollegen publiziert wurde ${ }^{185}$. Bei weiblichen Tieren führte die Transplantation gesunden Knochenmarks zu einer Verschlechterung der motorischen Fähigkeiten. Diese Ergebnisse sind im Einklang mit denen Ergebnissen der Arbeitsgruppen von Andrew Pieper, Antonio Bedalov und Jeffrey Neul, die in anderen Mausmodellen die Wirkung der Knochenmarktransplantation untersuchten ${ }^{185}$. Die Ergebnisse aller beteiligten Arbeitsgruppen legen daher nahe, dass eine Knochenmarktransplantation nach einer Ganzkörperbestrahlung keine geeignete Therapie für das Rett Syndroms darstellt. 


\section{Literaturverzeichnis}

1. Rett A. [On a unusual brain atrophy syndrome in hyperammonemia in childhood]. Wiener medizinische Wochenschrift (1946) 1966;116:723-6.

2. Percy AK. Rett syndrome. Current status and new vistas. Neurologic clinics 2002;20:1125-41.

3. Hagberg B. Rett syndrome: clinical peculiarities and biological mysteries. Acta Paediatr 1995;84:971-6.

4. Hook EB, Cross PK, Schreinemachers DM. Chromosomal abnormality rates at amniocentesis and in live-born infants. JAMA 1983;249:2034-8.

5. Amir RE, Van den Veyver IB, Wan M, Tran CQ, Francke U, Zoghbi HY. Rett syndrome is caused by mutations in X-linked MECP2, encoding methyl-CpG-binding protein 2. Nature genetics 1999;23:185-8.

6. Hagberg B, Aicardi J, Dias K, Ramos O. A progressive syndrome of autism, dementia, ataxia, and loss of purposeful hand use in girls: Rett's syndrome: report of 35 cases. Annals of neurology 1983;14:471-9.

7. Nomura Y. Early behavior characteristics and sleep disturbance in Rett syndrome. Brain Dev 2005;27 Suppl 1:S35-S42.

8. Glaze DG, Percy AK, Skinner S, et al. Epilepsy and the natural history of Rett syndrome. Neurology 2010;74:909-12.

9. Jian L, Nagarajan L, de Klerk N, et al. Predictors of seizure onset in Rett syndrome. The Journal of pediatrics 2006;149:542-7.

10. Mount RH, Hastings RP, Reilly S, Cass H, Charman T. Behavioural and emotional features in Rett syndrome. Disability and rehabilitation 2001;23:129-38.

11. Neul JL, Zoghbi HY. Rett syndrome: a prototypical neurodevelopmental disorder. Neuroscientist 2004;10:118-28.

12. Trappe R, Laccone F, Cobilanschi J, et al. MECP2 mutations in sporadic cases of Rett syndrome are almost exclusively of paternal origin. American journal of human genetics 2001;68:1093-101.

13. Christodoulou J, Grimm A, Maher T, Bennetts B. RettBASE: The IRSA MECP2 variation database-a new mutation database in evolution. Hum Mutat 2003;21:466-72.

14. Ravn K, Nielsen JB, Skjeldal OH, Kerr A, Hulten M, Schwartz M. Large genomic rearrangements in MECP2. Hum Mutat 2005;25:324.

15. Archer HL, Whatley SD, Evans JC, et al. Gross rearrangements of the MECP2 gene are found in both classical and atypical Rett syndrome patients. J Med Genet 2006;43:451-6.

16. Pan H, Li MR, Nelson P, Bao XH, Wu XR, Yu S. Large deletions of the MECP2 gene in Chinese patients with classical Rett syndrome. Clinical genetics 2006;70:418-9.

17. Smeets E, Terhal P, Casaer P, et al. Rett syndrome in females with CTS hot spot deletions: a disorder profile. American journal of medical genetics 2005;132:117-20.

18. Krepischi AC, Kok F, Otto PG. X chromosome-inactivation patterns in patients with Rett syndrome. Human genetics 1998;102:319-21. 
19. Lyon MF. Gene action in the X-chromosome of the mouse (Mus musculus L.). Nature 1961;190:372-3.

20. Chahrour M, Zoghbi HY. The story of Rett syndrome: from clinic to neurobiology. Neuron 2007;56:422-37.

21. Ogawa A, Mitsudome A, Yasumoto S, Matsumoto T. Japanese monozygotic twins with Rett syndrome. Brain Dev 1997;19:568-70.

22. Gillberg C. The borderland of autism and Rett syndrome: five case histories to highlight diagnostic difficulties. J Autism Dev Disord 1989;19:545-59.

23. Coleman M. Is classical Rett syndrome ever present in males? Brain Dev 1990;12:31-2.

24. Eeg-Olofsson O, al-Zuhair AG, Teebi AS, Zaki M, Daoud AS. A boy with the Rett syndrome? Brain Dev 1990;12:529-32.

25. Philippart M. The Rett syndrome in males. Brain Dev 1990;12:33-6.

26. Christen HJ, Hanefeld F. Male Rett variant. Neuropediatrics 1995;26:81-2.

27. Jan MM, Dooley JM, Gordon KE. Male Rett syndrome variant: application of diagnostic criteria. Pediatric neurology 1999;20:238-40.

28. Pieras JI, Munoz-Cabello B, Borrego S, et al. Somatic mosaicism for Y120X mutation in the MECP2 gene causes atypical Rett syndrome in a male. Brain Dev 2010;33:608-11.

29. Maiwald R, Bonte A, Jung H, et al. De novo MECP2 mutation in a 46,XX male patient with Rett syndrome. Neurogenetics 2002;4:107-8.

30. Budden SS, Dorsey HC, Steiner RD. Clinical profile of a male with Rett syndrome. Brain Dev 2005;27 Suppl 1:S69-S71.

31. Masuyama T, Matsuo M, Jing JJ, et al. Classic Rett syndrome in a boy with R133C mutation of MECP2. Brain Dev 2005;27:439-42.

32. Dayer AG, Bottani A, Bouchardy I, et al. MECP2 mutant allele in a boy with Rett syndrome and his unaffected heterozygous mother. Brain Dev 2007;29:47-50.

33. Lewis JD, Meehan RR, Henzel WJ, et al. Purification, sequence, and cellular localization of a novel chromosomal protein that binds to methylated DNA. Cell 1992;69:905-14.

34. Quaderi NA, Meehan RR, Tate PH, et al. Genetic and physical mapping of a gene encoding a methyl $\mathrm{CpG}$ binding protein, Mecp2, to the mouse $\mathrm{X}$ chromosome. Genomics 1994;22:648-51.

35. D'Esposito M, Quaderi NA, Ciccodicola A, et al. Isolation, physical mapping, and northern analysis of the X-linked human gene encoding methyl CpG-binding protein, MECP2. Mamm Genome 1996;7:533-5.

36. Kriaucionis S, Bird A. The major form of $\mathrm{MeCP} 2$ has a novel N-terminus generated by alternative splicing. Nucleic acids research 2004;32:1818-23.

37. Mnatzakanian GN, Lohi H, Munteanu I, et al. A previously unidentified MECP2 open reading frame defines a new protein isoform relevant to Rett syndrome. Nature genetics 2004;36:339-41. 
38. Adams VH, McBryant SJ, Wade PA, Woodcock CL, Hansen JC. Intrinsic disorder and autonomous domain function in the multifunctional nuclear protein, MeCP2. $\mathrm{J}$ Biol Chem 2007;282:15057-64.

39. Uversky VN, Oldfield CJ, Dunker AK. Showing your ID: intrinsic disorder as an ID for recognition, regulation and cell signaling. J Mol Recognit 2005;18:343-84.

40. Pullen RA, Jenkins JA, Tickle IJ, Wood SP, Blundell TL. The relation of polypeptide hormone structure and flexibility to receptor binding: the relevance of X-ray studies on insulins, glucagon and human placental lactogen. Mol Cell Biochem 1975;8:5-20.

41. Liu XI, Korde N, Jakob U, Leichert LI. CoSMoS: Conserved Sequence Motif Search in the proteome. BMC Bioinformatics 2006;7:37.

42. Shahbazian MD, Antalffy B, Armstrong DL, Zoghbi HY. Insight into Rett syndrome: $\mathrm{MeCP} 2$ levels display tissue- and cell-specific differences and correlate with neuronal maturation. Hum Mol Genet 2002;11:115-24.

43. Pelka GJ, Watson CM, Christodoulou J, Tam PP. Distinct expression profiles of Mecp2 transcripts with different lengths of 3'UTR in the brain and visceral organs during mouse development. Genomics 2005;85:441-52.

44. Jung BP, Jugloff DG, Zhang G, Logan R, Brown S, Eubanks JH. The expression of methyl $\mathrm{CpG}$ binding factor $\mathrm{MeCP} 2$ correlates with cellular differentiation in the developing rat brain and in cultured cells. Journal of neurobiology 2003;55:86-96.

45. Skene PJ, Illingworth RS, Webb S, et al. Neuronal MeCP2 is expressed at near histone-octamer levels and globally alters the chromatin state. Mol Cell 2010;37:45768.

46. Nan X, Campoy FJ, Bird A. MeCP2 is a transcriptional repressor with abundant binding sites in genomic chromatin. Cell 1997;88:471-81.

47. Meehan RR, Lewis JD, Bird AP. Characterization of MeCP2, a vertebrate DNA binding protein with affinity for methylated DNA. Nucleic acids research 1992;20:5085-92.

48. Mellen M, Ayata P, Dewell S, Kriaucionis S, Heintz N. MeCP2 binds to 5hmC enriched within active genes and accessible chromatin in the nervous system. Cell 2012;151:1417-30.

49. Jones PL, Veenstra GJ, Wade PA, et al. Methylated DNA and MeCP2 recruit histone deacetylase to repress transcription. Nature genetics 1998;19:187-91.

50. $\mathrm{Ng} \mathrm{HH}$, Zhang Y, Hendrich B, et al. MBD2 is a transcriptional repressor belonging to the MeCP1 histone deacetylase complex. Nature genetics 1999;23:58-61.

51. Kokura K, Kaul SC, Wadhwa R, et al. The Ski protein family is required for MeCP2-mediated transcriptional repression. The Journal of biological chemistry 2001;276:34115-21.

52. Chahrour M, Jung SY, Shaw C, et al. MeCP2, a key contributor to neurological disease, activates and represses transcription. Science (New York, NY 2008;320:12249.

53. Forlani G, Giarda E, Ala U, et al. The MeCP2/YY1 interaction regulates ANT1 expression at 4q35: novel hints for Rett syndrome pathogenesis. Hum Mol Genet 2010;19:3114-23. 
54. Kaludov NK, Wolffe AP. MeCP2 driven transcriptional repression in vitro: selectivity for methylated DNA, action at a distance and contacts with the basal transcription machinery. Nucleic acids research 2000;28:1921-8.

55. Kimura H, Shiota K. Methyl-CpG-binding protein, MeCP2, is a target molecule for maintenance DNA methyltransferase, Dnmt1. The Journal of biological chemistry 2003;278:4806-12.

56. Harikrishnan KN, Chow MZ, Baker EK, et al. Brahma links the SWI/SNF chromatin-remodeling complex with MeCP2-dependent transcriptional silencing. Nature genetics 2005;37:254-64.

57. Nan X, Hou J, Maclean A, et al. Interaction between chromatin proteins MECP2 and ATRX is disrupted by mutations that cause inherited mental retardation. Proceedings of the National Academy of Sciences of the United States of America 2007;104:2709-14.

58. Tao J, Hu K, Chang Q, et al. Phosphorylation of MeCP2 at Serine 80 regulates its chromatin association and neurological function. Proceedings of the National Academy of Sciences of the United States of America 2009;106:4882-7.

59. Gonzales ML, Adams S, Dunaway KW, LaSalle JM. Phosphorylation of distinct sites in $\mathrm{MeCP} 2$ modifies cofactor associations and the dynamics of transcriptional regulation. Mol Cell Biol 2012;32:2894-903.

60. Zhou Z, Hong EJ, Cohen S, et al. Brain-specific phosphorylation of MeCP2 regulates activity-dependent Bdnf transcription, dendritic growth, and spine maturation. Neuron 2006;52:255-69.

61. Zocchi L, Sassone-Corsi P. SIRT1-mediated deacetylation of MeCP2 contributes to BDNF expression. Epigenetics 2007;7:695-700.

62. Li W, Pozzo-Miller L. BDNF deregulation in Rett syndrome. Neuropharmacology 2013;76 Pt C:737-46.

63. Chang Q, Khare G, Dani V, Nelson S, Jaenisch R. The disease progression of Mecp2 mutant mice is affected by the level of BDNF expression. Neuron 2006;49:3418.

64. Wang H, Chan SA, Ogier M, et al. Dysregulation of brain-derived neurotrophic factor expression and neurosecretory function in Mecp2 null mice. J Neurosci 2006;26:10911-5.

65. Ogier M, Wang H, Hong E, Wang Q, Greenberg ME, Katz DM. Brain-derived neurotrophic factor expression and respiratory function improve after ampakine treatment in a mouse model of Rett syndrome. J Neurosci 2007;27:10912-7.

66. Kline DD, Ogier M, Kunze DL, Katz DM. Exogenous brain-derived neurotrophic factor rescues synaptic dysfunction in Mecp2-null mice. J Neurosci 2010;30:5303-10.

67. Lonetti G, Angelucci A, Morando L, Boggio EM, Giustetto M, Pizzorusso T. Early environmental enrichment moderates the behavioral and synaptic phenotype of MeCP2 null mice. Biol Psychiatry 2010;67:657-65.

68. Li W, Calfa G, Larimore J, Pozzo-Miller L. Activity-dependent BDNF release and TRPC signaling is impaired in hippocampal neurons of Mecp2 mutant mice. Proceedings of the National Academy of Sciences of the United States of America 2012;109:17087-92. 
69. Huang EJ, Reichardt LF. Neurotrophins: roles in neuronal development and function. Annu Rev Neurosci 2001;24:677-736.

70. Guyenet SJ, Furrer SA, Damian VM, Baughan TD, La Spada AR, Garden GA. A simple composite phenotype scoring system for evaluating mouse models of cerebellar ataxia. J Vis Exp 2010.

71. Guy J, Hendrich B, Holmes M, Martin JE, Bird A. A mouse Mecp2-null mutation causes neurological symptoms that mimic Rett syndrome. Nature genetics 2001;27:322-6.

72. Yasui DH, Gonzales ML, Aflatooni JO, et al. Mice with an isoform-ablating Mecp2 exon 1 mutation recapitulate the neurologic deficits of Rett syndrome. Hum Mol Genet 2013;23:2447-58.

73. Chen RZ, Akbarian S, Tudor M, Jaenisch R. Deficiency of methyl-CpG binding protein-2 in CNS neurons results in a Rett-like phenotype in mice. Nature genetics 2001;27:327-31.

74. Pelka GJ, Watson CM, Radziewic T, et al. Mecp2 deficiency is associated with learning and cognitive deficits and altered gene activity in the hippocampal region of mice. Brain 2006;129:887-98.

75. Shahbazian M, Young J, Yuva-Paylor L, et al. Mice with truncated MeCP2 recapitulate many Rett syndrome features and display hyperacetylation of histone H3. Neuron 2002;35:243-54.

76. Lawson-Yuen A, Liu D, Han L, et al. Ube3a mRNA and protein expression are not decreased in Mecp2R168X mutant mice. Brain Res 2007;1180:1-6.

77. Schaevitz LR, Gomez NB, Zhen DP, Berger-Sweeney JE. MeCP2 R168X male and female mutant mice exhibit Rett-like behavioral deficits. Genes Brain Behav 2013;12:732-40.

78. Cohen S, Gabel HW, Hemberg M, et al. Genome-wide activity-dependent $\mathrm{MeCP} 2$ phosphorylation regulates nervous system development and function. Neuron 2011;72:72-85.

79. Jentarra GM, Olfers SL, Rice SG, et al. Abnormalities of cell packing density and dendritic complexity in the MeCP2 A140V mouse model of Rett syndrome/Xlinked mental retardation. BMC Neurosci 2010;11:19.

80. Goffin D, Allen M, Zhang L, et al. Rett syndrome mutation MeCP2 T158A disrupts DNA binding, protein stability and ERP responses. Nat Neurosci 2011;15:274-83.

81. Katz DM, Berger-Sweeney JE, Eubanks JH, et al. Preclinical research in Rett syndrome: setting the foundation for translational success. Dis Model Mech 2012;5:733-45.

82. Guy J, Gan J, Selfridge J, Cobb S, Bird A. Reversal of neurological defects in a mouse model of Rett syndrome. Science 2007;315:1143-7.

83. Moazed D, Noller HF. Interaction of antibiotics with functional sites in $16 \mathrm{~S}$ ribosomal RNA. Nature 1987;327:389-94.

84. Vicens Q, Westhof E. Crystal structure of geneticin bound to a bacterial $16 \mathrm{~S}$ ribosomal RNA A site oligonucleotide. J Mol Biol 2003;326:1175-88.

85. Keeling KM, Xue X, Gunn G, Bedwell DM. Therapeutics based on stop codon readthrough. Annu Rev Genomics Hum Genet 2014;15:371-94. 
86. Burke JF, Mogg AE. Suppression of a nonsense mutation in mammalian cells in vivo by the aminoglycoside antibiotics G-418 and paromomycin. Nucleic Acids Res 1985;13:6265-72.

87. Howard M, Frizzell RA, Bedwell DM. Aminoglycoside antibiotics restore CFTR function by overcoming premature stop mutations. Nat Med 1996;2:467-9.

88. Barton-Davis ER, Cordier L, Shoturma DI, Leland SE, Sweeney HL. Aminoglycoside antibiotics restore dystrophin function to skeletal muscles of mdx mice. J Clin Invest 1999;104:375-81.

89. Du M, Jones JR, Lanier J, et al. Aminoglycoside suppression of a premature stop mutation in a Cftr-/- mouse carrying a human CFTR-G542X transgene. J Mol Med (Berl) 2002;80:595-604.

90. Loufrani L, Dubroca C, You D, et al. Absence of dystrophin in mice reduces NO-dependent vascular function and vascular density: total recovery after a treatment with the aminoglycoside gentamicin. Arterioscler Thromb Vasc Biol 2004;24:671-6.

91. Yang C, Feng J, Song W, et al. A mouse model for nonsense mutation bypass therapy shows a dramatic multiday response to geneticin. Proc Natl Acad Sci U S A 2007; 104:15394-9.

92. Guerin K, Gregory-Evans CY, Hodges MD, et al. Systemic aminoglycoside treatment in rodent models of retinitis pigmentosa. Exp Eye Res 2008;87:197-207.

93. Keeling KM, Brooks DA, Hopwood JJ, Li P, Thompson JN, Bedwell DM. Gentamicin-mediated suppression of Hurler syndrome stop mutations restores a low level of alpha-L-iduronidase activity and reduces lysosomal glycosaminoglycan accumulation. Hum Mol Genet 2001;10:291-9.

94. Brendel C, Klahold E, Gartner J, Huppke P. Suppression of nonsense mutations in Rett syndrome by aminoglycoside antibiotics. Pediatric research 2009;65:520-3.

95. Brendel C, Belakhov V, Werner H, et al. Readthrough of nonsense mutations in Rett syndrome: evaluation of novel aminoglycosides and generation of a new mouse model. J Mol Med (Berl) 2010;89:389-98.

96. Popescu AC, Sidorova E, Zhang G, Eubanks JH. Aminoglycoside-mediated partial suppression of MECP2 nonsense mutations responsible for Rett syndrome in vitro. $\mathrm{J}$ Neurosci Res 2010;88:2316-24.

97. Martinez-Salgado C, Lopez-Hernandez FJ, Lopez-Novoa JM. Glomerular nephrotoxicity of aminoglycosides. Toxicol Appl Pharmacol 2007;223:86-98.

98. Balakumar P, Rohilla A, Thangathirupathi A. Gentamicin-induced nephrotoxicity: Do we have a promising therapeutic approach to blunt it? Pharmacol Res 2010;62:179-86.

99. Rybak LP, Ramkumar V. Ototoxicity. Kidney Int 2007;72:931-5.

100. Nudelman I, Rebibo-Sabbah A, Shallom-Shezifi D, et al. Redesign of aminoglycosides for treatment of human genetic diseases caused by premature stop mutations. Bioorg Med Chem Lett 2006;16:6310-5.

101. Nudelman I, Rebibo-Sabbah A, Cherniavsky M, et al. Development of novel aminoglycoside (NB54) with reduced toxicity and enhanced suppression of diseasecausing premature stop mutations. Journal of medicinal chemistry 2009;52:2836-45. 
102. Nudelman I, Glikin D, Smolkin B, Hainrichson M, Belakhov V, Baasov T. Repairing faulty genes by aminoglycosides: development of new derivatives of geneticin (G418) with enhanced suppression of diseases-causing nonsense mutations. Bioorganic \& medicinal chemistry 2010;18:3735-46.

103. Baasov T, Atia-Glikin D, Kandasamy J, Belakhov V. Aminoglycosides and uses thereof in treating genetic disorders. In: Google Patents; 2013.

104. Wang D, Belakhov V, Kandasamy J, et al. The designer aminoglycoside NB84 significantly reduces glycosaminoglycan accumulation associated with MPS I-H in the Idua-W392X mouse. Mol Genet Metab 2012;105:116-25.

105. Goldmann T, Rebibo-Sabbah A, Overlack N, et al. Beneficial read-through of a USH1C nonsense mutation by designed aminoglycoside NB30 in the retina. Invest Ophthalmol Vis Sci 2010;51:6671-80.

106. Goldmann T, Overlack N, Moller F, et al. A comparative evaluation of NB30, NB54 and PTC124 in translational read-through efficacy for treatment of an USH1C nonsense mutation. EMBO Mol Med 2012;4:1186-99.

107. Xue X, Mutyam V, Tang L, et al. Synthetic aminoglycosides efficiently suppress cystic fibrosis transmembrane conductance regulator nonsense mutations and are enhanced by ivacaftor. Am J Respir Cell Mol Biol 2014;50:805-16.

108. Kandasamy J, Atia-Glikin D, Shulman E, et al. Increased selectivity toward cytoplasmic versus mitochondrial ribosome confers improved efficiency of synthetic aminoglycosides in fixing damaged genes: a strategy for treatment of genetic diseases caused by nonsense mutations. Journal of medicinal chemistry 2012;55:10630-43.

109. Du L, Damoiseaux R, Nahas S, et al. Nonaminoglycoside compounds induce readthrough of nonsense mutations. J Exp Med 2009;206:2285-97.

110. Gatti RA. SMRT compounds correct nonsense mutations in primary immunodeficiency and other genetic models. Ann N Y Acad Sci 2012;1250:33-40.

111. Lee P, Martin NT, Nakamura K, et al. SMRT compounds abrogate cellular phenotypes of ataxia telangiectasia in neural derivatives of patient-specific hiPSCs. Nat Commun 2013;4:1824.

112. Fan-Minogue H, Bedwell DM. Eukaryotic ribosomal RNA determinants of aminoglycoside resistance and their role in translational fidelity. RNA 2008;14:148-57.

113. Jung ME, Ku JM, Du L, Hu H, Gatti RA. Synthesis and evaluation of compounds that induce readthrough of premature termination codons. Bioorg Med Chem Lett 2011;21:5842-8.

114. Thompson J, Pratt CA, Dahlberg AE. Effects of a number of classes of 50S inhibitors on stop codon readthrough during protein synthesis. Antimicrob Agents Chemother 2004;48:4889-91.

115. Linde L, Kerem B. Introducing sense into nonsense in treatments of human genetic diseases. Trends Genet 2008;24:552-63.

116. Finkel RS. Read-through strategies for suppression of nonsense mutations in Duchenne/ Becker muscular dystrophy: aminoglycosides and ataluren (PTC124). J Child Neurol 2010;25:1158-64.

117. Welch EM, Barton ER, Zhuo J, et al. PTC124 targets genetic disorders caused by nonsense mutations. Nature 2007;447:87-91. 
118. Wang B, Yang Z, Brisson BK, et al. Membrane blebbing as an assessment of functional rescue of dysferlin-deficient human myotubes via nonsense suppression. $\mathrm{J}$ Appl Physiol (1985) 2010;109:901-5.

119. Goldmann T, Overlack N, Wolfrum U, Nagel-Wolfrum K. PTC124-mediated translational readthrough of a nonsense mutation causing Usher syndrome type 1C. Hum Gene Ther 2011;22:537-47.

120. Sarkar C, Zhang Z, Mukherjee AB. Stop codon read-through with PTC124 induces palmitoyl-protein thioesterase-1 activity, reduces thioester load and suppresses apoptosis in cultured cells from INCL patients. Mol Genet Metab 2011;104:338-45.

121. Bartolomeo R, Polishchuk EV, Volpi N, Polishchuk RS, Auricchio A. Pharmacological read-through of nonsense ARSB mutations as a potential therapeutic approach for mucopolysaccharidosis VI. J Inherit Metab Dis 2012;36:363-71.

122. Gonzalez-Hilarion S, Beghyn T, Jia J, et al. Rescue of nonsense mutations by amlexanox in human cells. Orphanet J Rare Dis 2012;7:58.

123. Peltz SW, Morsy M, Welch EM, Jacobson A. Ataluren as an agent for therapeutic nonsense suppression. Annu Rev Med 2012;64:407-25.

124. Du M, Liu X, Welch EM, Hirawat S, Peltz SW, Bedwell DM. PTC124 is an orally bioavailable compound that promotes suppression of the human CFTR-G542X nonsense allele in a CF mouse model. Proceedings of the National Academy of Sciences of the United States of America 2008;105:2064-9.

125. Haas M, Vlcek V, Balabanov P, et al. European Medicines Agency review of ataluren for the treatment of ambulant patients aged 5 years and older with Duchenne muscular dystrophy resulting from a nonsense mutation in the dystrophin gene. Neuromuscul Disord 2015;25:5-13.

126. Iqbal N, Salzman D, Lazenby AJ, Wilcox CM. Diagnosis of gastrointestinal graft-versus-host disease. Am J Gastroenterol 2000;95:3034-8.

127. Dreger P, Schmitz N. Allogeneic transplantation of blood stem cells: coming of age? Ann Hematol 2001;80:127-36.

128. Atkinson K, Champlin R, Ritz J, Fibbe WE, Ljungman P, Brenner MK. Clinical Bone Marrow and Blood Stem Cell Transplantation. Camebridge University Press 2003.

129. Oduncu FS, Schroth U, Vossenkuhl W. Transplantation : Organgewinnung und allokation. Göttingen : Vandenhoeck und Ruprecht 2003.

130. Maezawa I, Swanberg S, Harvey D, LaSalle JM, Jin LW. Rett syndrome astrocytes are abnormal and spread MeCP2 deficiency through gap junctions. J Neurosci 2009;29:5051-61.

131. Lioy DT, Garg SK, Monaghan CE, et al. A role for glia in the progression of Rett's syndrome. Nature 2011;475:497-500.

132. Maezawa I, Jin LW. Rett syndrome microglia damage dendrites and synapses by the elevated release of glutamate. J Neurosci 2010;30:5346-56.

133. Davalos D, Grutzendler J, Yang G, et al. ATP mediates rapid microglial response to local brain injury in vivo. Nat Neurosci 2005;8:752-8.

134. Nimmerjahn A, Kirchhoff F, Helmchen F. Resting microglial cells are highly dynamic surveillants of brain parenchyma in vivo. Science 2005;308:1314-8. 
135. Derecki NC, Cronk JC, Lu Z, et al. Wild-type microglia arrest pathology in a mouse model of Rett syndrome. Nature 2012;484:105-9.

136. Karlsson U, Schultz RL. Fixation of the Central Nervous System from Electron Microscopy by Aldehyde Perfusion. I. Preservation with Aldehyde Perfusates Versus Direct Perfusion with Osmium Tetroxide with Special Reference to Membranes and the Extracellular Space. J Ultrastruct Res 1965;12:160-86.

137. Richardson KC, Jarett L, Finke EH. Embedding in epoxy resins for ultrathin sectioning in electron microscopy. Stain Technol 1960;35:313-23.

138. Crawley J. What's Wrong With My Mouse? Behavioral Phenotyping of Transgenic and Knockout Mice. New York: John Wiley and Sons, Inc 2000.

139. Paylor R, Nguyen M, Crawley JN, Patrick J, Beaudet A, Orr-Urtreger A. Alpha7 nicotinic receptor subunits are not necessary for hippocampal-dependent learning or sensorimotor gating: a behavioral characterization of Acra7-deficient mice. Learn Mem 1998;5:302-16.

140. Deacon RM. Assessing nest building in mice. Nat Protoc 2006;1:1117-9.

141. Barthe JY, Clarac F. Modulation of the spinal network for locomotion by substance $\mathrm{P}$ in the neonatal rat. Exp Brain Res 1997;115:485-92.

142. Telgkamp P, Cao YQ, Basbaum AI, Ramirez JM. Long-term deprivation of substance $\mathrm{P}$ in PPT-A mutant mice alters the anoxic response of the isolated respiratory network. Journal of neurophysiology 2002;88:206-13.

143. Lee CT. Genetic analyses of nest-building behavior in laboratory mice (Mus musculus). Behav Genet 1973;3:247-56.

144. Van de Weerd HA, Van Loo PL, Van Zutphen LF, Koolhaas JM, Baumans V. Preferences for nesting material as environmental enrichment for laboratory mice. Lab Anim 1997;31:133-43.

145. Gaskill BN, Karas AZ, Garner JP, Pritchett-Corning KR. Nest building as an indicator of health and welfare in laboratory mice. J Vis Exp 2013:51012.

146. Wilschanski M, Yahav Y, Yaacov Y, et al. Gentamicin-induced correction of CFTR function in patients with cystic fibrosis and CFTR stop mutations. The New England journal of medicine 2003;349:1433-41.

147. Allamand V, Bidou L, Arakawa M, et al. Drug-induced readthrough of premature stop codons leads to the stabilization of laminin alpha2 chain mRNA in CMD myotubes. J Gene Med 2008;10:217-24.

148. Simon AJ, Lev A, Wolach B, et al. The effect of gentamicin-induced readthrough on a novel premature termination codon of CD18 leukocyte adhesion deficiency patients. PLoS One 2010;5:e13659.

149. Tan L, Narayan SB, Chen J, Meyers GD, Bennett MJ. PTC124 improves readthrough and increases enzymatic activity of the CPT1A R160X nonsense mutation. J Inherit Metab Dis 2011;34:443-7.

150. Drake KM, Dunmore BJ, McNelly LN, Morrell NW, Aldred MA. Correction of nonsense BMPR2 and SMAD9 mutations by ataluren in pulmonary arterial hypertension. Am J Respir Cell Mol Biol 2013;49:403-9.

151. Bushby K, Finkel R, Wong B, et al. Ataluren treatment of patients with nonsense mutation dystrophinopathy. Muscle Nerve 2014;50:477-87. 
152. Duran-Struuck R, Dysko RC. Principles of bone marrow transplantation (BMT): providing optimal veterinary and husbandry care to irradiated mice in BMT studies. $\mathrm{J}$ Am Assoc Lab Anim Sci 2009;48:11-22.

153. Stearns NA, Schaevitz LR, Bowling H, Nag N, Berger UV, Berger-Sweeney J. Behavioral and anatomical abnormalities in Mecp2 mutant mice: a model for Rett syndrome. Neuroscience 2007;146:907-21.

154. Samaco RC, Fryer JD, Ren J, et al. A partial loss of function allele of methylCpG-binding protein 2 predicts a human neurodevelopmental syndrome. Hum Mol Genet 2008;17:1718-27.

155. Pratte M, Panayotis N, Ghata A, Villard L, Roux JC. Progressive motor and respiratory metabolism deficits in post-weaning Mecp2-null male mice. Behav Brain Res 2010;216:313-20.

156. Garg SK, Lioy DT, Cheval H, et al. Systemic delivery of MeCP2 rescues behavioral and cellular deficits in female mouse models of Rett syndrome. J Neurosci 2013;33:13612-20.

157. Bond TL, Neumann PE, Mathieson WB, Brown RE. Nest building in nulligravid, primigravid and primiparous C57BL/6J and DBA/2J mice (Mus musculus). Physiol Behav 2002;75:551-5.

158. Moretti P, Bouwknecht JA, Teague R, Paylor R, Zoghbi HY. Abnormalities of social interactions and home-cage behavior in a mouse model of Rett syndrome. Hum Mol Genet 2005;14:205-20.

159. McGraw CM, Samaco RC, Zoghbi HY. Adult neural function requires MeCP2. Science 2011;333:186.

160. Lang M, Wither RG, Brotchie JM, Wu C, Zhang L, Eubanks JH. Selective preservation of MeCP2 in catecholaminergic cells is sufficient to improve the behavioral phenotype of male and female Mecp2-deficient mice. Hum Mol Genet 2012;22:358-71.

161. Lugaresi E, Cirignotta F, Montagna P. Abnormal breathing in the Rett syndrome. Brain Dev 1985;7:329-33.

162. Kerr AM, Armstrong DD, Prescott RJ, Doyle D, Kearney DL. Rett syndrome: analysis of deaths in the British survey. Eur Child Adolesc Psychiatry 1997;6 Suppl $1: 71-4$.

163. Bissonnette JM, Knopp SJ. Separate respiratory phenotypes in methyl-CpGbinding protein 2 (Mecp2) deficient mice. Pediatr Res 2006;59:513-8.

164. Stettner GM, Huppke P, Brendel C, Richter DW, Gartner J, Dutschmann M. Breathing dysfunctions associated with impaired control of postinspiratory activity in Mecp2-/y knockout mice. J Physiol 2007;579:863-76.

165. Voituron N, Zanella S, Menuet C, Dutschmann M, Hilaire G. Early breathing defects after moderate hypoxia or hypercapnia in a mouse model of Rett syndrome. Respir Physiol Neurobiol 2009;168:109-18.

166. Ramirez JM, Ward CS, Neul JL. Breathing challenges in Rett syndrome: lessons learned from humans and animal models. Respir Physiol Neurobiol 2013;189:280-7.

167. Lang M, Wither RG, Colic S, et al. Rescue of behavioral and EEG deficits in male and female Mecp2-deficient mice by delayed Mecp2 gene reactivation. Hum Mol Genet 2013;23:303-18. 
168. Robinson L, Guy J, McKay L, et al. Morphological and functional reversal of phenotypes in a mouse model of Rett syndrome. Brain 2012;135:2699-710.

169. Abdala AP, Lioy DT, Garg SK, Knopp SJ, Paton JF, Bissonnette JM. Effect of Sarizotan, a 5-HT1a and D2-like receptor agonist, on respiration in three mouse models of Rett syndrome. Am J Respir Cell Mol Biol 2013;50:1031-9.

170. Levitt ES, Hunnicutt BJ, Knopp SJ, Williams JT, Bissonnette JM. A selective 5HT1a receptor agonist improves respiration in a mouse model of Rett syndrome. J Appl Physiol (1985) 2013;115:1626-33.

171. Bissonnette JM, Schaevitz LR, Knopp SJ, Zhou Z. Respiratory phenotypes are distinctly affected in mice with common Rett syndrome mutations MeCP2 T158A and R168X. Neuroscience 2014;267:166-76.

172. Wegener E, Brendel C, Fischer A, Hulsmann S, Gartner J, Huppke P. Characterization of the MeCP2R168X knockin mouse model for Rett syndrome. PLoS One 2014;9:e115444.

173. Ricceri L, De Filippis B, Laviola G. Rett syndrome treatment in mouse models: searching for effective targets and strategies. Neuropharmacology 2012;68:106-15.

174. Jugloff DG, Vandamme K, Logan R, Visanji NP, Brotchie JM, Eubanks JH. Targeted delivery of an Mecp2 transgene to forebrain neurons improves the behavior of female Mecp2-deficient mice. Hum Mol Genet 2008;17:1386-96.

175. Rastegar M, Hotta A, Pasceri P, et al. MECP2 isoform-specific vectors with regulated expression for Rett syndrome gene therapy. PLoS One 2009;4:e6810.

176. Gadalla KK, Bailey ME, Spike RC, et al. Improved survival and reduced phenotypic severity following AAV9/MECP2 gene transfer to neonatal and juvenile male Mecp2 knockout mice. Mol Ther 2012;21:18-30.

177. Silva AL, Romao L. The mammalian nonsense-mediated mRNA decay pathway: to decay or not to decay! Which players make the decision? FEBS Lett 2009;583:499505 .

178. Popp MW, Maquat LE. Organizing principles of mammalian nonsense-mediated mRNA decay. Annu Rev Genet 2013;47:139-65.

179. Yang ZR, Thomson R, McNeil P, Esnouf RM. RONN: the bio-basis function neural network technique applied to the detection of natively disordered regions in proteins. Bioinformatics 2005;21:3369-76.

180. Du M, Keeling KM, Fan L, et al. Clinical doses of amikacin provide more effective suppression of the human CFTR-G542X stop mutation than gentamicin in a transgenic CF mouse model. J Mol Med (Berl) 2006;84:573-82.

181. University of Minnesota M, MN USA. MT2013-31:Allogeneic Hematopoietic Cell Transplantation for Inherited Metabolic Disorders, Sever

Osteoporosis and Males with Rett Syndrome Following Conditioning with Busulfan (Therapeutic Drug

Monitoring), Fludarabine +/- ATG. 2014.

182. Tomita Y, Sachs DH, Sykes M. Myelosuppressive conditioning is required to achieve engraftment of pluripotent stem cells contained in moderate doses of syngeneic bone marrow. Blood 1994;83:939-48. 
183. Ribes S, Ebert S, Regen T, et al. Toll-like receptor stimulation enhances phagocytosis and intracellular killing of nonencapsulated and encapsulated Streptococcus pneumoniae by murine microglia. Infect Immun 2012;78:865-71.

184. NIH. Guidance for Industry: Preclinical Assessment of Investigational Cellular and Gene Therapy Products. Guidance, Compliance \& Regulatory Information (Biologics) 2014:4-7.

185. Wang J, Wegener JE, Huang T-W, et al. Wild-type microglia do not reverse pathology in mouse models of Rett syndrome. Nature 2015;521:E1-E4. 


\section{Danksagung}

Ich möchte mich bei allen Menschen und Mäusen bedanken die bei der Entstehung dieser Arbeit geholfen haben. Ohne Euch wäre das nicht möglich gewesen!

Als erstes möchte ich mich bei Frau Prof. Gärtner und Peter für die herzliche Aufnahme in die Abteilung und die Bereitstellung des spannenden Themas bedanken.

Weiter gilt mein Dank den Herrn Professoren André Fiala und Martin Göpfert sowohl für die Begutachtung dieser Arbeit als auch für die konstruktiven und anregenden Diskussionen im Rahmen der Thesis Commitee Treffen bedanken.

Ganz herzlich möchte ich mich auch bei Prof. Blanche Schwappach, Prof. Ralf Heinrich, Prof. Michael Müller und Prof. Holger Reichardt für die Teilnahme an der Prüfungskommission bedanken.

Ein großer Dank gilt den Kooperationspartnern Prof. Swen Hülsmann, Prof. André Fischer, Prof. Holger Reichardt, Dr. Wiebke Möbius und Prof. UweKarsten Hanisch für die Bereitstellung Eurer Expertise, Technik und Man- bzw. Women-Power.

Ein weiterer Dank gilt an meine Korrekturleser Julia, Peter und Torben. Es tut mir wirklich leid Eure Gehirne derart strapaziert zu haben! Ich geb dann gerne mal ein aus...oder zwei...oder solange bis ihr alles wieder vergessen habt.

Auch bei der Labormannschaft möchte ich mich für die schöne Zeit und die freundliche Aufnahme in Eure Reihen bedanken. Besonders möchte ich Monika und Ellen danken, die mir geholfen haben in Göttingen anzukommen und mich des Öfteren davor bewahrt haben im Labor zu platzen.

Auch bei meiner Familie möchte ich mich für die tolle Unterstützung in den vergangenen Jahren bedanken.

Mein größter Dank gilt jedoch Diana und Oskar. Durch Euch weiß ich, dass das spannendste und schönste Experiment eine eigene kleine Familie mit schlaflosen Nächten ist. 


\section{Lebenslauf}

Jan Eike Wegener

Geburtsdatum: 02.10.1980

Geburtsort: Berlin

Staatsangehörigkeit: Deutsch

Familienstand: Ledig

\section{Ausbildung}

2003 bis 2009 Studium an der Martin-Luther-Universität Halle-Wittenberg

Diplomstudiengang Biologie

Titel der Diplomarbeit:

„Identification of a potential biomarker of Neurofibromatosis type I

implicated in refulation of bone andcartilage metabolism“

Disputation: 22.4.2009

\section{Beruflicher Werdegang}

02. 2010 bis 11.2010

Wissenschaftlicher Mitarbeiter der Klinik für

Kinder- und Jugendmedizin, Abteilung Neuropädiatrie

Universitätsmedizin der Georg-August-Universität Göttingen

2010 bis 2015

Doktorand in der AG Huppke,

Klinik für Kinder- und Jugendmedizin, Abteilung Neuropädiatrie der

Universitätsmedizin der Georg-August-Universität Göttingen

Titel der Arbeit:

„Charakterisierung und experimentelle Therapie eines neuen Mausmodells für das Rett Syndrom “ 


\section{Veröffentlichungen}

\subsection{Publikationen}

Brendel C, Belakhov V, Werner H, Wegener $\mathbf{E}$ et al. Readthrough of nonsense mutations in Rett syndrome: evaluation of novel aminoglycosides and generation of a new mouse model. J Mol Med (Berl) 2010;89:389-98

Huppke P, Wegener E, Bohrer-Rabel H, et al. Tectonic gene mutations in patients with Joubert syndrome. Eur J Hum Genet 2014;23:616-20.

Wegener E, Brendel C, Fischer A, Hulsmann S, Gartner J, Huppke P. Characterization of the MeCP2R168X knockin mouse model for Rett syndrome. PLoS One 2014;9:e115444.

Wang J, Wegener JE, Huang T-W, et al. Wild-type microglia do not reverse pathology in mouse models of Rett syndrome. Nature 2015;521:E1-E4

\subsection{Kongressbeiträge}

5th biennial NEURIZONS Conference „Solving The Brain Puzzle: Building Minds From Molecules“, Mai 2013, Göttingen

Posterbeitrag: „Gentamicin treatment of a new mouse model for Rett syndrome“

3rd European Rett Syndrome Conference "Research Update and Preventive Management", Oktober 2013, Maastricht, Niederlande

Vortrag: „Bone marrow transplantation in Rett mice. A cure for Rett syndrome?” 